Aus der Poliklinik für Zahnärztliche Prothetik

(Prof. Dr. med. dent. R. Bürgers)

im Zentrum Zahn-, Mund- und Kieferheilkunde

der Medizinischen Fakultät der Universität Göttingen

\title{
In-vitro-Untersuchungen zum Polierverhalten neu entwickelter hochfester Keramikwerkstoffe für die Anfertigung monolithischer Restaurationen
}

\author{
INAUGURAL-DISSERTATION \\ zur Erlangung des Doktorgrades \\ für Zahnheilkunde \\ der Medizinischen Fakultät der \\ Georg-August-Universität zu Göttingen \\ vorgelegt von \\ Josephine Theus \\ aus \\ Heilbad Heiligenstadt
}

Göttingen 2019 
Dekan:

\section{Betreuungsausschuss}

Betreuer/in:

Ko-Betreuer/in:

\section{Prüfungskommission}

Referent/in:

Ko-Referent/in:

Drittreferent/in:
Prof. Dr. rer. nat. H. K. Kroemer

PD Dr. med. dent. S. Rinke

Prof. Dr. med. dent. M. Hülsmann
PD Dr. med. dent. S. Rinke

Prof. Dr. med. dent. M. Hülsmann

Datum der mündlichen Prüfung: 14.01.2020 
Hiermit erkläre ich, die Dissertation mit dem Titel "In-vitro-Untersuchungen zum Polierverhalten neu entwickelter hochfester Keramikwerkstoffe für die Anfertigung monolithischer Restaurationen" eigenständig angefertigt und keine anderen als die von mir angegebenen Quellen und Hilfsmittel verwendet zu haben.

Göttingen, den

(Unterschrift) 


\section{Inhaltsverzeichnis}

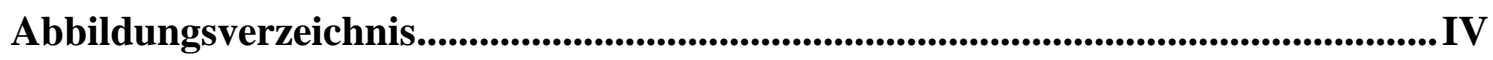

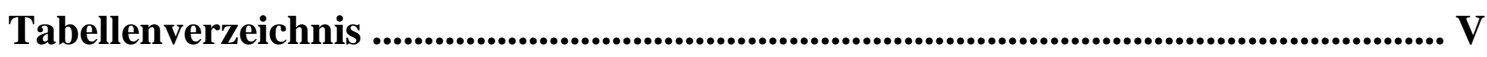

Abkürzungsverzeichnis .................................................................................................. VI

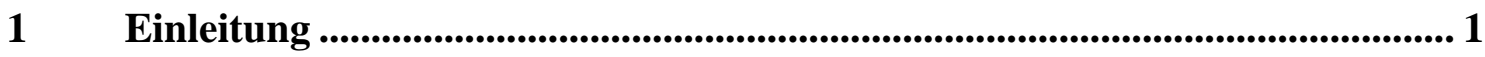

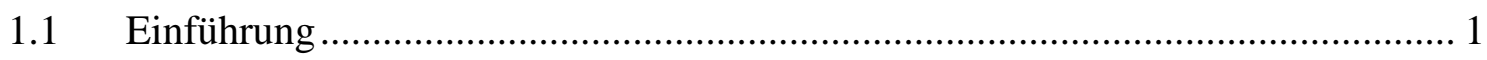

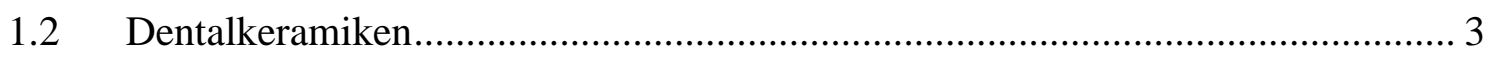

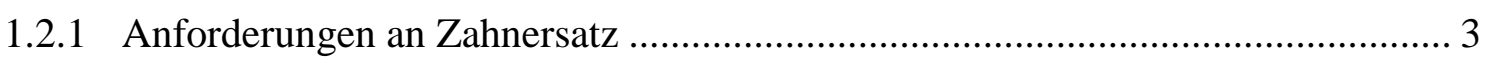

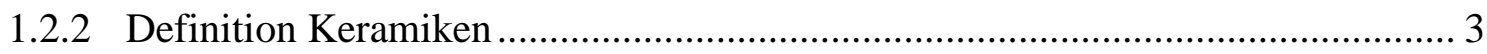

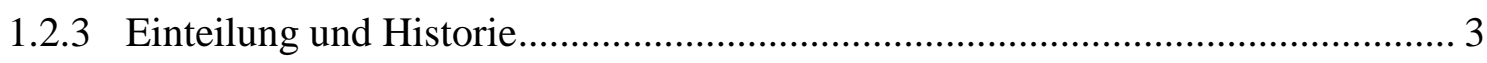

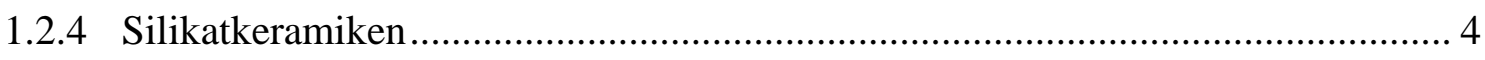

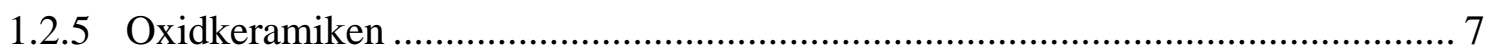

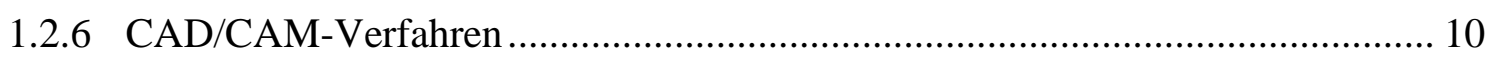

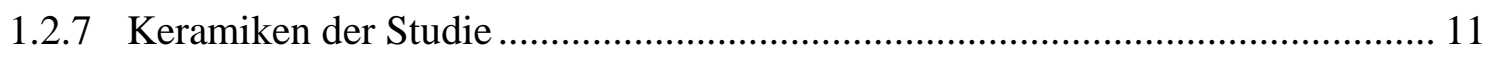

1.3 Literaturübersicht Oberflächenbearbeitung ................................................ 13

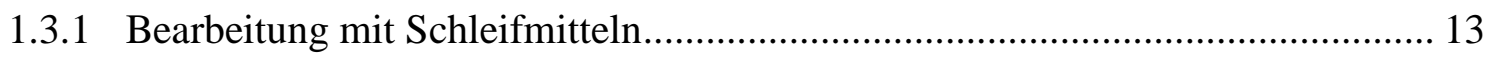

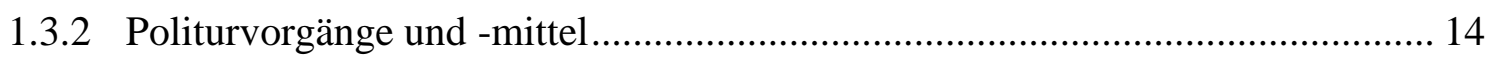

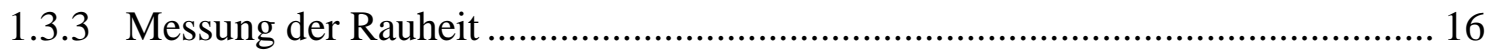

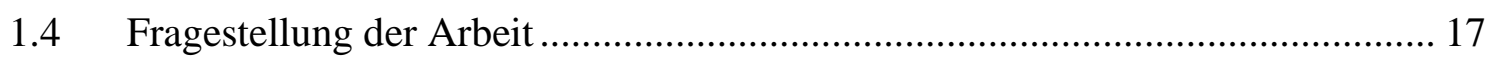

2 Material und Methoden ........................................................................................ 18

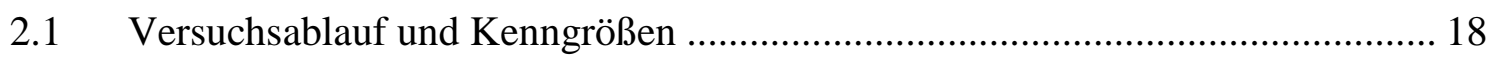

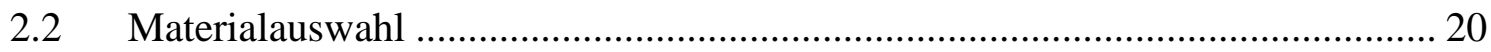

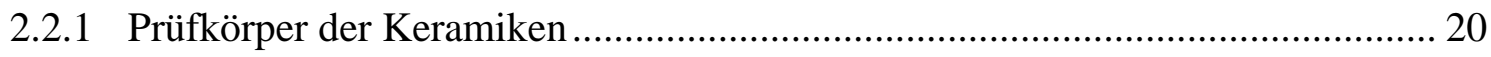

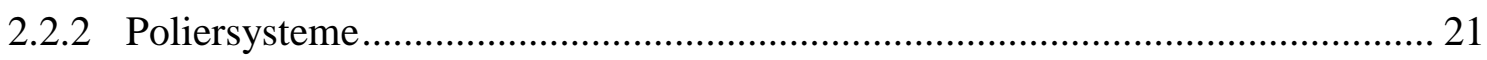

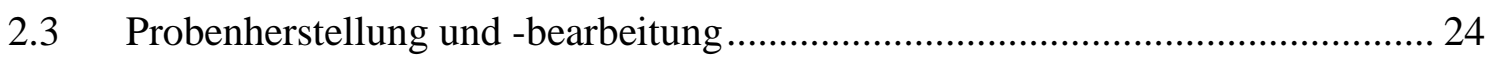

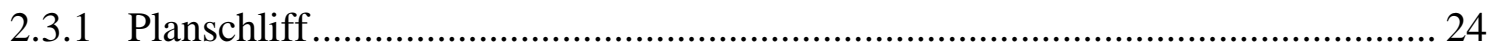

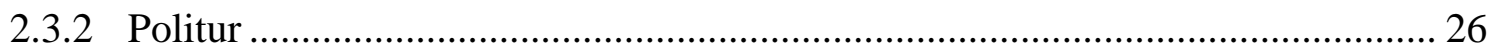




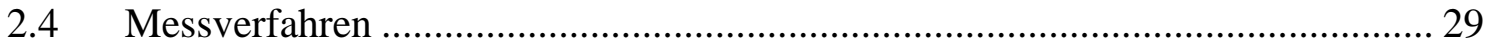

2.4.1 PC-basierendes Rauheitsmessgerät der Mahr GmbH...................................... 29

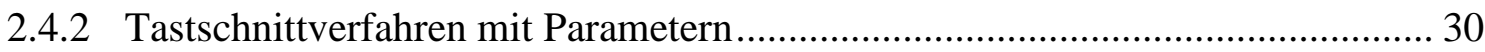

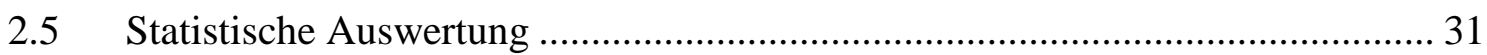

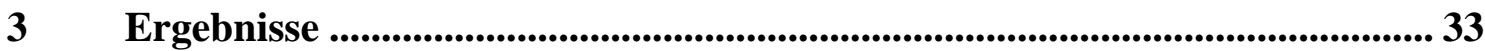

3.1 Oberflächenrauigkeit nach dem Planschliff .................................................. 34

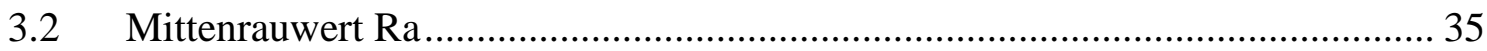

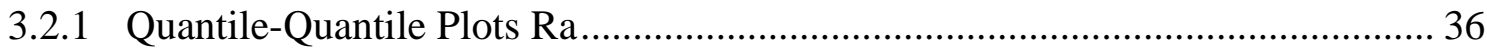

3.2.2 Statistische Auswertung über two-way ANOVA und post-hoc Tukey test ......... 36

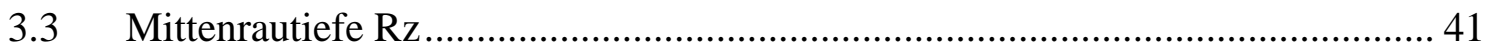

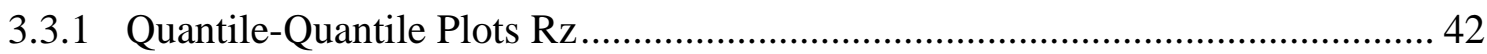

3.3.2 Statistische Auswertung über two-way ANOVA und post-hoc Tukey test ......... 42

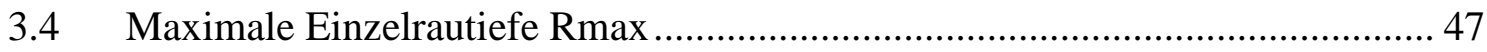

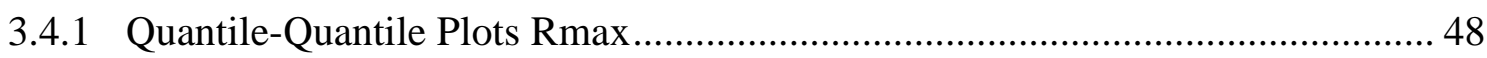

3.4.2 Statistische Auswertung über two-way ANOVA und post-hoc Tukey test ......... 48

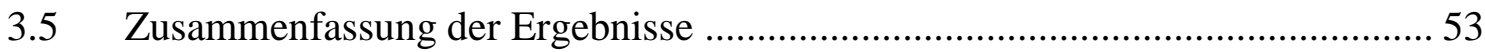

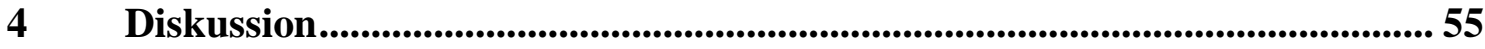

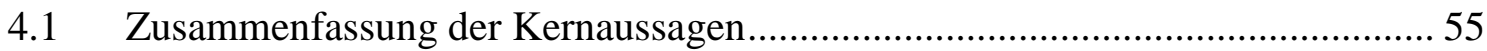

4.2 Diskussion der Ergebnisse im Vergleich mit relevanter Literatur ...................... 56

4.3 Stärken und Limitationen der vorliegenden Studie ..........................................6 60

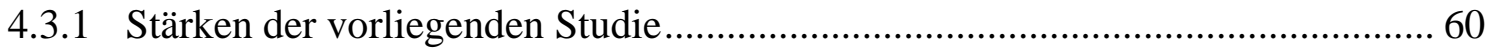

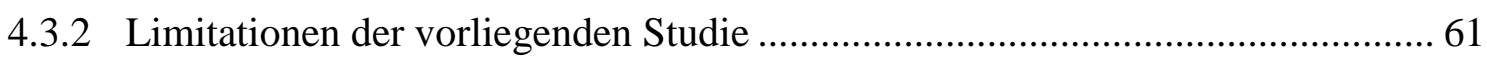

4.3.3 Zusammenfassung der Stärken und Limitationen ........................................... 62

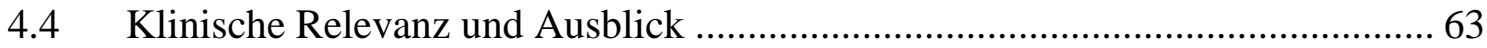

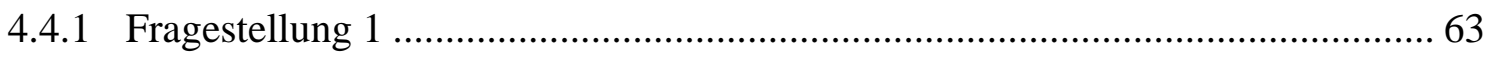

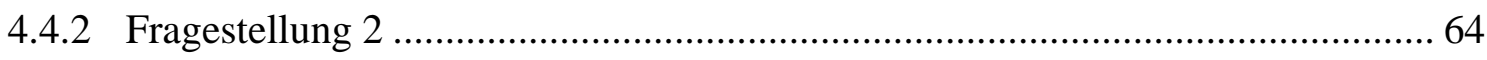

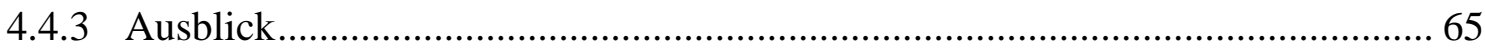

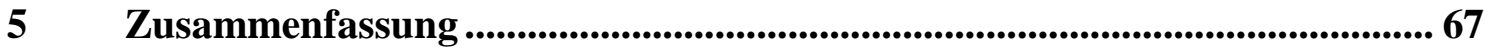


Literaturverzeichnis .......................................................................................69 


\section{Abbildungsverzeichnis}

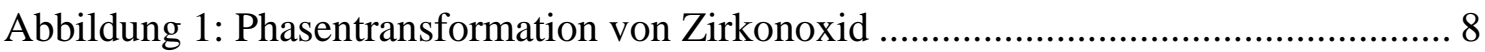

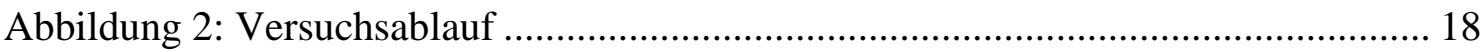

Abbildung 3: Beispiel Rauheitsprofil im 2D-Tastschnittverfahren .............................. 19

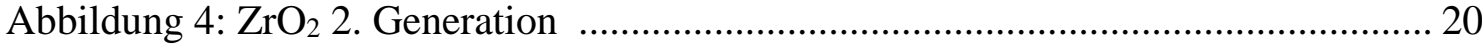

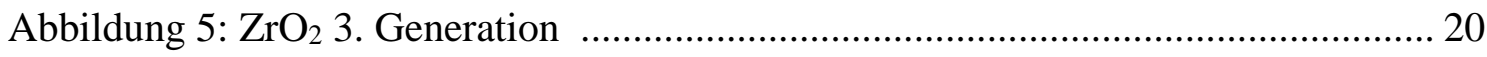

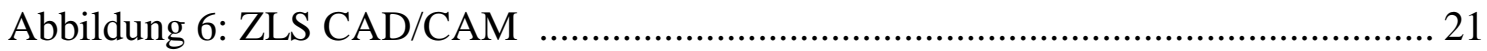

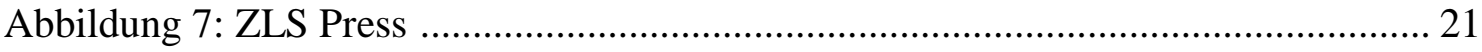

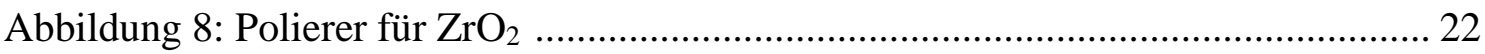

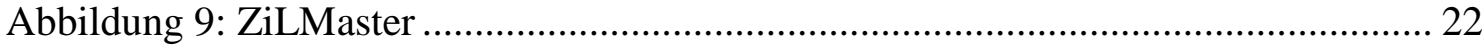

Abbildung 10: A: Diamantpolierpaste 9300 D3 und B: Wollrad .................................. 23

Abbildung 11: A: Dura-Polish DZ, B: Ziegenhaarbürste, C: Filzrad ........................... 23

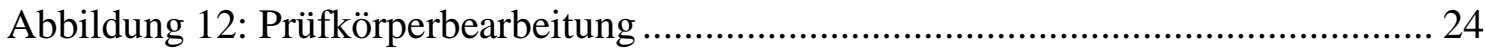

Abbildung 13: A: Nassplanschleifer und B: Prüfkörper.............................................. 25

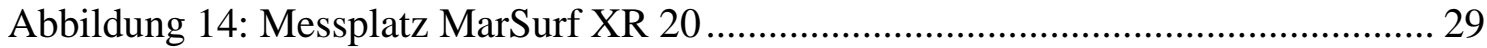

Abbildung 15: Prüfkörperausmessung mit Tastsystem ............................................ 30

Abbildung 16: Flussdiagramm der statistischen Auswertemethodik ............................ 32

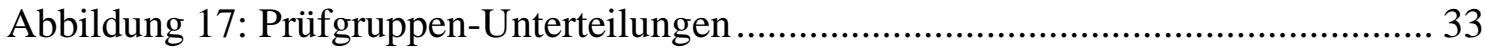

Abbildung 18: Quantile-Quantile Plots der Variablen Ra in Bezug auf jede Keramik.. 36

Abbildung 19: Ra-Wert ohne Paste in Abhängigkeit vom Poliersystem........................ 37

Abbildung 20: Ra-Wert mit Paste in Abhängigkeit vom Poliersystem ......................... 37

Abbildung 21: Ra-Wert im Poliersystem 1 in Abhängigkeit von der Polierpaste.......... 38

Abbildung 22: Ra-Wert im Poliersystem 2 in Abhängigkeit von der Polierpaste.......... 38

Abbildung 23: post-hoc Tukey tests der ANOVA-Auswertung .................................... 39

Abbildung 24: Quantile-Quantile Plots der Variablen Rz in Bezug auf jede Keramik .. 42

Abbildung 25: Rz-Wert ohne Paste in Abhängigkeit vom Poliersystem....................... 43

Abbildung 26: Rz-Wert mit Paste in Abhängigkeit vom Poliersystem .......................... 43

Abbildung 27: Rz-Wert im Poliersystem 1 in Abhängigkeit von der Polierpaste.......... 44

Abbildung 28: Rz-Wert im Poliersystem 2 in Abhängigkeit von der Polierpaste.......... 44 
Abbildung 29: post-hoc Tukey tests der ANOVA-Auswertung 45

Abbildung 30: Quantile-Quantile Plots der Variablen Ra in Bezug auf jede Keramik .. 48

Abbildung 31: Rmax-Wert ohne Paste in Abhängigkeit vom Poliersystem 49

Abbildung 32: Rmax-Wert mit Paste in Abhängigkeit vom Poliersystem 49

Abbildung 33: Rmax-Wert im Poliersystem 1 in Abhängigkeit von der Polierpaste..... 50

Abbildung 34: Rmax-Wert im Poliersystem 2 in Abhängigkeit von der Polierpaste..... 50

Abbildung 35: post-hoc Tukey tests der ANOVA-Auswertung 51

\section{Tabellenverzeichnis}

Tabelle 1: Einteilung der Dentalkeramiken 4

Tabelle 2: Zusammensetzung ZLS-Keramiken ........................................................ 6

Tabelle 3: Zusammensetzung Celtra ${ }^{\circledR}$ Press und Celtra ${ }^{\circledR}$ Duo ..................................... 11

Tabelle 4: Zusammensetzung Cercon ${ }^{\circledR}$ ht und Cercon ${ }^{\circledR}$ xt ......................................... 12

Tabelle 5: Vorexperiment Polierdurchläufe im Poliersystem 1 ................................... 27

Tabelle 6: durchschnittliche Rauheitsparameter der plangeschliffenen Prüfkörper ....... 34

Tabelle 7: Ra-Werte jeder Keramikart im PS 1 und 2, mit und ohne Paste ................... 35

Tabelle 8: Rz-Werte jeder Keramikart im PS 1 und 2, mit und ohne Paste .................. 41

Tabelle 9: Rmax-Werte jeder Keramikart im PS 1 und 2, mit und ohne Paste .............. 47

Tabelle 10: Effekt der Polierpaste auf die Oberflächenparameter................................ 54 
Abkürzungsverzeichnis

$\begin{array}{ll}\text { ANOVA } & \text { analysis of variance, Varianzanalyse } \\ \text { CAD/CAM } & \text { computer-aided design/computer-aided manufacturing } \\ \text { EN } & \text { europäische Norm } \\ \text { FSZ } & \text { fully stabilized zirconia } \\ \text { Mol\% } & \text { Molprozent, veraltet für Stoffmengenanteil } \\ \text { MPa } & \text { Megapascal } \\ \text { MPam }{ }^{0,5} & \text { Megapascal pro Quadratmeter } \\ \mathrm{N} & \text { Newton } \\ \text { PS } & \text { Poliersystem } \\ \text { PSZ } & \text { partially stabilized zirconia } \\ \text { Ra } & \text { arithmetisches Mittel der Rauheit [ } \mu \mathrm{m}] \\ \mathrm{Rmax} & \text { maximale Einzelrautiefe [ } \mu \mathrm{m}] \\ \mathrm{Rz} & \text { arithmetisches Mittel der Einzelrautiefen }[\mu \mathrm{m}] \\ \mathrm{U} / \mathrm{min} & \text { Umdrehungen pro Minute } \\ \mathrm{ZLS}-\mathrm{Keramik} & \text { Zirkonoxid-verstärkte Lithium-Silikat-Keramik } \\ \mathrm{ZrO}{ }_{2} & \text { Zirconiumdioxid oder auch Zirkonoxid } \\ \end{array}$




\section{$1 \quad$ Einleitung}

\subsection{Einführung}

Keramische Werkstoffe haben in den letzten 30 Jahren insbesondere aufgrund der ästhetischen Eigenschaften und der hohen Biokompatibilität verstärkt Anwendung für die Herstellung dentaler Restaurationen gefunden (Kelly und Benetti 2011; Zarone et al. 2011). Anfängliche Probleme dieser Werkstoffgruppe durch eine erhöhte Frakturanfälligkeit konnten durch die Entwicklung hochfester Keramiken gelöst werden (Cionca et al. 2017). Dentalkeramiken mit deutlich verbesserten Festigkeiten wie z. B. Glaskeramiken auf Lithiumdisilikatbasis oder polykristalline Zirkonoxidkeramiken haben daher zunehmend Anwendung in der Praxis für die Herstellung von festsitzendem Zahnersatz gefunden (Miyazaki et al. 2013).

Technische Komplikation bei vollkeramischen Restaurationen treten trotz der verbesserten mechanischen Eigenschaften der Gerüstmaterialien gehäuft im Bereich der Verblendung auf (Ma et al. 2013). Eine Lösung für die Keramikverblendfrakturen ist die Entwicklung von Materialien, die für die Herstellung von „monolithischen“ Restaurationen geeignet sind (Kozmacs et al. 2017). Bei diesen Versorgungen wird die gesamte Restauration aus einem Material hergestellt (Beuer et al. 2012).

Für monolithische Restaurationen sind Werkstoffe mit einer Kombination von ausreichender Festigkeit und hoher Transluzenz erforderlich. Zirkonoxid-Keramiken sind sehr fest, aber bislang noch nicht ausreichend transluzent gewesen. Glaskeramiken hingegen haben eine erhöhte Transluzenz, aber eine reduzierte Festigkeit. Neuentwicklungen in beiden Bereichen sollen nun Festigkeit und Transluzenz vereinen (Hmaidouch et al. 2014; Pieger et al. 2014).

Neuentwickelte Werkstoffe für diesen Anwendungsbereich, die eine günstige Kombination aus Festigkeit und Lichtdurchlässigkeit aufweisen, sind zirkonoxidverstärkte Glaskeramiken und supertransluzente kubische Zirkonoxidvarianten. Mit dem Fortschritt im Bereich der Keramik-Restaurationen ist auch die Entwicklung der computerunterstützten Planung und Fertigung vorangeschritten. Bei diesen Materialien erfolgt der Herstellungsablauf meist über die CAD/CAM-Technik. CAD/CAM steht für computer-aided design/computer-aided manufacturing und beschreibt eine computergestützte Planung und 
Herstellung der Restaurationen (Li et al. 2014). Dieses Verfahren hat den klinischen Ablauf für Zahnärzte, Zahntechniker und auch die Behandlungsoptionen für den Patienten stark verändert. Die größtenteils maschinelle automatisierte Fertigung weist auch wirtschaftliche Vorteile wie eine Zeit- und Kostenersparnis auf (Beuer et al. 2009a).

Neben anderen Parametern wie der Passung, der Festigkeit und der Lichtdurchlässigkeit spielt die Oberflächenqualität dieser Keramik-Restaurationen eine entscheidende Rolle. Die monolithischen Restaurationen können nach der Politur direkt eingesetzt werden. Daher ist die Polierbarkeit entscheidend für das klinische Verhalten insbesondere unter dem Aspekt der Plaqueakkumulation und des Abrasionsverhaltens. Eine optimierte Oberflächenbeschaffenheit minimiert das Risiko der Plaqueanlagerung und verbessert die Ästhetik. Außerdem wurde festgestellt, dass die Oberflächenrauigkeit auch Auswirkungen auf den Verschleiß des Antagonisten hat (Amer et al. 2014; Beuer et al. 2012). Daher sind Neuentwicklungen mit einer guten Polierbarkeit wichtig.

Im Rahmen der vorliegenden Arbeit wurde das Polierverhalten neu entwickelter Hochleistungskeramiken für monolithische Restaurationen in vitro mit unterschiedlichen Polierverfahren untersucht. 


\subsection{Dentalkeramiken}

\subsubsection{Anforderungen an Zahnersatz}

Die Materialien, die sich dauerhaft oder intermittierend als Zahnersatz in der Mundhöhle befinden, müssen bestimmten Anforderungen entsprechen. Entscheidende Kriterien sind hierbei die Festigkeit, die Biokompatibilität, die Ästhetik, die Passgenauigkeit, die Substanzschonung und die geringe Plaqueakkumulation, welche durch glatte Oberflächen erleichtert wird. Dentalkeramiken können die genannten Anforderungen erfüllen (Hmaidouch et al. 2014). Obwohl Keramiken eine hohe Druckfestigkeit aufweisen, liegt ihr Schwachpunkt in der geringen Biege- und Zugfestigkeit. Sie sind somit frakturanfälliger als Metallrestaurationen (Kern et al. 2012b).

\subsubsection{Definition Keramiken}

Als Keramiken werden "alle nichtmetallischen anorganischen Werkstoffe, die weitestgehend wasserbeständig und zu einem großen Teil oder ganz kristalline Werkstoffe beziehungsweise Stoffgemische sind, die durch Sintern hergestellt werden“ (Tinschert et al. 2007, S. 5) bezeichnet.

Es handelt sich um Materialien, die sich in ihren mechanischen Eigenschaften von Metallen unterscheiden. Während es bei Metallen erst nach einer plastischen Verformung zu einem „Duktilbruch“ kommt, sind Keramiken durch einen „Sprödbruch“ gekennzeichnet (Marxkors et al. 2012). In der Mundhöhle sind diese Werkstoffe Belastungen durch den Kaudruck und durch unphysiologische Vorgänge wie Knirschen oder Pressen ausgesetzt. Durch Unregelmäßigkeiten, wie Kerben in der Oberfläche und Spannungen, kann es zu Rissen kommen. Diese Risse können wiederum zu einem Bruch der Keramik führen (Rösler et al. 2016).

\subsubsection{Einteilung und Historie}

Dentalkeramiken können anhand ihrer Herstellungsart, der Brenntemperatur, des Anwendungsbereiches und des chemischen Aufbaus unterteilt werden. Aus zahnmedizinischer Sicht bietet sich letztere Variante als sinnvollste an (Tinschert et al. 2007) (Tabelle 1). 
Tabelle 1: Einteilung der Dentalkeramiken (modifiziert nach Rinke 2012)

\begin{tabular}{|c|c|c|c|}
\hline \multicolumn{4}{|c|}{ Dentalkeramik } \\
\hline \multicolumn{2}{|c|}{$\begin{array}{l}\text { Silikatkeramiken } \\
\text { mehrphasig: glasreiche Matrix mit kristallinen Phasen }\end{array}$} & \multicolumn{2}{|c|}{$\begin{array}{l}\text { Oxidkeramiken } \\
\text { einphasige Metalloxide (>90\%); kein bis geringer } \\
\text { Glasanteil }\end{array}$} \\
\hline $\begin{array}{l}\text { Feldspatkeramiken } \\
\text { Gemahlenes } \\
\text { Feldspatglas (Pulver) } \\
\text { wird gesintert. (z.B. } \\
\text { Verblendkeramiken, } \\
\text { VITABLOCS } ® \text { Mark II) }\end{array}$ & $\begin{array}{l}\text { Glaskeramiken } \\
\text { Glas als Ausgangsprodukt } \\
\text { wird einem } \\
\text { Kristallisationsprozess } \\
\text { unterworfen. (z.B. Dicor }{ }^{\circledR}, \\
\left.\text { Empress }{ }^{\circledR}\right) \\
\text { Lithiumdisilikatkeramik } \\
\text { IPS e.max }{ }^{\circledR} \\
\text { Zirkonoxidverstärkte } \\
\text { Lithiumsilikatkeramik (z.B. } \\
\text { Celtra }{ }^{\circledR} \text { Press, Celtra }{ }^{\circledR} \text { Duo) }\end{array}$ & $\begin{array}{l}\text { Glasinfiltriert } \\
\text { Angesintertes Aluminium- } \\
\text { oxidpulver (Weißkörper) } \\
\text { wird mit Glas infiltriert. } \\
\text { (z.B. In-Ceram }{ }^{\circledR} \text { Alumina; } \\
\text { In-Ceram }{ }^{\circledR} \text { Zirconia; In- } \\
\text { Ceram }{ }^{\circledR} \text { Spinell) }\end{array}$ & $\begin{array}{l}\text { Polykrsitallin } \\
\text { Glasphasenfreies sehr } \\
\text { gleichmäßiges Mikrogefüge. } \\
\text { (z.B. Cercon }{ }^{\circledR} \text { Base wie } \\
\text { Cercon }{ }^{\circledR} \text { ht, Cercon }{ }^{\circledR} \text { xt; } \\
\text { DC-Zirkon }{ }^{\circledR} \text {; LAVATM } \\
\text { Frame; Procera }{ }^{\circledR} \text { AllCeram) }\end{array}$ \\
\hline
\end{tabular}

\subsubsection{Silikatkeramiken}

Die amorph-strukturierten Silikatkeramiken sind heterogene Stoffgefüge, bestehend aus Feldspat, Quarz und Kaolin. Sie sind von einer Glasphase umgeben und zeichnen sich durch ihre gute Transluzenz, Lichtbrechung und Transparenz aus (Marxkors et al. 2012). Mit einer Biegefestikeit von 50 - $200 \mathrm{MPa}$ und einer Bruchzähigkeit von $<2,5 \mathrm{MPam}^{0,5}$ eignen sie sich für Einsatzgebiete wie Verblendungen, Inlays, Teilkronen oder Veneers (Rinke 2012). Sie lassen sich in Feldspat- und Glaskeramiken unterteilen.

Die Feldspatkeramiken bestehen zu über $50 \%$ aus einer Siliziumdioxid-Glasphase und einem geringfügigen Zusatz von Oxiden, um zahnähnliche Farben zu erreichen (z. B. $\mathrm{K}_{2} \mathrm{O}, \mathrm{Na}_{2} \mathrm{O}, \mathrm{Al}_{2} \mathrm{O}_{3}$ ). Die Leuzitkristalle, die in die Glasmatrix eingebettet sind, erhöhen die Festigkeit (Tinschert et al. 2007). Bei dem Feldspat handelt es sich um ein Mischkristallsystem aus Kalifeldspat, Natronfeldspat und Kalkfeldspat (Lang und Friedl 2013). Der Kaolin-Anteil ist nur gering, da Kaolin mit dem Feldspat Kristallverbindungen ausbildet. Dies führt zu einer Verringerung der Transluzenz und Festigkeit (Erdelt et al. 2004). Die Festigkeit liegt bei den für das CAD/CAM-Verfahren angewandten Feldspatkeramiken bei circa $150 \mathrm{MPa}$ (Tinschert et al. 2007). Sie kommen bei der Verblendung von Metall- 
und Keramikgerüsten zum Einsatz (Rinke 2012). Bei Verblendkeramiken kann es zum Abplatzen - dem sogenannten „Chipping“ - der Verblendung kommen (Pospiech 2011).

In der Zusammensetzung ähneln die Glaskeramiken den Feldspatkeramiken. Sie unterscheiden sich jedoch anhand ihrer vorwiegend amorphen Glasstruktur, welche durch einen sekundären Kristallisationsprozess entsteht (Tinschert et al. 2007). Durch den steigenden Kristallanteil verringert sich die Rissanfälligkeit. Glaskeramiken zeichnen sich durch ihre Transluzenz aus und stellen hinsichtlich ihrer Festigkeit - auch wenn diese mit $120 \mathrm{MPa}$ immer noch niedrig ist - einen Fortschritt gegenüber den klassischen Verblendkeramiken dar. Indikationen für Glaskeramiken sind Veneers, Inlays und Kronen (Zarone et al. 2016).

Mit der Einführung der Lithiumdisilikat-Keramiken wurde die Herstellung von kleineren Brücken bis zum Prämolarenbereich möglich (Strub et al. 2011; Kern et al. 2012c). Lithiumdisilikat hat verbesserte mechanische Eigenschaften, da die Anzahl der plättchenförmigen Glaskristalle verringert und die Verzahnung zwischen den Kristallen verstärkt wurde (Kang et al. 2013; Wendler et al. 2017). Diese Glaskeramiken auf LithiumdisilikatBasis haben im Vergleich zu den älteren leuzitbasierenden Glaskeramiken höhere Biegefestigkeitswerte von 300 - $400 \mathrm{MPa}$ und eine Risszähigkeit von 2,8 - 3,5 MPam ${ }^{0,5}$ (Raptis et al. 2006; Chen et al. 2008).

Die Weiterentwicklung der Glaskeramiken schritt trotz der großen Nachfrage und breiten Verwendung von Lithiumdisilikat-Keramiken voran. Diese neuen Keramiken enthalten Lithiumdisilikat als Hauptkristallphase, wurden jedoch in ihrer Glasmatrix mit Zirkonoxidkristallen verstärkt (Rinke et al. 2016). Diese zirkonoxidverstärkten Lithiumdisilikatkeramiken (ZLS-Keramiken) besitzen eine höhere Festigkeit als konventionelle Glaskeramiken, da die Glasphase durch die Zugabe von gelöstem Zirkonoxid optimiert wurde. Ihre Festigkeit ist mit den Lithiumdisilikatkeramiken vergleichbar, erreicht teilweise auch höhere Werte von $500 \mathrm{MPa}$. Das Zirkonoxid wird mit 10 Volumenprozent in die Glasmatrix eingebracht (Pospiech und Kern 2016) (Tabelle 2). Dadurch erreichen die Kristalle während des Kristallisationsprozesses eine mittlere Größe von 0,5 bis $1 \mu \mathrm{m}$, die bis zu sechsmal kleiner als bei den Lithiumdisilikatglaskeramiken ist (Belli et al. 2017). Die Bildung einer kleineren und feineren kristallinen Phase tritt aufgrund der Anwesenheit von Zirconiumdioxidteilchen im Material auf, da dieses die Kristallisation beeinflusst, indem es das Kristallwachstums behindert. Diese feinere Mikrostruktur führt zu 
einer Verbesserung der mechanischen Eigenschaften und einem den Lithiumdisilikat-Keramiken überlegenem Polierverhalten (Wendler et al. 2017).

Glaskeramiken sind hinsichtlich der Transluzenz bislang die Werkstoffe mit der höchsten Lichtdurchlässigkeit gewesen und werden aus diesem Grund schon seit Jahrzehnten in der Praxis verwendet (Gins 2012). Sie können aber noch nicht die natürliche Transluzenz von Zahnschmelz imitieren (Shenoy und Shenoy 2010). Bei den ZLS-Keramiken konnte im Vergleich zu den Lithiumdisilikatkeramiken eine Verbesserung der Transluzenz von circa $5-10 \%$ erreicht werden. Laut Hersteller kommen die verbesserten optischen Eigenschaften nun näher an das Lichtleitverhalten von Zahnschmelz heran. Sie sind somit für die monolithische Herstellung von Restaurationen gut geeignet und eine gute Ästhetik lässt sich meist leichter erzielen als mit Zirkonoxiden (Kern et al. 2012a; Pospiech und Kern 2016).

Neben den ZLS-Keramiken, welche für die CAD/CAM-Verarbeitung geeignet sind, gibt es mit Celtra ${ }^{\circledR}$ Press auch eine Keramikvariante für das konventionelle Pressverfahren. Beide Keramiken haben verbesserte optische Eigenschaften und weisen durch ihren hohen Glasmatrix-Anteil eine verbesserte Polierbarkeit auf (Krüger et al. 2013).

Tabelle 2: Zusammensetzung ZLS-Keramiken (modifiziert nach Gracis et al. 2015)

\begin{tabular}{|c|c|}
\hline Bestandteil & Gewichtsprozent (\%) \\
\hline $\mathrm{SiO}_{2}$ & $56-64$ \\
\hline $\mathrm{Al}_{2} \mathrm{O}_{3}$ & $1-4$ \\
\hline $\mathrm{CeO}_{2}$ & $0-4$ \\
\hline $\mathrm{ZrO}_{2}$ & $\mathbf{8}-\mathbf{1 2}$ \\
\hline $\mathrm{K}_{2} \mathrm{O}$ & $1-4$ \\
\hline $\mathrm{Li}_{2} \mathrm{O}$ & $15-21$ \\
\hline $\mathrm{P}_{2} \mathrm{O}_{5}$ & $3-8$ \\
\hline
\end{tabular}




\subsubsection{Oxidkeramiken}

Bei den Oxidkeramiken handelt es sich um Sinterprodukte von Metalloxiden, wie Aluminiumoxid $\left(\mathrm{Al}_{2} \mathrm{O}_{3}\right)$ oder Zirconiumdioxid $\left(\mathrm{ZrO}_{2}\right)$ (Marxkors et al. 2012). Durch einen geringen, bis hin zu einem fehlenden Anteil einer Glasphase, ist die Transluzenz verringert. Allerdings zeichnen sie sich durch ihre Härte aus (Miyazaki et al. 2013). Die Biegefestigkeit liegt bei $900-1200 \mathrm{MPa}$ und die Risszähigkeit beträgt bis zu $12 \mathrm{MPam}^{0,5}$ (Tinschert et al. 2007). Zum besseren Vergleich: Feldspatkeramiken weisen eine Festigkeit von $50 \mathrm{MPa}$, Lithiumdisilikatkeramiken von 300 - $400 \mathrm{MPa}$ und ZLS-Keramiken von 300 - $500 \mathrm{MPa}$ auf. Oxidkeramiken wurden bislang bevorzugt für verblendete Restaurationen genutzt. Die mechanische Stabilität von monolithischen Zirkonoxidrestaurationen konnte jedoch in vielen Studien bestätigt werden und steigt zunehmend (Zhang und Lawn 2018). Hierbei erfolgt also ein Ersatz der „metallischen Substruktur einer klassischen metallkeramischen Krone“" (Pospiech 2011). Unterteilt werden die Oxidkeramiken in glasinfiltriert und polykristallin.

Bei den glasinfiltrierten Oxidkeramiken werden die porösen Keramikgerüste mit Lanthanglas infiltriert (Kern et al. 2012a). Die Umsetzung dieses Verfahrens erfolgt über die VITA In-Ceram®-Technik. Hierbei wird ein oxidkeramisch-gesintertes Kerngerüst mit Lanthanglas in einem Brennprozess verschlossen und anschließend mit Verblendmassen beschichtet (Tinschert et al. 2007). Durch diese Technik entsteht die hohe Endfestigkeit und die Ästhetik wird durch den Glasanteil verbessert (Pospiech 2011). Problematisch bei diesem Prozess ist jedoch, dass sich das infiltrierte Lanthanglas innerhalb der Verbindungsfugen befindet und somit die Dauerfestigkeit zweifelhaft ist. Daher ist diese Technik nicht mehr gebräuchlich (Rodiger et al. 2004).

Bei den polykristallinen Oxidkeramiken handelt es sich um Hochleistungskeramiken aus Metalloxiden (Marxkors et al. 2012). Durch das Fehlen der Glasphase besitzen diese feinkörnige Gefüge, die bei sehr hohen Temperaturen gesintert werden und gute mechanische Eigenschaften aufweisen (Rinke 2012). Als Metalloxide werden Aluminumoxid oder Zirconiumdioxid genutzt. Für diese Studie ist Zirconiumdioxid, auch als Zirkonoxid bezeichnet, von großer Bedeutung und wird daher näher erklärt. 
Zirkonoxid liegt nach dem intensiven Herstellungs- und Reinigungsprozess als weiß-kristallines Pulver vor (Stawarczyk et al. 2016b). Es kann - temperaturabhängig - in drei Modifikationen vorkommen: monoklin (bis $1170^{\circ}$ ), tetragonal (bis $2370^{\circ}$ ) und kubisch (oberhalb von $2370^{\circ}$ ) (Tinschert et al. 2007) (Abbildung 1).

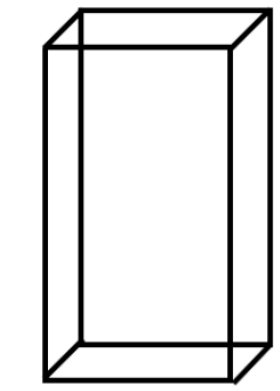

monoklin $\mathrm{a} \neq \mathrm{b} \neq \mathrm{c}$ $\alpha=\gamma 90^{\circ} \beta>90^{\circ}$

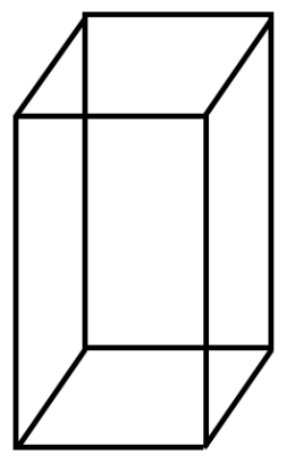

$$
\begin{gathered}
\text { tetragonal } \\
\mathrm{a}=\mathrm{b} \neq \mathrm{c} \\
\alpha=\beta=\gamma=90^{\circ}
\end{gathered}
$$

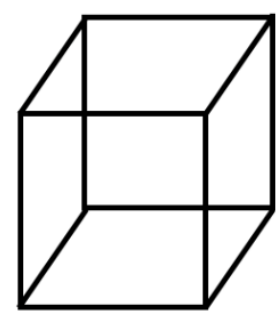

kubisch

$$
\mathrm{a}=\mathrm{b}=\mathrm{c}
$$$$
\alpha=\beta=\gamma=90^{\circ}
$$

Abbildung 1: Phasentransformation von Zirkonoxid

Das hochschmelzende Pulver wird dichtgesintert. Sobald sich das Material abkühlt setzt die Phasenumwandlung von tetragonal zu monoklin ein. Dies führt zu einer Volumenexpansion, welche durch den Zusatz von Stabilisierungsoxiden umgangen werden kann (Strub et al. 2011). Bevorzugt kommt hierbei Yttriumoxid zum Einsatz, da es verbesserte mechanische Eigenschaften aufweist (Miyazaki et al. 2013). Dies wirkt sich vorteilhaft auf die Langlebigkeit aus und reduziert die Bruchgefahr.

Je nach Gehalt wird in partially stabilized zirconia (PSZ, 3 Mol\%) und fully stabilized zirconia (FSZ, 8 - 10 Mol\%) unterteilt (Strub et al. 2011).

Das partially stabilized zirconia, also das teilstabilisierte Zirkonoxid, ist auch als konventionelles Zirkonoxid oder Zirkonoxid der 1. Generation bekannt und weist eine Festigkeit von 1000 - $12000 \mathrm{MPa}$ auf (Stawarczyk et al. 2013). Bei dem teilstabilisierten Zirkonoxid (PSZ) ist anteilig die tetragonale Phase eingelagert (Tinschert et al. 2007). Daher kann der oben beschriebene ungünstige Volumenzuwachs genutzt werden. Kristalle aus PSZ können fein verteilt werden und in der tetragonalen Phase bleiben, bis sie sich bei Auftreten von Rissen in die monokline Phase umwandeln (Strub et al. 2011). Hierdurch kann die fortschreitende Rissbildung eingedämmt und somit der Bruch verhindert werden. Durch diesen Mechanismus ist die Bruchfestigkeit der Oxidkeramiken höher als die der 
Silikatkeramiken (Tinschert et al. 2007). Aufgrund der reduzierten Lichtdurchlässigkeit erfordern die konventionellen Zirkonoxidkeramiken eine Verblendung zur Erzielung eines ästhetisch zufriedenstellenden Ergebnisses.

Die Transluzenz hängt von der chemischen Zusammensetzung, also dem vorhandenen Mikrogefüge und dessen lichtresorbierenden, -absorbierenden und -reflektierenden Eigenschaften, ab (Jiang et al. 2011). Aufgrund reduzierter Ästhetik muss hier eine Verblendung mit Glaskeramiken erfolgen, daher hat sich diese Generation nicht im monolithischen Bereich durchgesetzt.

Obwohl konventionelle Zirkonoxid-Keramiken sich durch ihre Festigkeit auszeichnen, sind sie noch nicht ausreichend transluzent. Neuentwicklungen sind daher Zirkonoxide der zweiten und dritten Generation, die eine bessere Transluzenz aufweisen.

Bei der zweiten Generation von Zirkonoxid wurden die Alumiumoxidkörner im Zirkonoxidgefüge umplatziert und reduziert. Somit konnten eine höhere Lichtdurchlässigkeit und eine gute Langzeitstabilität bei gleichzeitig hoher Festigkeit von 900 - 1000 MPa erreicht werden. Diese Generation überzeugt bei in-vitro-Untersuchungen mit einer höheren Transluzenz und Festigkeit (Stawarczyk et al. 2016a).

Mit dem Ziel, eine noch transluzentere Version des Zirkonoxids herzustellen, begann die Entwicklung der dritten Generation, des vollstabilisierten Zirkonoxids (FSZ). Die kubische Phase bleibt hier bei Raumtemperatur erhalten. Die kubischen Kristalle sind homogener als die tetragonalen Kristalle. So kann die Lichtstreuung gleichmäßiger in alle Richtungen gestrahlt werden (Stawarczyk et al. 2016a). Die Transluzenz der neuen Generation des kubischen Zirkonoxids ist von $40 \%$ auf $49 \%$ gestiegen, da die Lichtstreuung an den Grenzen der größeren Kristallform stark reduziert wird (Preis und Rosentritt 2017). Die dritte Generation hat zwar eine verbesserte Transluzenz, jedoch im Vergleich zu den Zirkonoxiden der ersten und zweiten Generation die geringsten Festigkeitswerte mit $500-650 \mathrm{MPa}$ (Stawarczyk et al. 2016b).

Ursprünglich wurden Zirkonoxid-Restaurationen mit Silikatkeramiken verblendet. Dadurch kam es besonders im Bereich der Molaren häufig zu Verlusten durch Verblendkeramikfrakturen, dem sogenannten Chipping (Heintze und Rousson 2010; Schmitter et al. 2012). Um das Chipping der Keramik zu vermeiden wurden nach und nach monolithische Vollkeramik-Restaurationen in weniger sichtbaren Bereichen eingesetzt (Beuer et al. 2009b; Beuer et al. 2009a). Eine vermehrte Antagonisten-Abrasion aufgrund der hohen Festigkeit dieser Materialien wurde erwartet. Diese Vermutung konnte aber - solange eine 
gute Oberflächenbearbeitung stattfand - widerlegt werden (Janyavula et al. 2013; Amer et al. 2014; Hmaidouch et al. 2014).

Die Zirkonoxide der zweiten (900 - $1000 \mathrm{MPa}$ ) und dritten Generation (500 - 650 MPa) sind für den monolithischen Einsatz geeignet und bieten eine günstige Kombination aus Transluzenz und Dauerbiegefestigkeit.

\subsubsection{CAD/CAM-Verfahren}

Bei der CAD/CAM-Technik handelt es sich um computergestützte Verfahren, bei denen die Planung und Herstellung von Restaurationen in der Zahnmedizin möglich ist. Dieser digitale Workflow bietet viele Vorteile und findet zunehmend Anwendung im Dentallabor und der zahnärztlichen Praxis (Baroudi und Ibraheem 2015; Alghazzawi 2016).

Durch den maschinellen Ablauf können Fertigungsprozesse effizient beschleunigt und die Qualität der Restaurationen beständig und vorhersagbar gemacht werden. Diese Vorteile kommen dem Zahnarzt, dem Zahntechniker und dem Patienten zugute (Miyazaki et al. 2013). Das CAD/CAM-Gerät übernimmt zeitaufwändige Herstellungsabläufe, die andernfalls im Labor vorgenommen werden müssten. Hierzu gehört beispielweise das Aufwachsen und Überführen der Restauration in ein fertiges Gerüst (Fasbinder 2010).

Die CAD/CAM-Systeme können in laborgestützte (labside) und praxisgestützte (chairside) Systeme unterteilt werden. Bei den labside-Systemen werden entweder die Modelle im Labor eingescannt oder aber der Zahnarzt sendet seine eingescannten Daten an eine zentrale Fertigungsstelle. Eine andere Variante ist die chairside-Fertigung der Restaurationen, also die Fertigung der Restauration in der Praxis. Der Zahnarzt verfügt in diesem Fall über das komplette CAD/CAM-System mit einer Scan-Einheit und dem Fräsgerät. Dies ermöglicht dem Zahnarzt und dem Patienten eine Präparation des Zahnes und die Herstellung der Restauration innerhalb von nur einer Sitzung (Baroudi und Ibraheem 2015; Alghazzawi 2016). Die computergestützte Konstruktion der Gerüste ersetzt die Modellation in Wachs und laborbezogene Vorgänge wie das Ein- und Ausbetten der Gerüste entfallen. Der digitale Workflow der chairside- und labside-Systeme ist im Vergleich zu dem konventionellen Vorgehen signifikant kürzer (Spitznagel et al. 2018).

Die in dieser Studie untersuchten Keramiken Cercon ${ }^{\circledR}$ ht, Cercon ${ }^{\circledR}$ xt und Celtra ${ }^{\circledR}$ Duo (Dentsply Sirona Prothetics, Hanau) können über CAD/CAM-Verfahren verarbeitet werden. 


\subsubsection{Keramiken der Studie}

Im Rahmen dieser Arbeit wurden neu entwickelte Dentalkeramiken aus dem Bereich der Glas- und Oxidkeramiken gewählt. Es wurden Zirkonoxid-Keramiken der zweiten und dritten Generation, sowie ZLS-Keramiken für die CAD/CAM und Press-Technik untersucht. Während Glaskeramiken in ästhetischer Hinsicht eine höhere Qualität aufweisen, überzeugen die Oxidkeramiken durch ihre Festigkeit (Tinschert et al. 2007). Die neu entwickelten Hochleistungskeramiken sollen nach Herstellerangaben eine günstige Kombination von Festigkeit und Transluzenz aufweisen, die sie besonders für monolithische Restaurationen geeignet erscheinen lassen. Die zwei untersuchten ZLS-Keramiken sind Celtra ${ }^{\circledR}$ Press und Celtra ${ }^{\circledR}$ Duo (Dentsply Sirona Prothetics, Hanau). Ihre genaue Zusammensetzung ist in Tabelle 3 dargestellt (Dentsply Sirona Prosthetics 2016, 2017b). Die in die Glasmatrix eingelagerten Lithium-Silikat-Kristallite sollen laut Herstellerangaben für eine gut polierbare Oberfläche sorgen (Dentsply Sirona Prosthetics 2017b).

Celtra ${ }^{\circledR}$ Duo ist für die CAD/CAM-Technik geeignet und bietet zwei Verarbeitungsmöglichkeiten. Entweder kann das Material nur mit einer manuellen Politur direkt nach dem CAM-Schleifen oder nach einem Mal- und Glasurbrand eingesetzt werden. Die Festigkeit beträgt laut Hersteller, je nach Verarbeitungsmöglichkeit, $210 \mathrm{MPa}$ nach der Politur und $370 \mathrm{MPa}$ nach einem zusätzlichen Brand (Dentsply Sirona Prosthetics 2017b).

Mit Celtra ${ }^{\circledR}$ Press wird die neue Materialklasse dem Labor im traditionellen Pressverfahren zugänglich. Bei diesem konventionellen Herstellungsverfahren wird der spätere Zahnersatz im Labor in Wachs geformt und mit der Lost-Wax-Technik ausgebrannt (Marxkors et al. 2012). Celtra ${ }^{\circledR}$ Press weist nach Herstellerangaben gute Fließeigenschaften beim Pressvorgang auf. Durch ein spezielles Brandverfahren entstehen Festigkeitswerte von über $500 \mathrm{MPa}$. Diese Werte sind mit der Festigkeit der dritten Generation der Zirkonoxide gleichzusetzen (Dentsply Sirona Prosthetics 2016).

Tabelle 3: Zusammensetzung Celtra® Press und Celtra® Duo

\begin{tabular}{|c|c|}
\hline \multicolumn{2}{|c|}{ Celtra ${ }^{\circledR}$ - Zirkonoxidverstärktes Lithium-Silikat (ZLS) } \\
\hline Celtra ${ }^{\circledR}$ Press & Celtra ${ }^{\circledR}$ Duo \\
\hline Lithiumdisilikatkristalle $(500-1400 \mathrm{~nm})$ & Lithiumdisilikatkristalle $(500-700 \mathrm{~nm})$ \\
\hline \multicolumn{2}{|c|}{$\mathrm{Li}_{2} \mathrm{O}, \mathrm{SiO}_{2}$} \\
\hline \multicolumn{2}{|c|}{$\begin{array}{c}\text { Ca. } 10 \% \text { Zirkoniumdioxid }\left(\mathrm{ZrO}_{2}\right) \text { ist komplett in der Glasphase gelöst } \\
\text { und liegt nicht kristallin vor. }\end{array}$} \\
\hline $500 \mathrm{MPa}$ & $210-370 \mathrm{MPa}$ \\
\hline
\end{tabular}


Bei den Zirkonoxidkeramiken handelt es sich um Cercon ${ }^{\circledR}$ ht und Cercon ${ }^{\circledR}$ xt (Dentsply Sirona Prosthetics, Hanau), von welchen die genaue Zusammensetzung in Tabelle 4 dargestellt ist (Dentsply Sirona Prosthetics 2017a). Beide Werkstoffe basieren auf Cercon® base, einem teilstabilisierten Zirkonoxid der ersten Generation. Die neuen Materialien sind transluzenter als Cercon ${ }^{\circledR}$ base. Durch eine Veränderung der Aluminiumoxidkörner im Gefüge ist mit Cercon® ht ein konventionell teilstabilisiertes Zirkonoxid der zweiten Generation entstanden. Bei Cercon ${ }^{\circledR}$ xt handelt es sich um ein Zirkonoxid der dritten Generation, welches zu den vollstabilisierten Zirkonoxiden gehört, bei denen anteilig die kubische Phase bei Raumtemperatur erhalten bleibt. Es ist im Vergleich zu Cercon ${ }^{\circledR}$ ht transluzenter, hat aber eine reduzierte Festigkeit. Bei Cercon® ht beträgt der Yttriumoxidanteil $5 \%$, während er bei Cercon® xt um $4 \%$ höher ist. Cercon® ht verfügt mit $1200 \mathrm{MPa}$ über eine höhere Festigkeit als Cercon® xt mit circa $750 \mathrm{MPa}$ nach Herstellerangaben.

Tabelle 4: Zusammensetzung Cercon ${ }^{\circledR}$ ht und Cercon® xt

\begin{tabular}{|c|c|}
\hline \multicolumn{2}{|c|}{ Cercon ${ }^{\circledR}-$ Yttriumoxid-stabilisiertes Zirkonoxid (Y-TZP) } \\
\hline Cercon ${ }^{\circledR}$ ht & Cercon ${ }^{\circledR} \mathbf{x t}$ \\
\hline Yttriumoxid $(5 \%)$ & Zirkonoxid \\
\hline \multicolumn{2}{|c|}{ Hafniumoxid $(<3 \%)$} \\
\hline Aluminiumoxid und Siliziumoxid $<1 \%$ \\
\hline$\sim 1200 \mathrm{MPa}$ & $\sim 750 \mathrm{MPa}$ \\
\hline
\end{tabular}

Gemeinsam ist diesen neuen Entwicklungen im Bereich der Dentalkeramiken aufgrund ihres Eigenschaftenprofils (Festigkeit, Transluzenz) die Eignung für monolithische Restaurationen. Diese monolithischen Restaurationen, welche insbesondere im Seitenzahnbereich verstärkt eingesetzt werden, sind aktuell von hohem Interesse. Da bei diesen Materialien neben der Festigkeit und der Transluzenz auch eine gute Polierbarkeit wichtig ist, wird dieses Kriterium untersucht. Bislang gibt es Untersuchungen zu den mechanischen Kennwerten dieser Werkstoffe. Daten zur Polierbarkeit sind allerdings noch sehr selten bei der Zirkonoxidkeramik der 3. Generation und der pressbaren ZLS-Keramik (Matzinger et al. 2018). Daher wird die Polierbarkeit in dieser Studie mit einem zweistufigen und einem dreistufigem Universalpoliersystem für Zirkonoxid- und ZLS-Keramiken und anschließend mit verschiedenen Diamantpolierpasten ermittelt. 


\subsection{Literaturübersicht Oberflächenbearbeitung}

Maßgebend für den Erfolg einer Restauration sind neben anderen Parametern insbesondere die Festigkeit/Härte, Passgenauigkeit, Biokompatibilität und Transluzenz einer Restauration. Aber auch die Oberflächenbearbeitung spielt eine wichtige Rolle. Neben der Präparation, der technischen Umsetzung und dem geeigneten Material muss die Oberflächengüte beachtet werden. Es ist bekannt, dass die menschliche Zunge sich schon durch geringste Rauigkeiten irritiert fühlt. Patienten können Rauheitsunterschiede von $0,5 \mu \mathrm{m}$ erkennen (Jones et al. 2004). Gründe für eine bestmögliche Oberflächenausarbeitung/ -politur sind außerdem: (Craig et al. 2006)

- die Entfernung von überschüssigem Material, insbesondere in Gingivanähe um unnötige Reizungen zu vermeiden,

- Glättung rauer Oberflächen, um eine vermehrte Plaqueanlagerung zu verhindern

- und die Verminderung der Abrasionsanfälligkeit und Abrasivität.

Eine raue Oberfläche fördert die Plaquebildung und erhöht somit das Risiko von Karies, Entzündungen der Mundschleimhaut und Parodontopathien (Marxkors et al. 2012). Darüber hinaus begünstigen raue Oberflächen auch exogene Verfärbungen (Rauchen, Tee, Kaffee, Rotwein) und beeinträchtigen somit ebenso die Ästhetik. Durch anschließende Politur nach dem eigentlichen Schleifvorgang kann eine feinere Oberflächenbeschaffenheit wiederhergestellt werden (Aykent et al. 2010; Mühlemann et al. 2018).

Zum Erreichen glatter Oberflächen können wesentliche Schleif- und Poliermittel eingesetzt werden. Sie werden je nach Einsatzbereich unterteilt in: Ausarbeitungs- und Poliermittel (Craig et al. 2006). Die in Frage kommenden Arbeitsmittel werden im nächsten Abschnitt näher erläutert.

\subsubsection{Bearbeitung mit Schleifmitteln}

In der Zahnmedizin gibt es verschiedene Arten von Schleifmitteln. Das Schleifen an sich ist ein spanabhebendes Verfahren (Marxkors et al. 2012).

Zu den Schleifmitteln gehören: Diamant, Silicium- und Wolframcarbid, Korund, Schmirgel, Quarz, Granat, Bimsstein und Tripel. Zur Vermeidung einer zu hohen Wärmeentwicklung und unerwünschter Phasenumwandlungen wird die grundsätzliche Verwendung einer Wasserkühlung empfohlen (Jung und Borchers 2005). 
Die Abrasionsrate wird bestimmt durch die Körnung der Schleifkörper, deren Geschwindigkeit, dem angewendeten Druck und der Art der Oberfläche (Craig et al. 2006). Problematisch ist, dass das Beschleifen eine eventuelle Glasurschicht entfernt und die Oberflächenrauigkeit erhöht (Hmaidouch et al. 2014).

\subsubsection{Politurvorgänge und -mittel}

Die Politur dient dazu, die beschliffene Oberfläche zu glätten. Sie ist unumgänglich, um nach dem Beschleifen der Restauration eine glatte, ebene Oberfläche zu erreichen (Park et al. 2017). Umgesetzt wird dies durch einen weiteren, jedoch nur geringfügigen Materialabtrag. Allgemeine Poliermittel sind: Schlämmkreide, Kalkspat, Wiener Kalk, Chrom-, Eisen-, Magnesium-, Zinn- und Zinkoxid (Jung und Borchers 2005).

Die glatte Oberfläche vermeidet nicht nur die Anlagerung von Plaque und somit die Entstehung von Karies und Parodontopathien (Marxkors et al. 2012). Es wurde weiterhin festgestellt, dass eine raue Oberfläche eine höhere Abnutzung des Antagonisten verursacht (Heintze et al. 2008; Jung et al. 2010; Mitov et al. 2012; Preis et al. 2012; Preis et al. 2013; Sabrah et al. 2013; Stawarczyk et al. 2013). Diese Feststellung weist auf die Notwendigkeit einer guten Oberflächenbehandlung hin (Ghazal und Kern 2009).

Bei keramischen Restaurationen kann die Oberflächenbearbeitung über eine Politur oder einen Glanzbrand erfolgen. In einer Studie von Janyavula et al. (2013) wurden bei Zirkonoxiden im Durchschnitt Rauheitswerte von 0,17 $\mu \mathrm{m}$ nach Politur im Vergleich zu $0,76 \mu \mathrm{m}$ nach Glasurbrand ermittelt (Janyavula et al. 2013). Diese Werte sind vergleichbar mit denen aus der Studie von Park et al. (2014), welche sich auch auf Zirkonoxidkeramiken bezog (Park et al. 2014). In einer Studie von Amaya-Pajares et al. (2016) wurden Zirkonoxidkeramiken nach Politur und nach Glanzbrand und IPS® Empress (LeuzitGlaskeramik) und IPS ${ }^{\circledR}$ e.max (Lithium-Disilikat-Glaskeramik) nach Glanzbrand gegenübergestellt. Die Rauheitswerte bei den Zirkonoxiden betrugen 0,12 - 0,24 $\mu \mathrm{m}$ nach Glanzbrand und 0,04-0,07 $\mu \mathrm{m}$ nach Politur. Bei den Glaskeramiken wurden nach Glanzbrand Werte von 0,29-0,37 $\mu$ m ermittelt (Amaya-Pajares et al. 2016).

In einigen In-vitro-Studien wurde an polierten Oberflächen weniger Antagonistenabrasion festgestellt als an den Glasierten (Heintze et al. 2008; Jung et al. 2010; Janyavula et al. 2013; Amer et al. 2014; Lawson et al. 2014; Burgess et al. 2014). Die Studienlage ist 
allerdings gespalten darüber, welcher dieser Vorgänge eine bessere Oberfläche schafft (Kozmacs et al. 2017). In jedem Fall muss auch nach einem Glanzbrand die finale Anpassung im Mund über eine erneute Politur der eingeschliffenen Oberfläche erfolgen (Preis et al. 2015a). Laut Sethi et al. (2013) und Khayat et al. (2018) kann eine adäquate Politur eine mit einem zusätzlichen Glanzbrand vergleichbare Oberfläche schaffen (Sethi et al. 2013; Khayat et al. 2018).

Das Ziel der Politur ist eine Bearbeitung der Oberfläche bis zum Hochglanz, welcher bei einer maximalen Rautiefe von 0,25 $\mu \mathrm{m}$ erreicht ist (Marxkors et al. 2012). Zur Minimierung der Oberflächen-Rautiefe werden bei Dentalkeramiken rotierende Schleifkörper mit feinster Bindung und Struktur angewandt (Hoffmann 2009). Hierbei handelt es sich meist um diamantdurchsetzte Polierer, abrasive Gummikelche oder Steine und Keramikpolierpasten. Zu den Polierpasten gehören Aluminiumoxidpolierpasten und Diamantpolierpasten (Sasahara et al. 2006; Jefferies 2007; Silva et al. 2014).

Es sind verschiedenste Poliersysteme für die Endpolitur von keramischen Restaurationen erhältlich. Diese zeigen Rauheitswerte von 0,24 - 0,79 $\mu \mathrm{m}$ für Silikatkeramiken und 0,12 - 0,2 $\mu \mathrm{m}$ für Zirkonoxidkeramiken (Aravind et al. 2013; Amer et al. 2014; Preis et al. 2015b).

Spezielle Zirkonoxid-Poliersysteme wurden von Steiner et al. (2015) getestet und ihr Nutzen mit Rauheitswerten unter 0,5 $\mu \mathrm{m}$ belegt. Bei den untersuchten Keramiken handelt es sich um IPS $®$ Empress (Leuzit-Glaskeramik), IPS $®$ e.max (Lithium-Disilikat-Keramik), VITAPM® 9 (Feldspatkeramik), Cergo ${ }^{\circledR}$ Kiss und Imagine ${ }^{\circledR}$ Press X (Presskeramiken mit leuzithaltigem Silikatglas). Die Studie konnte belegen, dass die Wirkung der Zirkonoxid-Poliersysteme auch auf Feldspatkeramiken höher war als die der Feldspat-Poliersysteme (Steiner et al. 2015). Auch die Studie von Park et al. (2017) bestätigt die verbesserte Oberflächenpolitur durch speziell für Zirkonoxid entwickelte Poliersysteme im Vergleich zu den konventionellen Keramik-Poliersystemen (Park et al. 2017).

In einer Studie von Preis et al. (2015) wurden Cercon ${ }^{\circledR}$ base und Cercon ${ }^{\circledR}$ ht (Zirkonoxide), Cercon® ceram (Feldspatkeramik) und IPS® e.max (Lithiumdisilikatkeramik) untersucht. Es wurden zwei- und dreistufige Poliersysteme genutzt. Eine signifikante Reduktion der Oberflächenrauigkeit wurde bereits durch den ersten Polierschritt erreicht. Die weiteren Polierschritte verringerten die Oberflächenrauigkeit, jedoch nicht signifikant. Die zweistufigen Systeme sind nicht statistisch signifikant unterschiedlich zu den dreistufigen Systemen. Nach allen Polierschritten ergaben sich durchschnittliche Ra- 
Werte von $0,06 \mu \mathrm{m}$ bis $0,26 \mu \mathrm{m}$. In einem System wurde zudem ein Ra-Wert von 0,65 $\mu \mathrm{m}$ ermittelt, welcher von den anderen Werten abwich. Der Einsatz von zwei- und dreistufigen Poliersystemen verbesserte die Oberfläche, die Systeme unterschieden sich untereinander aber nicht signifikant in ihren Ergebnissen (Preis et al. 2015a).

Die Endbearbeitung mit einer zusätzlichen Polierpaste wird empfohlen, da unabhängig davon, mit welcher Paste poliert wurde, die Oberflächen der Probekörper ohne Paste höhere Rauheitswerte aufweisen (Camacho et al. 2006). Auch in einer Studie von Aravind et al. (2013) wurde der positive Effekt einer Diamantpolierpaste, in diesem Fall der Yeti Polierpaste, auf die Prüfkörper hervorgehoben (Aravind et al. 2013).

\subsubsection{Messung der Rauheit}

Die Rauheit der Oberflächen kann durch verschiedene lineare (Ra, Rz, Rmax) Parameter beschrieben werden (Zinelis et al. 2010; Odatsu et al. 2013; Fasbinder und Neiva 2016). Gemäß DIN EN ISO 4287 stellt Ra den arithmetischen Mittelwert der Beträge aller Profilwerte des Rauheitsprofils, Rz den arithmetischen Mittelwert der Einzelrautiefen und Rmax die maximale Einzelrautiefe dar (Volk 2018). Ra wird als häufigster Parameter für die Auswertung des Effekts von Endbearbeitungs-Protokollen dentaler Keramiken verwendet (Sasahara et al. 2006; Wang et al. 2009; Ozkan und Yilmaz 2010; Flury et al. 2010; Silva et al. 2014). 


\subsection{Fragestellung der Arbeit}

Ein wichtiges Qualitätskriterium neben anderen Parametern wie Festigkeit, Transluzenz, Passgenauigkeit und Biokompatibilität, stellt die Polierbarkeit dar, welche im Mittelpunkt der vorliegenden In-vitro-Studie steht. Es wurden neuentwickelte keramische Werkstoffe, die speziell für die Anfertigung monolithischer Restaurationen geeignet sind, hinsichtlich ihres Polierverhaltens untersucht. Dabei wurden eine Zirkonoxidkeramik der 2. Generation, eine Zirkonoxidkeramik der 3. Generation, eine CAD/CAM ZLS-Keramik und eine ZLS-Keramik für das Pressverfahren verglichen. Die vorliegende Arbeit setzt sich mit folgenden Fragestellungen auseinander:

1. Gibt es Unterschiede im Oberflächenprofil zwischen den unterschiedlichen Keramiken und zwischen den beiden Universalpoliersystemen für Zirkonoxid- und ZLS-Keramiken?

2. Verbessert die Endbearbeitung mit Diamantpolierpasten die Oberflächenrauigkeit monolithischer Keramik-Restaurationen? 


\section{Material und Methoden}

In der vorliegenden Studie wurde das Polierverhalten von vier unterschiedlichen Dentalkeramiken nach Bearbeitung mit zwei Poliersystemen - jeweils mit und ohne Diamantpolierpaste - untersucht. Die Oberflächenrauigkeit wurde über eine Messung mittels Tastschnittverfahren beurteilt.

Es wurden jeweils 30 Prüfkörper der folgenden Zirkonoxid- und ZLS-Keramiken untersucht. Die keramischen Prüfkörper sind von Dentsply Sirona Prosthetics, Hanau:

- Zirkonoxid der 2. Generation $\left(\mathrm{ZrO}_{2} 2\right.$. Generation): Cercon® ht

- Zirkonoxid der 3. Generation $\left(\mathrm{ZrO}_{2}\right.$ 3. Generation): Cercon® xt

- ZLS-Keramik für CAD/CAM (ZLS CAD/CAM): Celtra® Duo

- ZLS-Keramik zum Pressen (ZLS Press): Celtra® Press

\subsection{Versuchsablauf und Kenngrößen}

Insgesamt wurden 120 Prüfkörper aus vier verschiedenen Keramiken hergestellt. Jeweils 30 Prüfkörper jeder Keramik wurden an jeweils zwei Flächen untersucht. Die Oberflächenbearbeitung erfolgte mit zwei unterschiedlichen Poliersystemen und anschließend jeweils mit oder ohne Diamantpolierpaste (Abbildung 2). Beurteilt wurde die Veränderung der Oberflächenrauigkeit in Abhängigkeit vom Keramikwerkstoff und den unterschiedlichen Polierverfahren. Insbesondere der Einfluss der zusätzlichen Anwendung einer Diamantpolierpaste wurde ermittelt.

\begin{tabular}{|c|c|c|c|}
\hline $\begin{array}{l}\mathrm{ZrO}_{2} \text { 2. Generation } \\
\quad\left(\text { Cercon }{ }^{\circledR} \text { ht }\right)\end{array}$ & $\begin{array}{l}\mathrm{ZrO}_{2} \text { 3. Generation } \\
\quad\left(\text { Cercon }{ }^{\circledR} \mathbf{x t}\right)\end{array}$ & $\begin{array}{c}\text { ZLS CAD/CAM } \\
\text { (Celtra }{ }^{\circledR} \text { Duo) }\end{array}$ & $\begin{array}{c}\text { ZLS Press } \\
\text { (Celtra }{ }^{\circledR} \text { Press) }\end{array}$ \\
\hline Fläche 1 im Poliers & ystem 1 & Fläche 2 im Pol & rsystem 2 \\
\hline ohne Polierpaste & mit Polierpaste & ohne Polierpaste & mit Polierpaste \\
\hline
\end{tabular}

Abbildung 2: Versuchsablauf 
Nach der In-vitro-Poliersimulation erfolgten die Oberflächenauswertungen mit Hilfe des „Tastschnittverfahrens“ (MarSurf XR 20, Mahr, Göttingen).

Gemäß DIN EN ISO 3274 ist das Tastschnittverfahren eine messtechnische Methode zur zweidimensionalen Erfassung einer Oberfläche (Mahr GmbH Göttingen 2015): Eine Vorschubeinrichtung bewegt ein Tastsystem mit konstanter Geschwindigkeit horizontal über die Oberfläche. Die Ausmessungen beinhalten ein ertastetes Profil und die Kenngrößen (Abbildung 3). Es handelt sich um ein taktiles (abtastendes) messtechnisches Verfahren, welches in der Mehrzahl von Rauheitsuntersuchungen verwendet wird. Die typischen Kenngrößen sind die Rauheitsparameter Ra, Rz und Rmax, welche in dieser Arbeit untersucht werden. Gemäß DIN EN ISO 4287 stellt Ra den arithmetischen Mittelwert der Beträge aller Profilwerte des Rauheitsprofils, Rz den arithmetischen Mittelwert der Einzelrautiefen und Rmax die maximale Einzelrautiefe dar.

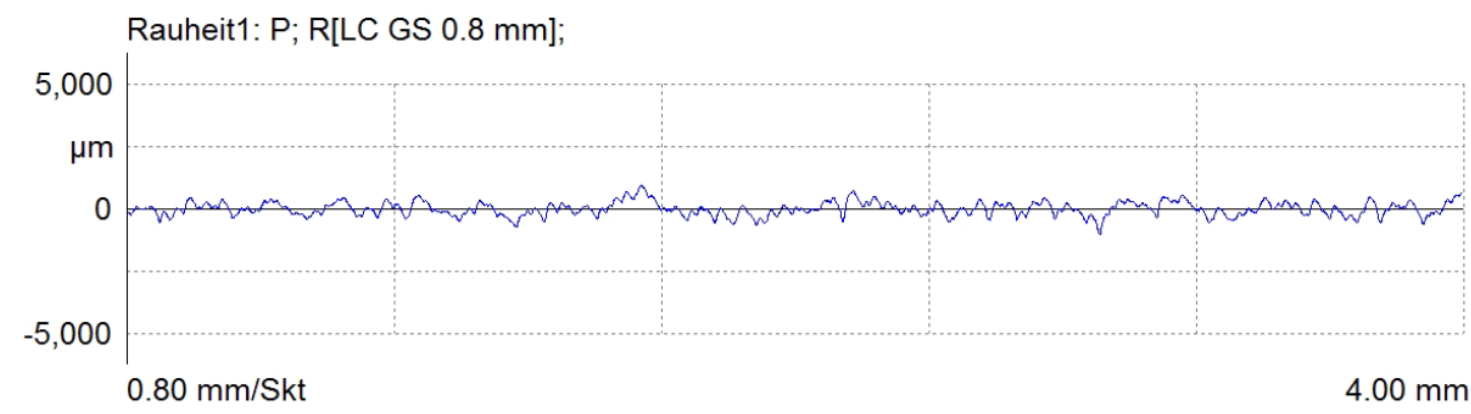

\begin{tabular}{|c|c|c|c|}
\hline & $\mathbf{R a}$ & Rz & Rmax \\
\hline & $\mu \mathrm{m}$ & $\mu \mathrm{m}$ & $\mu \mathrm{m}$ \\
\hline Mittelwert & 0,1878 & 1,2229 & 1,4530 \\
\hline Minimum & 0,1676 & 1,1226 & 1,2996 \\
\hline Maximum & 0,2219 & 1,3957 & 1,7020 \\
\hline Range & 0,0543 & 0,2731 & 0,4024 \\
\hline
\end{tabular}

Abbildung 3: Beispiel Rauheitsprofil im 2D-Tastschnittverfahren 


\subsection{Materialauswahl}

\subsubsection{Prüfkörper der Keramiken}

Die Prüfkörper von Celtra® Duo sind in Quaderform mit abgerundeten Ecken (Abbildung 6), die der anderen Keramiken in Scheibenform (Abbildungen 4, 5, 7). Bei der Quaderform von Celtra ${ }^{\circledR}$ Duo beträgt die Gesamtfläche 14,5 x 12,5 mm und die Höhe 4 mm. Die Gesamtfläche der scheibenförmigen Prüfkörper beträgt 12 x $12 \mathrm{~mm}$ und die Höhe $5 \mathrm{~mm}$. Die zwei verschiedenen Probengeometrien sind zu vernachlässigen, da nur die Lage der Prüffläche von Wichtigkeit ist, und diese wurde auf ein mittiges Prüffeld von $6 \times 6 \mathrm{~mm}$ festgelegt.

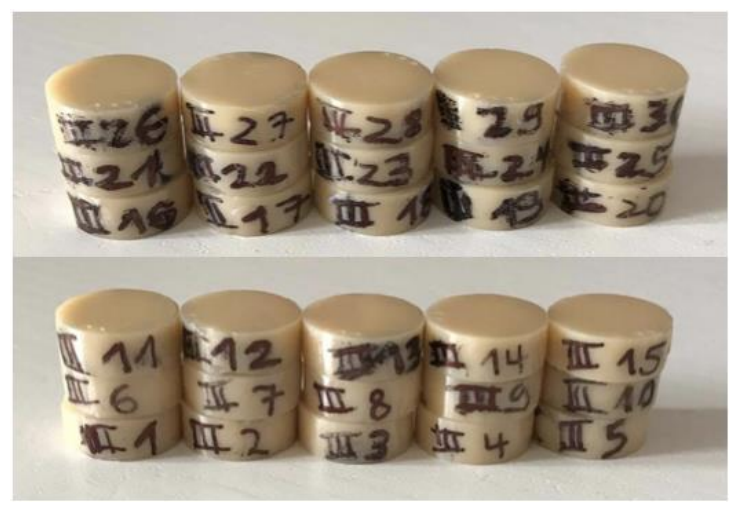

Abbildung 4: $\mathrm{ZrO}_{2}$ 2. Generation (Cercon® ht)

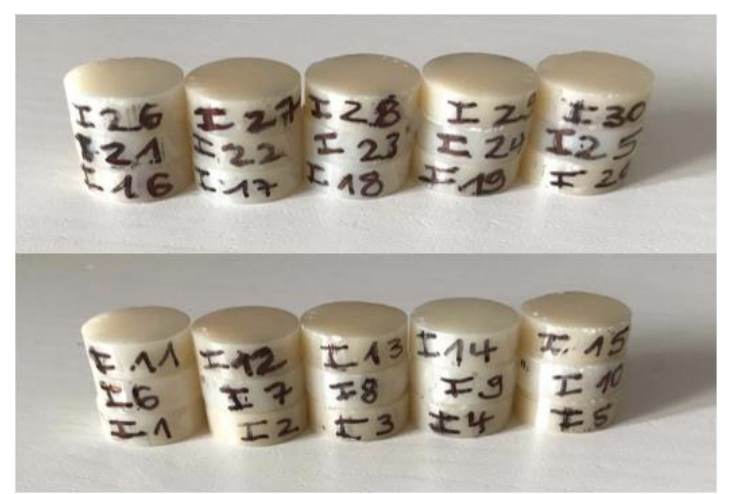

Abbildung 5: $\mathrm{ZrO}_{2}$ 3. Generation $\left(\mathrm{Cercon}{ }^{\circledR} \mathrm{xt}\right)$ 


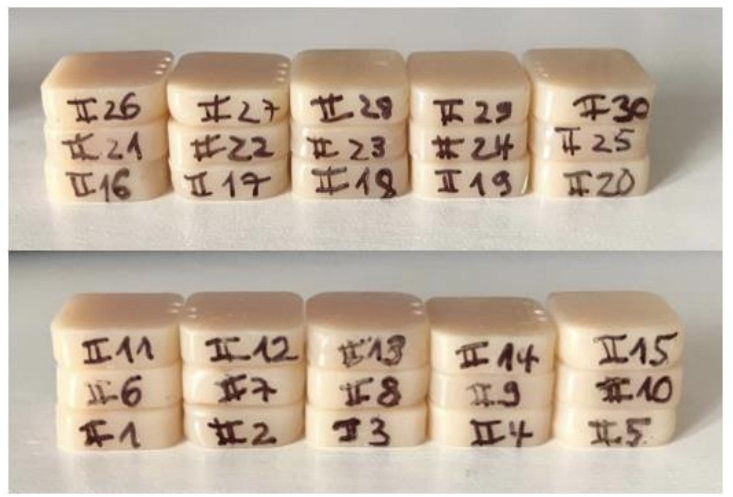

Abbildung 6: ZLS CAD/CAM (Celtra® Duo)

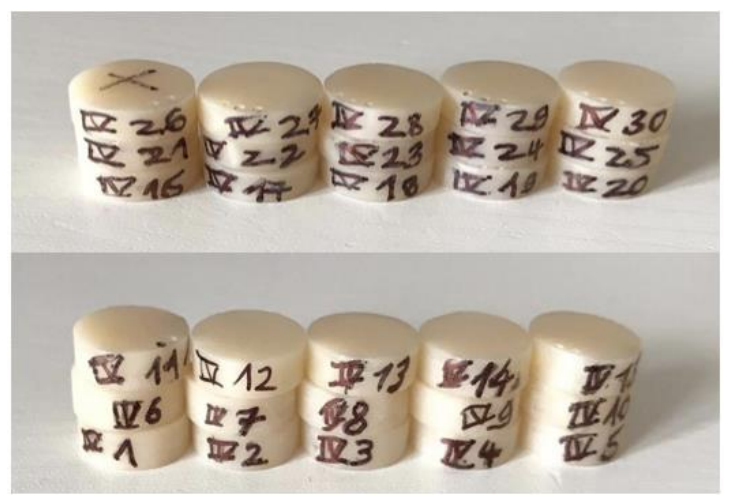

Abbildung 7: ZLS Press (Celtra ${ }^{\circledR}$ Press)

\subsubsection{Poliersysteme}

Jeder Prüfkörper wurde an den beiden jeweils gegenüberliegenden Oberflächen mit zwei unterschiedlichen Poliersystemen bearbeitet:

- Poliersystem 1 (zweistufiges Poliersystem für Hochleistungskeramiken): $\rightarrow$ Polierer für $\mathrm{ZrO}_{2}$, Komet Dental, Lemgo

- Poliersystem 2 (dreistufiges Poliersystem für Zirkonoxid- und Glaskeramiken): $\rightarrow$ ZiLMaster, SHOFU Dental GmbH, Ratingen

Die Polierer für $\mathrm{ZrO}_{2}$ (Komet Dental, Lemgo) sind mit Diamantkorn durchsetzte Polyurethanpolierer für Hochleistungskeramiken in zwei Polierstufen (Abbildung 8). Polierstufe 1 (blau) dient der Vorpolitur und die Polierstufe 2 (hellgrau) der Hochglanzpolitur. Die Polierer sind für Zirkonoxid, Alumiumoxid und Presskeramiken geeignet. Der 
Hersteller empfiehlt beide Stufen nacheinander anzuwenden mit einer optimalen Drehzahl von 6000 U/min und einer maximalen Drehzahl von 10000 U/min (Komet Dental 2016).

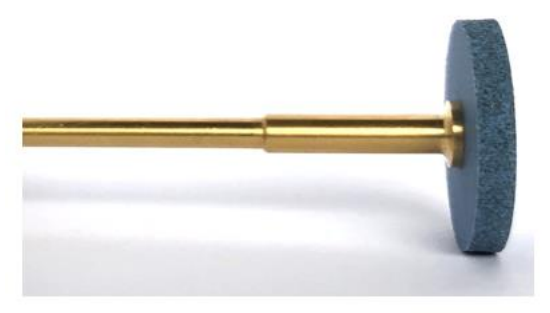

Polierstufe 1

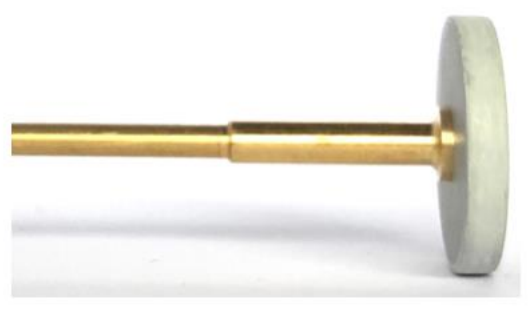

Polierstufe 2

Abbildung 8: Polierer für $\mathrm{ZrO}_{2}$ (Komet Dental, Lemgo)

Bei den ZilMaster Silikonpolierern (SHOFU Dental GmbH, Ratingen) handelt es sich um ein dreistufiges Poliersystem für Zirkonoxid- und Glaskeramiken (Abbildung 9). Die Polierer sind mit Diamantkörnern durchsetzt und das System besteht aus drei unterschiedlichen Körnungen. Die Körnung „Coarse“ (Anthrazit, grüne Schaftmarkierung) wird für das abrasive Vorpolieren und Finieren zuvor beschliffener Bereiche oder Zonen, die noch leicht abgetragen werden müssen, empfohlen. Zum Konturieren und Glätten anatomischer Details, sowie zur Vorbereitung für die Hochglanzpolitur, wird vom Hersteller die Körnung „Medium“ (Rotbraun, blaue Schaftmarkierung) vorgeschlagen. Die feinste Körnung „Fine“ (Hellgrau, gelbe Schaftmarkierung) soll die effiziente Politur bis zum brillanten Hochglanz - sogar ohne den Einsatz weiterer Polierpasten - sicherstellen. Die Polierer sind für Zirkonoxid und Lithiumdisilikat geeignet. Als maximale Drehzahl sind 20000 U/min vom Hersteller angegeben (SHOFU Dental GmbH 2016).

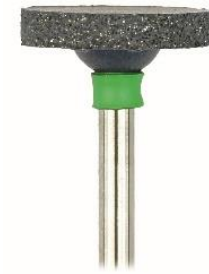

Coarse

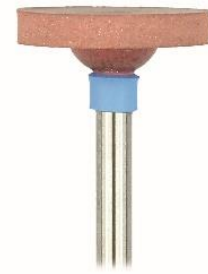

Medium

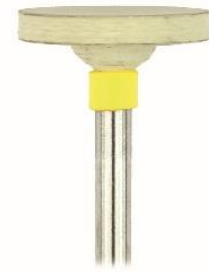

Fine

Abbildung 9: ZiLMaster; Quelle: SHOFU Dental GmbH, Ratingen 
Zusätzlich wurde die Hälfte der Prüfkörper jeder Sorte mit einer Diamantpolierpaste bearbeitet:

- Poliersystem 1: Diamant Polierpaste 9300 Körnung D3 (Komet Dental, Lemgo)

- Poliersystem 2: Dura-Polish DZ (SHOFU Dental GmbH, Ratingen)

Beide Pasten sind für die Hochglanzpolitur von Keramiken geeignet und haben einen hohen Gehalt an Industriediamanten, der für ihre Körnung verantwortlich ist.

Die Partikelstruktur der Diamantpolierpaste von Komet Dental (Komet Dental, Lemgo) liegt bei $2-5 \mu \mathrm{m}$ (Abbildung 10) (Komet Dental 2018).
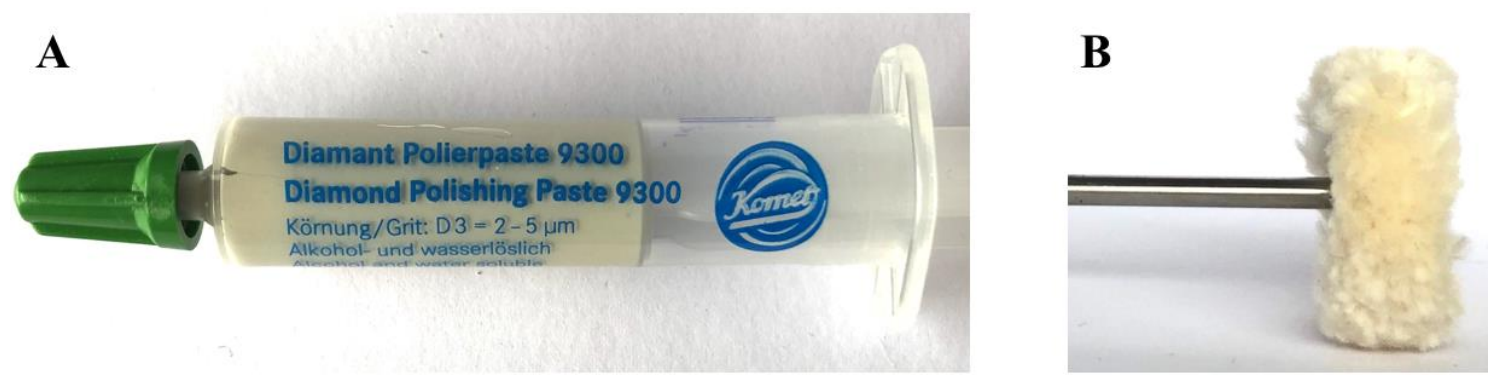

Abbildung 10: A: Diamantpolierpaste 9300 D3 (Komet Dental, Lemgo) und B: Wollrad

Die Dura-Polish Diamantpolierpaste (SHOFU Dental GmbH, Ratingen) ist zu $73 \mathrm{Ge}$ wichtsprozent mit feinen Aluminiumoxidpartikeln imprägniert (Abbildung 11). Sie enthält mit mehr als 67 Gewichtsprozent einen sehr hohen Anteil an Industriediamanten und hat mit $<1 \mu \mathrm{m}$ eine noch feinere Partikelstruktur als die Diamantpolierpaste von Komet Dental (Komet Dental, Lemgo) (SHOFU Dental GmbH 2018).

Die maximale Umdrehungszahl ist laut Herstellerangaben 10000 U/min.
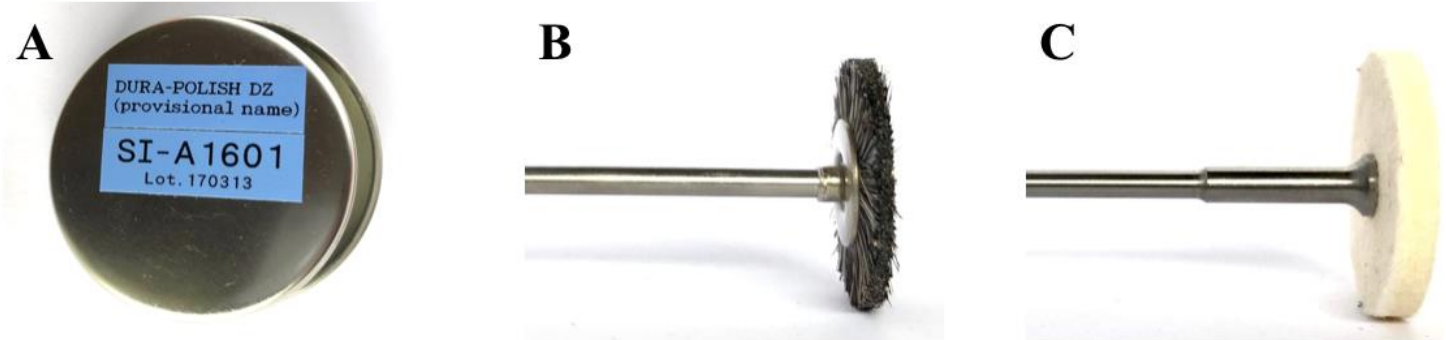

Abbildung 11: A: Dura-Polish DZ (SHOFU Dental GmbH, Ratingen), B: Ziegenhaarbürste, C: Filzrad 


\subsection{Probenherstellung und -bearbeitung}

Bei den Prüfkörpern von Cercon ${ }^{\circledR}$ ht, Cercon ${ }^{\circledR}$ xt und Celtra ${ }^{\circledR}$ Duo handelt es sich um Block-Rohlinge für die CAD/CAM Technik. Bei Celtra® Press handelt es sich um Pellets für die Press-Technologie. Von jeder Keramik gibt es 30 Prüfkörper mit jeweils zwei zu bearbeitenden Flächen.

Alle Oberflächen wurden zuerst mit einem Nassplanschleifer (DIGIREP 251, metkon, Bursa) in gleicher Art und Weise plangeschliffen. Anschließend wurden sie mit zweierlei Poliersystemen bearbeitet. Hierbei wurde jeweils die Hälfte zusätzlich mit Polierpasten poliert. Insgesamt vier Prüfkörper - jeweils von jeder Keramikart einer - wurde nach der Bearbeitung mit dem Planschleifer nicht weiter poliert. Diese plangeschliffenen Prüfkörper dienten dem Zweck, den Ausgangszustand darzustellen. Das Ziel bestand darin den Politurvorgang bei allen Prüfkörpern mit einer annähernd gleichgesetzten Oberfläche zu beginnen (Abbildung 12).

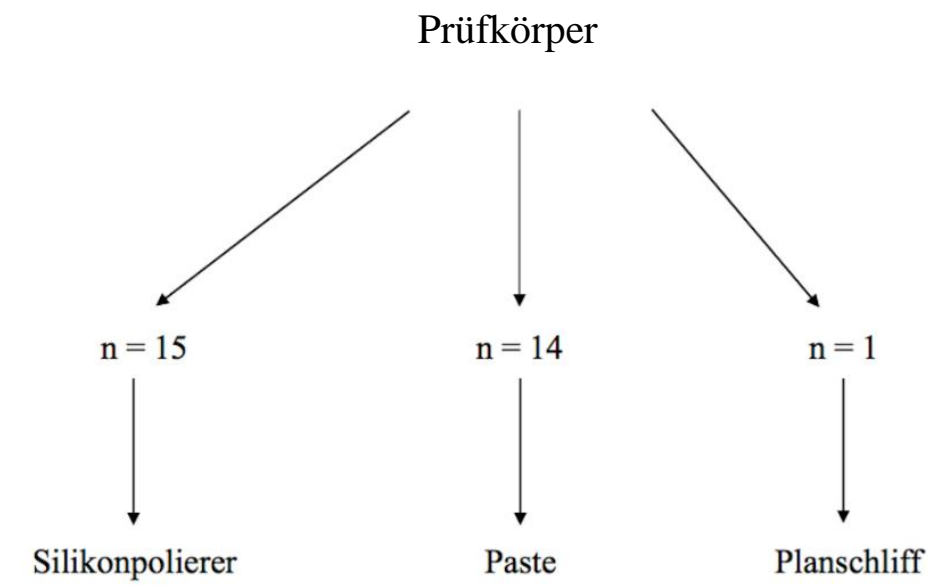

Abbildung 12: Prüfkörperbearbeitung

\subsubsection{Planschliff}

Auf jedem Prüfkörper wurde eine Fläche von ca. 6 x $6 \mathrm{~mm}$ bearbeitet. Zuerst erfolgte eine einheitliche Bearbeitung der Prüfkörperoberflächen mit einem Nassplanschleifer (DIGIREP 251, metkon, Bursa). Durch die feste Einstellung der Parameter Anpresskraft/Zentraldruck, Drehzahl und Zeit am Gerät konnten reproduzierbare Probenqualitäten erreicht werden. Der Planschleifer arbeitet vollautomatisch und die eingestellten Parameter lassen sich in Präparationsprogrammen abspeichern und jederzeit erneut aufrufen. Der Schleifkopf des Systems steuert den exakten Schleifdruck und drückt die 
Prüfkörper mit einer gewählten Anpresskraft von $10 \mathrm{~N}$ auf die Scheibe mit dem Schleifpapier. Die Drehzahl der Scheibe wurde auf 150 U/min und die des Schleifkopfes auf 75 U/min eingestellt. Scheibe und Schleifkörper bewegten sich unter Wasserkühlung in gegenläufigen Drehrichtungen zueinander. Als Schleifpapier wurde ein Papier der Körnung 1200 gewählt, um eine plane Oberfläche mit konstanter Oberflächen-Rauigkeit zu erhalten. Die Bearbeitungszeit wurde auf 60 s festgelegt. Die genaue Auswahl der einzelnen Parameter wurde in einem Vorexperiment ermittelt. Ziel war es, eine plane Fläche mit definierter Oberflächenrauigkeit zu erlangen, um die Poliersysteme mit vergleichbaren Prüfkörpern durchzuführen. Daher wurden die optimalen Parameter im Rahmen eines Vorversuchs evaluiert.

Die Anpresskraft von $10 \mathrm{~N}$ wurde festgelegt, da diese Kraft ausgereicht hat, um die Prüfkörper gut auf das Schleifpapier zu pressen. Ein höherer Druck war nicht nötig, da die Prüfkörper sich in einer Vorrichtung befanden (Abbildung 13). Mit einem niedrigeren Druck wurden die Prüfkörper nicht stark genug auf die Unterfläche gepresst. Die Zeit wurde auf $60 \mathrm{~s}$ festgelegt, da in diesem Zeitfenster ein ausreichender Planschliff möglich war. Experimente mit $30 \mathrm{~s}$ haben nicht zufriedenstellende plangeschliffene Oberflächen ergeben und die Bearbeitung von mehr als einer Minute hat die Oberfläche nicht besser plangeschliffen als die Einstellung mit 60 s. Die Drehzahl der Scheibe wurde doppelt so hoch gewählt wie die des Schleifkopfes. Der Schleifkopf sorgt mit einer gegenläufigen Drehzahl von 75 U/min für eine gute Rotation der Prüfkörper, ist jedoch nicht so entscheidend wie die höhere Drehzahl der Scheibe. Die Drehzahl der Scheibe ist bedeutender, da sich hier das Schleifpapier befindet, welches für den Planschliff der Oberflächen sorgt. Es hat sich gezeigt, dass bei einer Einstellung der Drehzahl der Scheibe auf $150 \mathrm{U} / \mathrm{min}$ gut vergleichbare plangeschliffene Oberflächen entstehen.
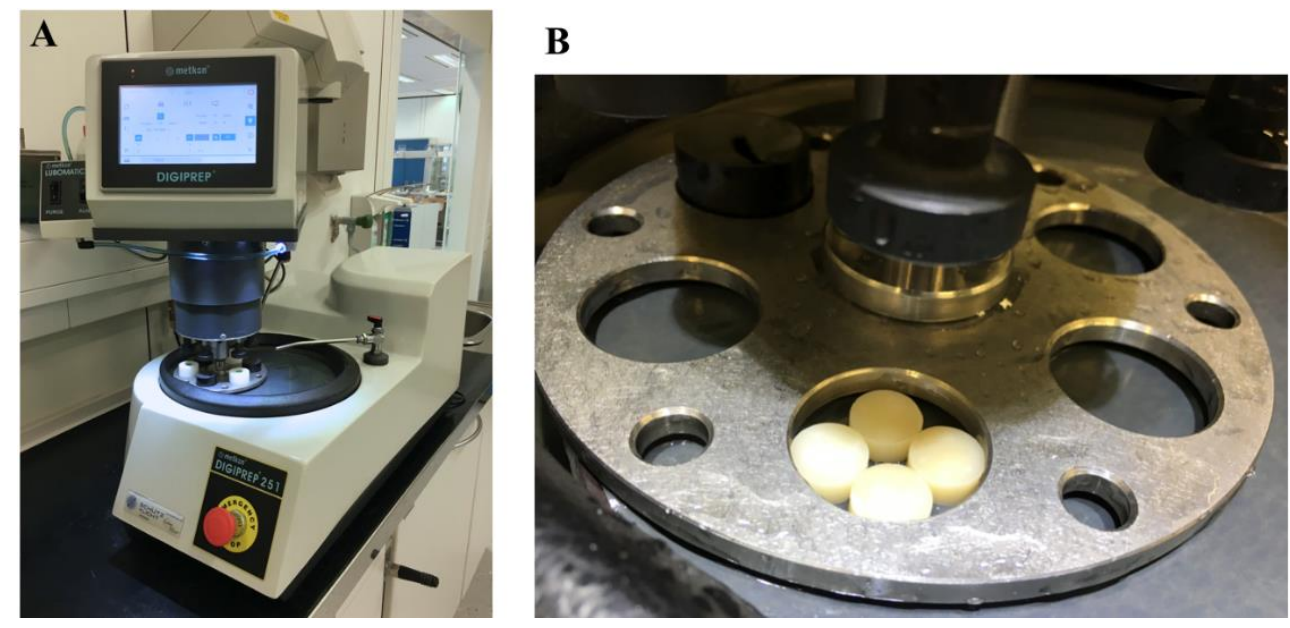

Abbildung 13: A: Nassplanschleifer (DIGIREP 251, metkon, Bursa) und B: Prüfkörper 


\subsubsection{Politur}

Bei der anschließenden Politur wurden die Prüfkörper per Hand in eine Richtung poliert, um standardisierte Auswertebedingungen zu schaffen. Die Politur erfolgte auf der einen Seite der Prüfkörper mit dem Poliersystem 1 (Komet Dental, Lemgo) und auf der anderen Seite mit dem Poliersystem 2 (SHOFU Dental GmbH, Ratingen). Jeder Prüfkörper wurde für in jeder Polierstufe für eine festgelegte Zeit poliert. Anschließend wurde die Hälfte derselben Prüfkörper für eine festgelegte Zeit mit einer Diamantpolierpaste bearbeitet. Als Umdrehungszahl wurden 6000 U/min festgelegt. Die maximale Umdrehungszahl - nach Herstellerangaben variierend - wurde nicht überschritten. Die Politur erfolgte ohne Wasserkühlung. Zur Kontrolle wurde jeweils ein Prüfkörper jeder Keramik nicht poliert, sondern im Zustand nach dem Planschliff belassen.

Um die Bearbeitungszeit zu evaluieren, gab es mit dem Poliersystem 1 ein Vorexperiment (Tabelle 5). Im ersten Durchlauf wurde jede Polierstufe für 30 s verwendet und anschlieBend die Hälfte der Prüfkörper für 30 s mit einer Polierpaste und einem Wollrad bearbeitet.

Im zweiten Durchlauf wurde versucht, die Methodik zu verbessern, indem die Kanten der Polierräder gebrochen und die Polierzeit auf 60 s erhöht wurde. Zwischen beiden Durchläufen erfolgte eine Auswertung der Oberflächenrauigkeiten. Die Oberflächenparameter des ersten Durchlaufs (30 s) wurden denen des zweiten Durchlaufs (60 s) gegenübergestellt.

Durch die Verlängerung der Bearbeitungszeit von 30 s auf 60 s konnte keine Verbesserung erreicht werden. Zudem spiegeln Polierzeiten von mehr als einer Minute für ein planes Areal von 6 × 6 mm keine realistischen Einsatzbedingungen wider und würden die klinische Relevanz dieser Studie reduzieren. Vor diesem Hintergrund wurde die Bearbeitungszeit auf $30 \mathrm{~s}$ pro Instrument begrenzt. 
Tabelle 5: Vorexperiment Polierdurchläufe im Poliersystem 1

\section{Cercon® ht}

\begin{tabular}{|l|c|c|c|c|c|c|}
\hline & \multicolumn{3}{|c|}{ PS 1, D1 } & \multicolumn{3}{c|}{ PS 1, D2 } \\
\hline Prüfkörper & Ra & Rz & Rmax & Ra & Rz & Rmax \\
\hline $1-15$ & $\mathbf{0 , 2 0 2}$ & 1,279 & 1,591 & $\mathbf{0 , 2 1 6}$ & 1,304 & 1,704 \\
\hline $16-29$ & $\mathbf{0 , 1 5 7}$ & 0,967 & 1,357 & $\mathbf{0 , 1 9 5}$ & 1,195 & 1,675 \\
\hline
\end{tabular}

\section{$\operatorname{Cercon}{ }^{\circledR} \mathbf{x t}$}

\begin{tabular}{|l|c|c|c|c|c|c|}
\hline & \multicolumn{3}{|c|}{ PS 1, D1 } & \multicolumn{3}{c|}{ PS 1, D2 } \\
\hline Prüfkörper & Ra & Rz & Rmax & Ra & Rz & Rmax \\
\hline $1-15$ & $\mathbf{0 , 2 2 9}$ & 1,450 & 1,812 & $\mathbf{0 , 2 3 3}$ & 1,446 & 1,762 \\
\hline $16-29$ & $\mathbf{0 , 1 7 2}$ & 1,076 & 1,323 & $\mathbf{0 , 2 1 7}$ & 1,321 & 1,708 \\
\hline
\end{tabular}

\section{Celtra ${ }^{\circledR}$ Press}

\begin{tabular}{|l|c|c|c|c|c|c|}
\hline & \multicolumn{3}{|c|}{ PS 1, D1 } & \multicolumn{3}{c|}{ PS 1, D2 } \\
\hline Prüfkörper & Ra & Rz & Rmax & Ra & Rz & Rmax \\
\hline $1-15$ & $\mathbf{0 , 3 6 6}$ & 2,536 & 3,230 & $\mathbf{0 , 2 4 1}$ & 1,508 & 2,193 \\
\hline $16-29$ & $\mathbf{0 , 2 3 2}$ & 1,774 & 2,498 & $\mathbf{0 , 1 7 1}$ & 1,201 & 1,835 \\
\hline
\end{tabular}

\section{Celtra ${ }^{\circledR}$ Duo}

\begin{tabular}{|l|c|c|c|c|c|c|}
\hline & \multicolumn{3}{|c|}{ PS 1, D1 } & \multicolumn{3}{c|}{ PS 1, D2 } \\
\hline Prüfkörper & Ra & Rz & Rmax & Ra & Rz & Rmax \\
\hline $1-15$ & $\mathbf{0 , 2 9 2}$ & 2,419 & 3,559 & $\mathbf{0 , 2 3 2}$ & 1,563 & 3,080 \\
\hline $16-29$ & $\mathbf{0 , 3 4 2}$ & 3,277 & 5,492 & $\mathbf{0 , 4 8 3}$ & 3,818 & 6,545 \\
\hline
\end{tabular}


Aufbau der Hauptversuche:

Poliersystem 1: $\mathrm{ZrO}_{2}$ Polierer, Komet Dental, Lemgo

- 60 s Planschleifer

- $\quad 30$ s Stufe 1

- $\quad 30$ s Stufe 2

- bei der Hälfte der Prüfkörper zusätzlich 30 s Diamantpolierpaste mit Wollrad

Poliersystem 2: ZiLMaster, SHOFU Dental GmbH, Ratingen

- 60 s Planschleifer

- $\quad 30$ s Stufe 1

- $\quad 30$ s Stufe 2

- $\quad 30$ s Stufe 3

- bei der Hälfte der Prüfkörper zusätzlich 30 s Diamantpolierpaste mit Ziegenhaarbürste und 30 s Diamantpolierpaste mit Filzrad 


\subsection{Messverfahren}

\subsubsection{PC-basierendes Rauheitsmessgerät der Mahr GmbH}

Die Oberflächenauswertung erfolgte mittels eines PC-basierenden Mess- und Auswertesystems der Mahr GmbH, Göttingen. Das System umfasst den Messplatz MarSurf XR20 (Mahr GmbH, Göttingen) und die MarSurf Software (Mahr GmbH, Göttingen) und gehört zu der Gruppe der Hochleistungsgeräte der Oberflächenmesstechnik. Die MarSurf Software ist Teil der „MarWin“-Software, eines PC-basierenden Mess- und Auswertesystems (Abbildung 14). Zu dem Messplatz gehört der MarWin-PC mit seinem Monitor und eine Hartgesteinplatte auf der ein XY-Tisch, ein Mesständer, ein Vorschubgerät und ein Tastsystem angebracht sind. Über ein Handbedienfeld werden das Vorschubgerät vertikal, sowie der Tastarm bzw. das Tastsystem horizontal und vertikal bewegt. Am Tastsystem ist der Tastarm mit der Tastspitze mit einem Radius von $2 \mu \mathrm{m}$ montiert.

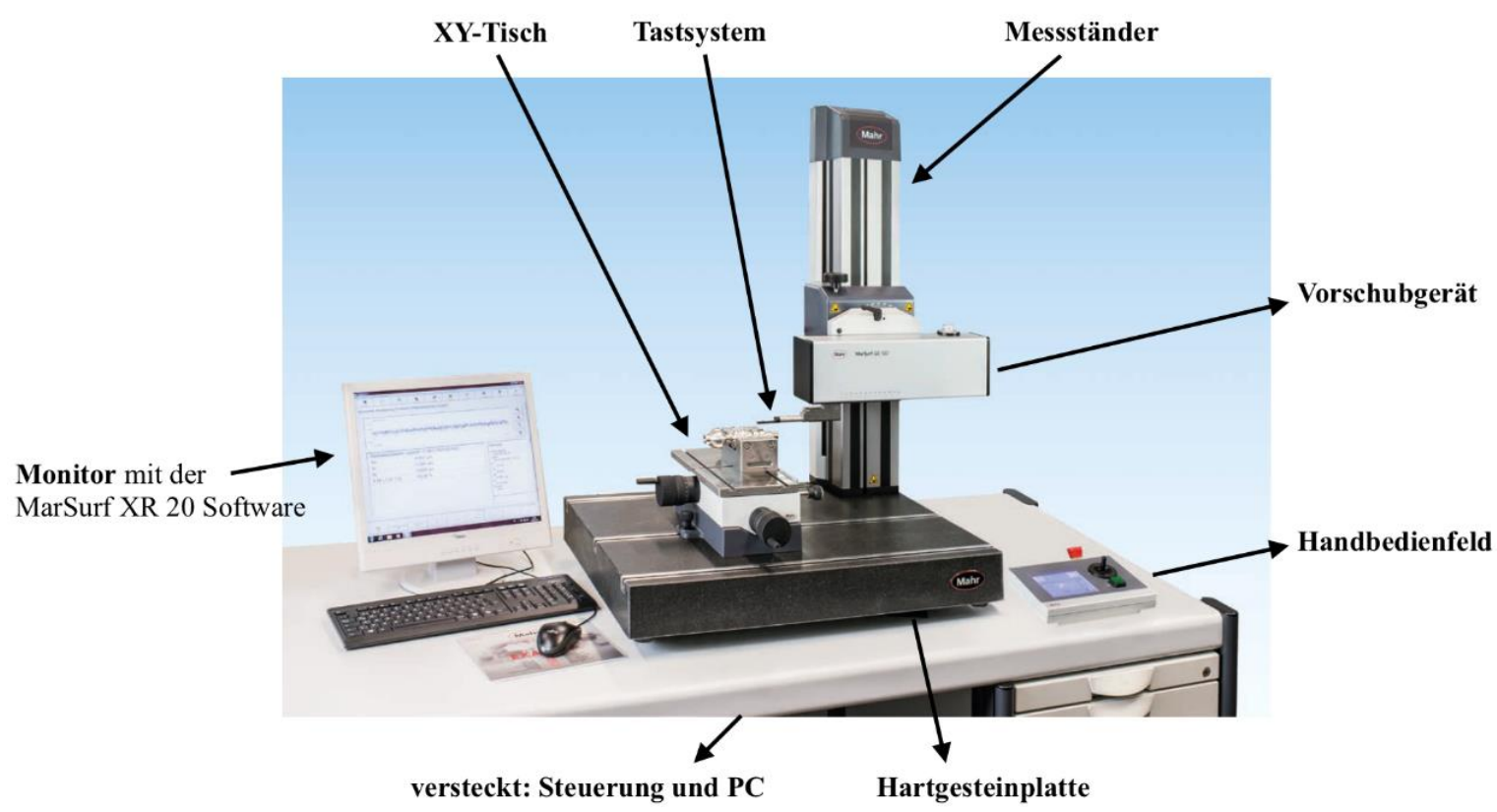

Abbildung 14: Messplatz MarSurf XR 20; Quelle: Mahr GmbH, Göttingen

Die Oberflächenrauigkeit der Prüfkörper wurde in einem standardisierten Aufbau ausgemessen (Abbildung 15). Der Prüfarm fuhr per Tatschnittverfahren in einem Abstand von 2 mm über die Oberfläche der Keramiken, mit einer Prüflänge von 5,6 mm. Es erfolgten drei Messungen pro Prüfkörper, jeweils in der Polierrichtung. Um diese Messungen durchzuführen war es nötig, nur in eine Richtung zu polieren. 


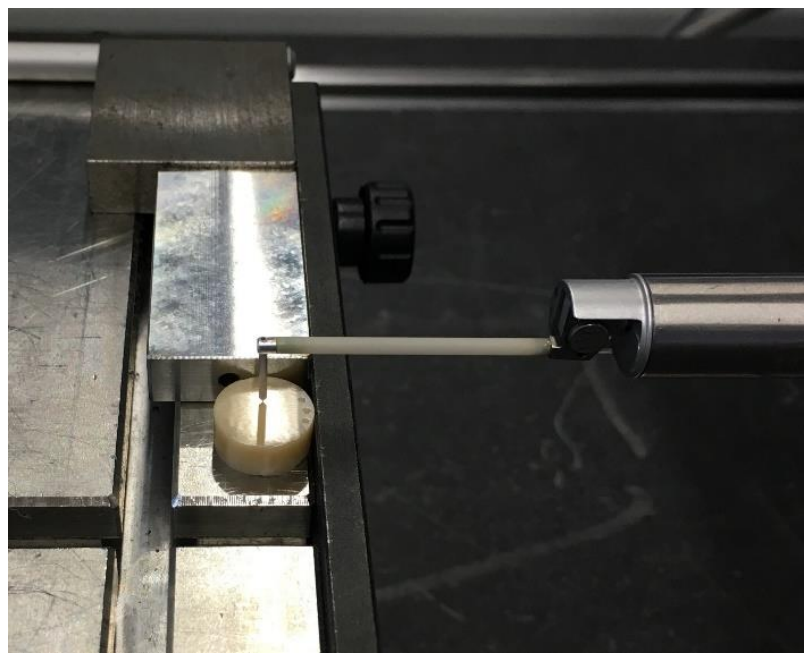

Abbildung 15: Prüfkörperausmessung mit Tastsystem (Mahr GmbH, Göttingen)

\subsubsection{Tastschnittverfahren mit Parametern}

Folgende Werte wurden zur Auswertung mittels Tastschnittverfahren zur 2D-Messung herangezogen:

- der arithmetische Mittenrauwert Ra,

- die gemittelte Rautiefe Rz

- $\quad$ und die maximale Einzelrautiefe Rmax.

Der winkelbewegliche Tastarm wird an einer Bezugsfläche über die Oberfläche der Prüfkörper gezogen. Die Tastspitze bewegte sich dreimal im Abstand von $2 \mathrm{~mm}$ über die Prüfkörper. 


\subsection{Statistische Auswertung}

Die gemessenen Oberflächen-Kenngrößen Ra, Rz und Rmax wurden in einer mit Microsoft Excel 2016 (Microsoft Corporation, Redmond) erstellten Tabelle zusammengetragen. Die statistische Auswertung und graphische Darstellung erfolgten mit der StatistikSoftware Statistica (StatSoft (Europe) GmbH, Berikon).

Über Quantile-Quantile-Plots wurde überprüft, ob eine Normalverteilung der Daten vorliegt. Ein Quantil ist ein Lagemaß und dient dazu, die Datenmenge zu unterteilen. Bei einem Quantil-Quantil-Diagramm werden zwei statistische Variablen gegeneinander abgetragen mit dem Ziel die Verteilungen zu vergleichen. Bilden die Werte der Datenmenge in etwa eine Diagonale bzw. siedeln sich um eine Hilfsdiagonale an, so ist grafisch eine Normalverteilung der Daten zu erkennen (Harms 2012).

Die einzelnen Gruppen sind normalverteilt und können daher über ein parametrisches Verfahren wie die ANOVA (analysis of variance) verglichen werden. Im Rahmen dieser Studie wurde eine zweifaktorielle (two-way) ANOVA verwendet. Bei diesem statistischen Verfahren werden Varianzen und Prüfgrößen berechnet, um Aufschluss über das vorliegende Datenmaterial zu erhalten. Die Varianz der Zielvariablen, in dieser Studie der Rauheitsparameter, wird bei der zweifaktoriellen Analyse durch den Einfluss von zwei Faktoren erklärt (Gaus und Muche 2017). Die zwei Faktoren sind in dieser Studie die Poliersysteme und die Polierpaste.

Die Signifikanz der Unterschiede der einzelnen Testgruppen wurde mittels des post-hoc Tukey tests ermittelt und mit einer anschließenden Bonferroni Korrektur adjustiert. Das Signifikanzniveau wurde auf $5 \%(\alpha=0,05)$ festgesetzt. Bei dem post-hoc Tukey test ist tabellarisch dargestellt, welche Mittelwerte sich signifikant voneinander unterscheiden. Bei der Varianzanalyse können durch das multiple Testen am Datenmaterial Fehler entstanden sein, welche eine anschließende Korrektur dringend notwendig machen. Hierfür werden die signifikanten Werte, die im post-hoc Tukey test aufgezeichnet wurden, mithilfe der Bonferroni-Korrektur adjustiert (Weiß 2013).

In Abbildung 16 ist die Methodik der Oberflächenauswertung in einem Flussdiagramm veranschaulicht. 


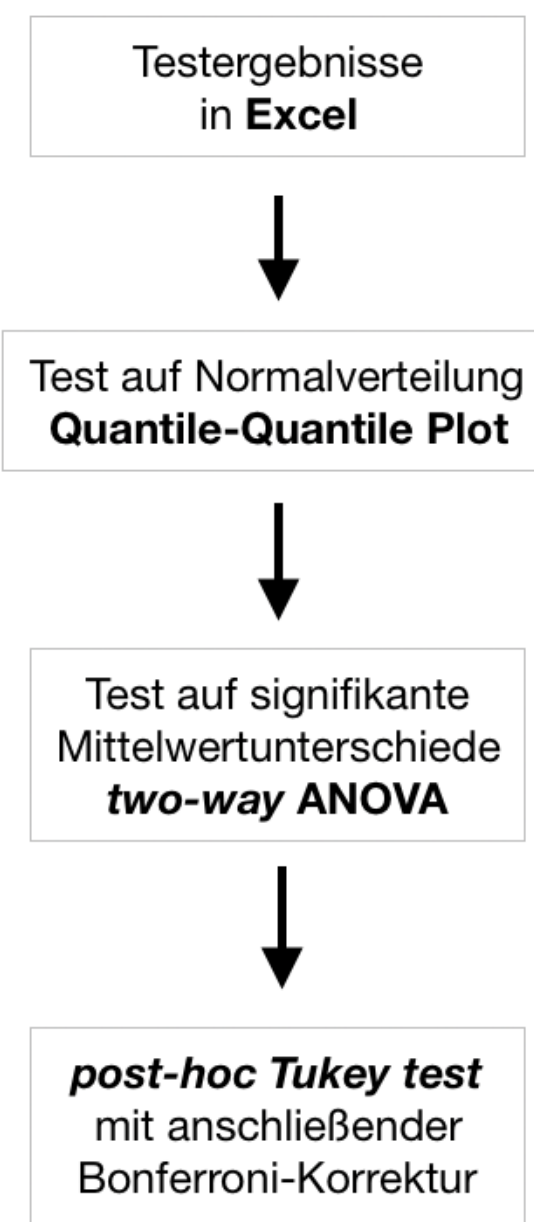

Abbildung 16: Flussdiagramm der statistischen Auswertemethodik 


\section{Ergebnisse}

Es gibt in dieser Studie verschiedene Unterteilungen der Prüfgruppen. Es gibt vier verschiedene Keramiken, zwei Poliersysteme und innerhalb der Poliersysteme den Verzicht und die Nutzung einer Polierpaste (ohne/mit Paste) (Abbildung 17).

\section{$\operatorname{Cercon}{ }^{\circledR}$ ht}

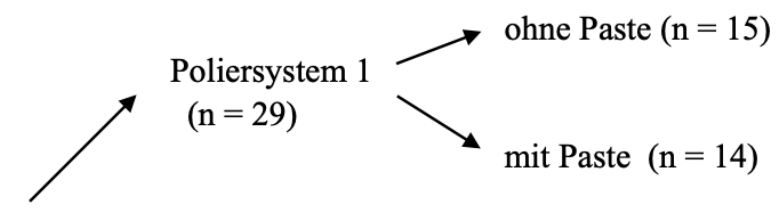

( $\mathrm{ZnO}_{2} 2$ 2. Generation)
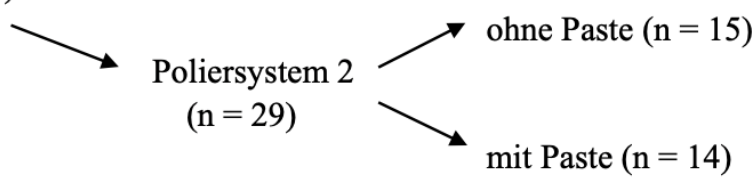

$\operatorname{Cercon}{ }^{\circledR} \mathbf{x t}$

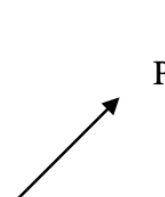

Poliersystem 1

(n=29)

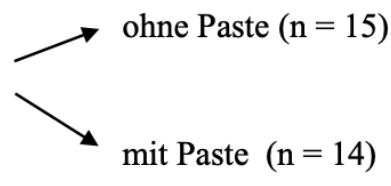

$\left(\mathrm{ZnO}_{2} 3\right.$. Generation)
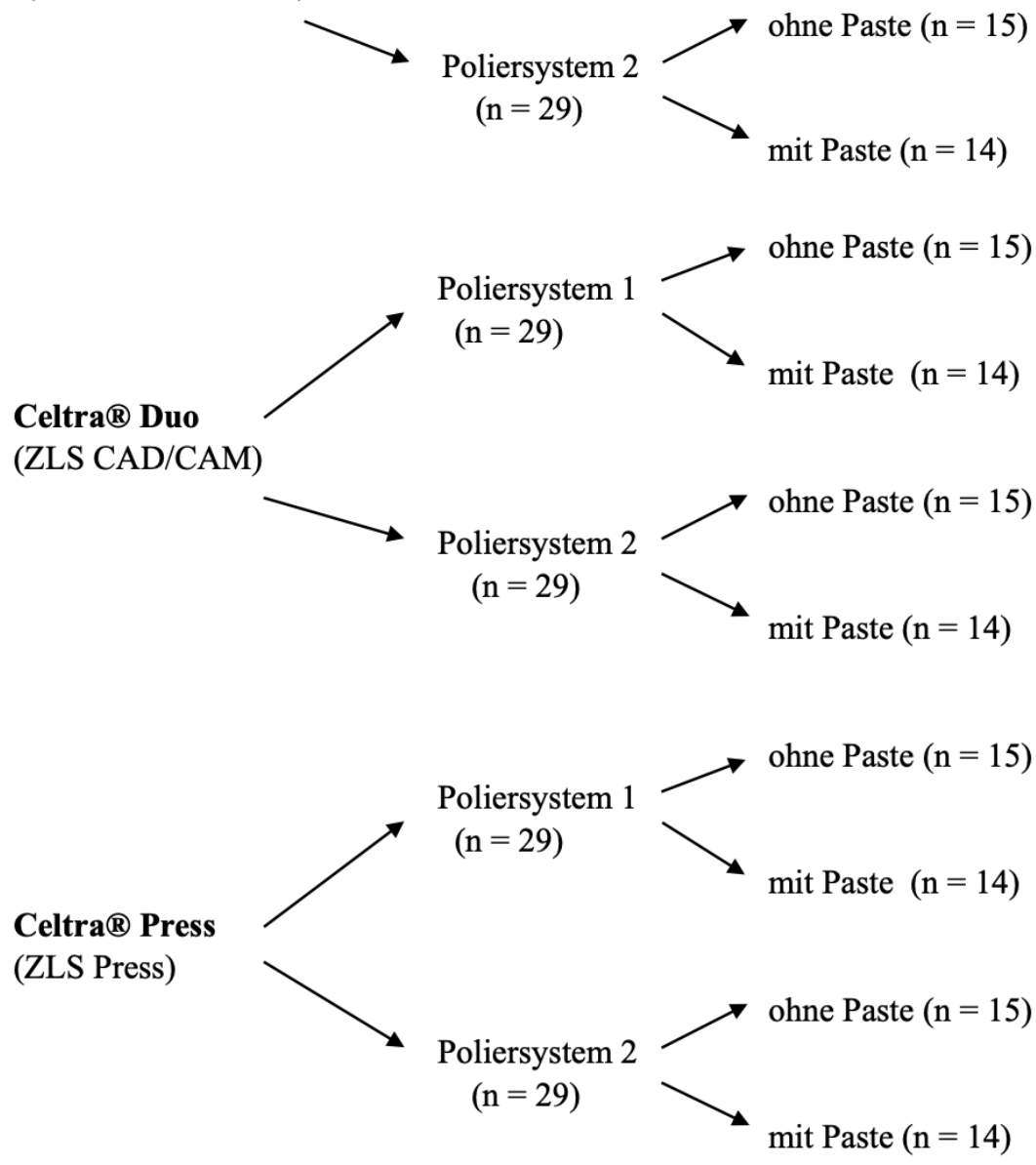

Abbildung 17: Prüfgruppen-Unterteilungen 
Die Messungen des arithmetischen Mittenrauwertes Ra, der arithmetischen Mittenrautiefe Rz und der maximalen Einzelrautiefe Rmax wurden in Polierrichtung durchgeführt.

\subsection{Oberflächenrauigkeit nach dem Planschliff}

Die Oberflächenbeschaffenheit wurde durch den Planschliff bei allen Prüfkörpern annähernd gleichgesetzt (Tabelle 6).

Tabelle 6: durchschnittliche Rauheitsparameter der plangeschliffenen Prüfkörper

\begin{tabular}{|l|l|l|l|}
\hline Cercon ${ }^{\circledR}$ ht & $\mathrm{Ra}=0,06 \mu \mathrm{m}$ & $\mathrm{Rz}=0,43 \mu \mathrm{m}$ & $\mathrm{Rmax}=0,64 \mu \mathrm{m}$ \\
\hline Cercon ${ }^{\circledR} \mathrm{xt}$ & $\mathrm{Ra}=0,05 \mu \mathrm{m}$ & $\mathrm{Rz}=0,42 \mu \mathrm{m}$ & $\mathrm{Rmax}=0,59 \mu \mathrm{m}$ \\
\hline Celtra ${ }^{\circledR}$ Press & $\mathrm{Ra}=0,07 \mu \mathrm{m}$ & $\mathrm{Rz}=0,59 \mu \mathrm{m}$ & $\mathrm{Rmax}=0,73 \mu \mathrm{m}$ \\
\hline Celtra ${ }^{\circledR}$ Duo & $\mathrm{Ra}=0,04 \mu \mathrm{m}$ & $\mathrm{Rz}=0,32 \mu \mathrm{m}$ & $\mathrm{Rmax}=0,44 \mu \mathrm{m}$ \\
\hline
\end{tabular}

Die Rauheitsparameter der Oberflächen der Prüfkörper sind vor der Politur gleichzusetzen. 


\subsection{Mittenrauwert Ra}

Bei den folgenden Werten handelt es sich immer um die durchschnittlichen Ra-Werte der Prüfkörper einer Gruppe (Tabelle 7).

Tabelle 7: Ra-Werte jeder Keramikart im PS 1 und 2, mit und ohne Paste

\begin{tabular}{|l|r|r|r|r|}
\hline Ra in $\mu \mathbf{m}$ & PS 1 ohne Paste & PS 1 mit Paste & PS 2 ohne Paste & PS 2 mit Paste \\
\hline Cercon ${ }^{\circledR}$ ht & 0,20 & 0,16 & 0,17 & 0,08 \\
\hline Cercon ${ }^{\circledR} \mathrm{xt}$ & 0,23 & 0,17 & 0,19 & 0,11 \\
\hline Celtra ${ }^{\circledR}$ Press & 0,37 & 0,23 & 0,27 & 0,12 \\
\hline Celtra ${ }^{\circledR}$ Duo & 0,29 & 0,34 & 1,17 & 0,61 \\
\hline
\end{tabular}

Cercon ${ }^{\circledR}$ ht hat in jeder Kategorie (PS 1/2, ohne/mit Paste) die geringsten Ra-Werte der Keramiken. Die Werte sind 0,20 $\mu \mathrm{m}$ und 0,17 $\mu \mathrm{m}$ ohne Paste und 0,16 $\mu \mathrm{m}$ und 0,08 $\mu \mathrm{m}$ mit Paste in den Poliersystemen 1 und 2 der Keramiken. Im Poliersystem 2 erreicht das Zirkonoxid der 2. Generation niedrigere Ra-Werte als im Poliersystem 1. Dieser Unterschied ist aber nicht statistisch signifikant

Die Ra-Werte von Cercon ${ }^{\circledR}$ xt sind in beiden Poliersystemen nicht signifikant unterschiedlich von denen von Cercon ${ }^{\circledR}$ ht.

Die ZLS-Keramik Celtra ${ }^{\circledR}$ Press weist minimal höhere, aber auch nicht signifikant unterschiedliche Ra-Werte zu den Zirkonoxiden auf. Die Ra-Werte von Celtra® Duo im Poliersystem 1 weisen keine Signifikanz, verglichen mit den anderen Keramiken auf. Im Poliersystem 2 sind die Werte von Celtra® Duo jedoch signifikant erhöht.

Der Effekt der Diamantpolierpaste zeigt sich in einer Reduzierung der Ra-Werte bei den Zirkonoxiden und Celtra ${ }^{\circledR}$ Press um 0,09 $\mu \mathrm{m}$ im Durchschnitt, ist aber nicht statistisch signifikant. Bei Celtra ${ }^{\circledR}$ Duo hat die Polierpaste im Poliersystem 1 keinen Effekt. Hier sind die Werte der Prüfkörper ohne Behandlung mit einer Polierpaste um 0,05 $\mu \mathrm{m}$ geringer. Im Poliersystem 2 zeigt sich jedoch eine statistisch signifikante Reduzierung der RaWerte bei den mit Polierpaste behandelten Prüfkörpern um 0,56 $\mu \mathrm{m}$. 


\subsubsection{Quantile-Quantile Plots Ra}

Mithilfe von Quantile-Quantile Plots wurden die Daten auf eine Normalverteilung geprüft (Abbildung 18). Als Variable wurden die Ra-Werte jeder Keramik erfasst. Anhand der vorliegenden grafischen Diagramme kann man erkennen, dass es sich um eine Normalverteilung handelt, da die Werte nahezu auf einer Diagonalen angesiedelt sind.
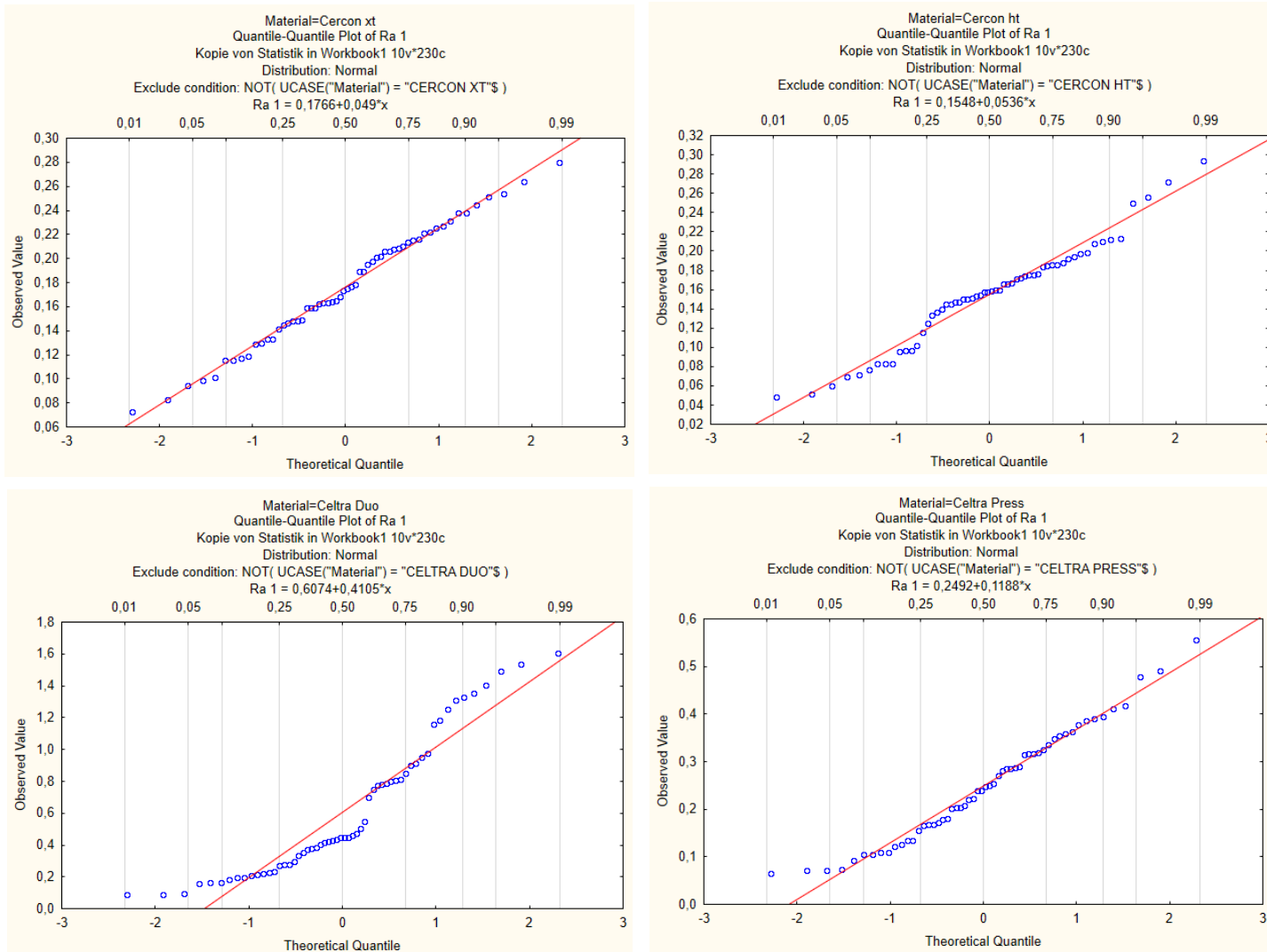

Abbildung 18: Quantile-Quantile Plots der Variablen Ra in Bezug auf jede Keramik

\subsubsection{Statistische Auswertung über two-way ANOVA und post-hoc Tukey test}

Die anschließende Auswertung wurde mit einer zweifaktoriellen Varianzanalyse (twoway) ANOVA durchgeführt, da die einzelnen Gruppen normal verteilt sind. Für die Variable Ra konnte die Oberflächengüte in Abhängigkeit vom Keramikmaterial, dem Poliersystem und der Polierpaste untersucht werden. Bei einem signifikanten p-Wert wurden paarweise Vergleiche zwischen den Parametern gemacht, um die Unterschiede zwischen den Keramiken und Poliersystemen mit und ohne Polierpaste zu ermitteln. Zur Analyse, welche Mittelwerte sich signifikant voneinander unterscheiden $(\alpha=0,05)$, 
wurde ein post-hoc Tukey test angewandt. Die p-Werte wurden mittels einer BonferroniKorrektur adjustiert und sind so im Text angegeben.

In den folgenden zwei Grafiken sind die ermittelten Ra-Werte für die unterschiedlichen Keramikmaterialien in Abhängigkeit vom verwendeten Poliersystem (Poliersystem 1: blau, Poliersystem 2: rot) mit und ohne Polierpaste dargestellt (Abbildung 19, 20).

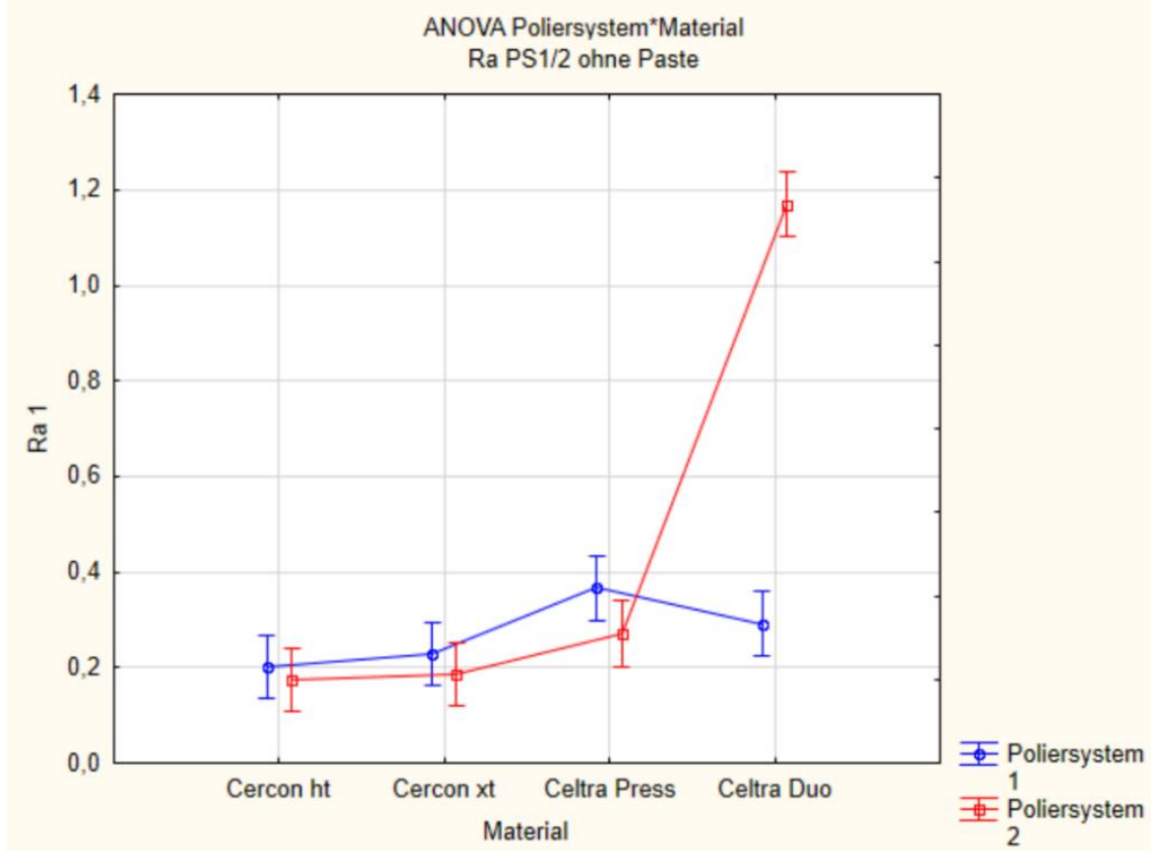

Abbildung 19: Ra-Wert ohne Paste in Abhängigkeit vom Poliersystem

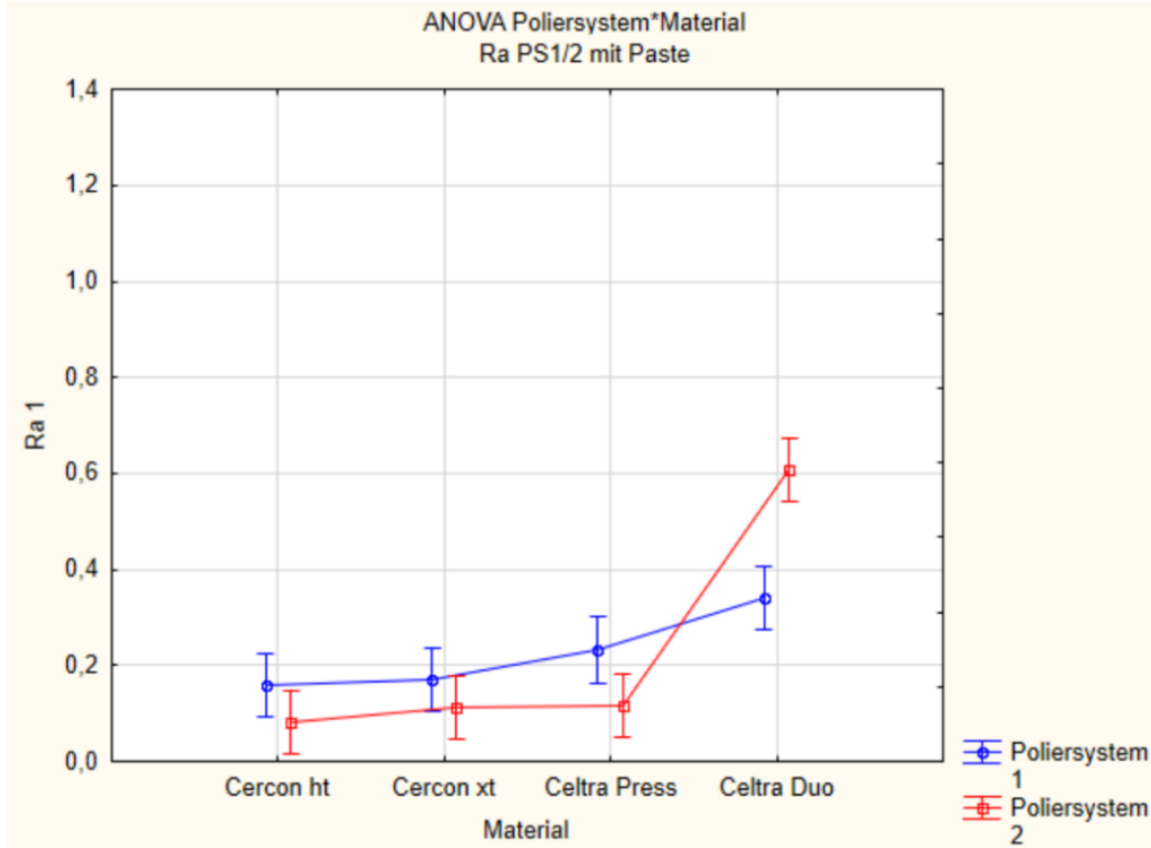

Abbildung 20: Ra-Wert mit Paste in Abhängigkeit vom Poliersystem 
In den weiteren zwei Grafiken sind die für die Keramiken ermittelten Ra-Werte in den Poliersystemen in Abhängigkeit von der Polierpaste (ohne Paste: blau, mit Paste: rot) dargestellt (Abbildung 21, 22).

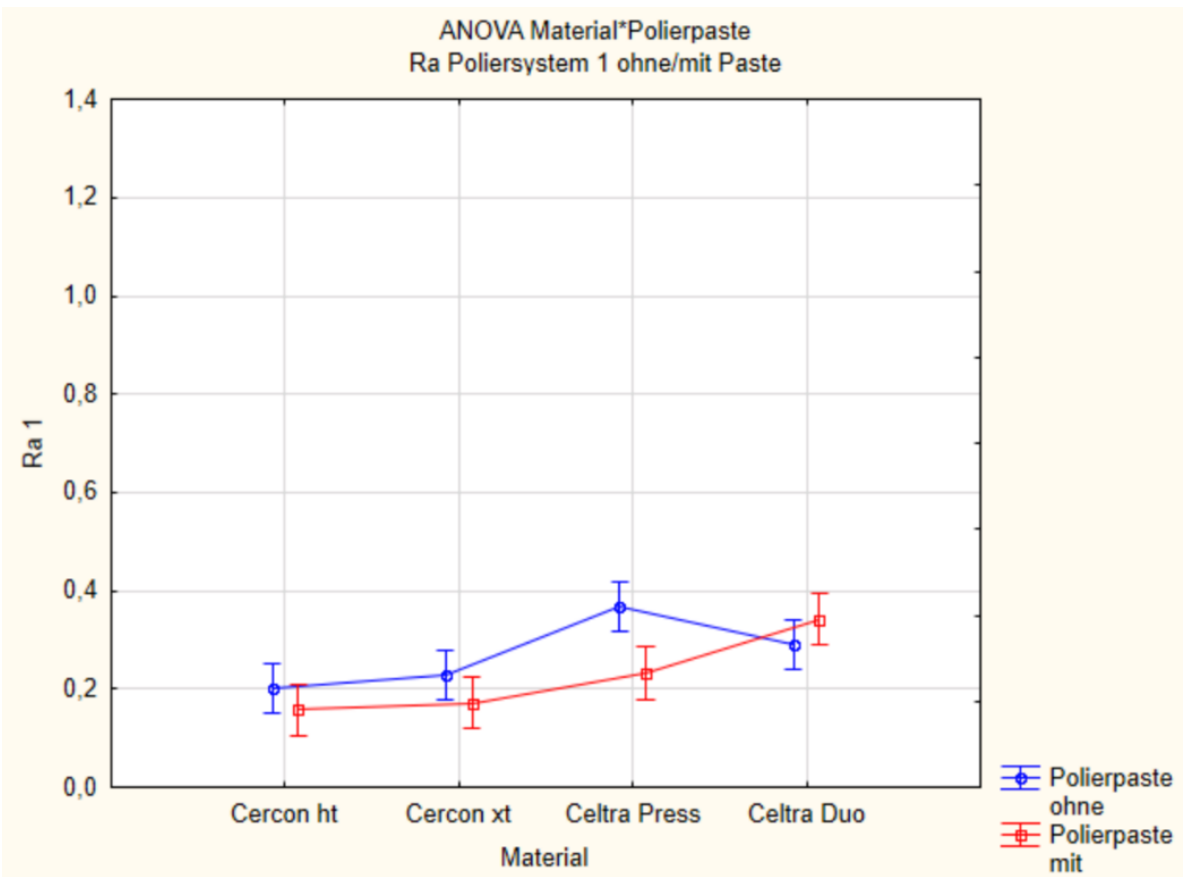

Abbildung 21: Ra-Wert im Poliersystem 1 in Abhängigkeit von der Polierpaste

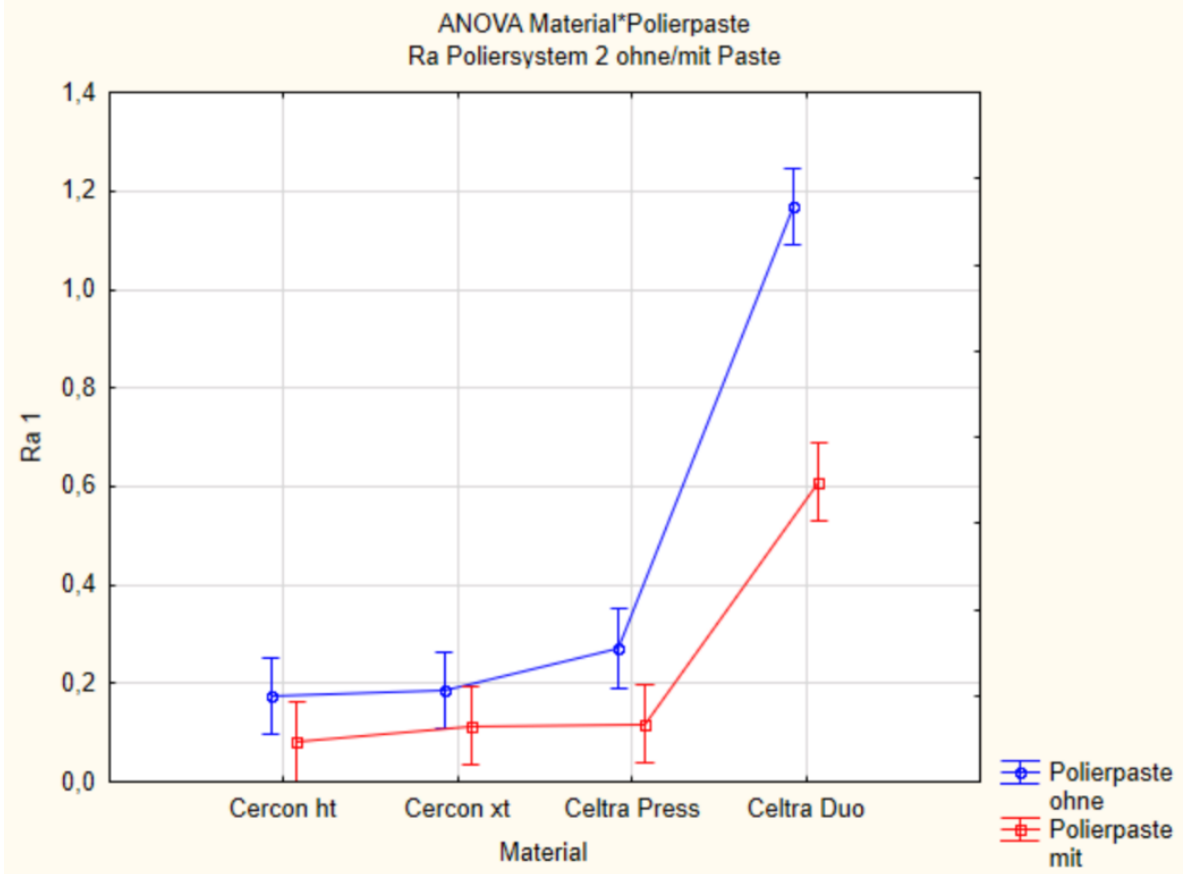

Abbildung 22: Ra-Wert im Poliersystem 2 in Abhängigkeit von der Polierpaste 
Bei der Varianzanalyse ergab sich ein signifikantes Ergebnis $(\mathrm{p}<0,0001)$ und somit sind Unterschiede zwischen den einzelnen Gruppen nachgewiesen. Zur näheren Darstellung dieser Unterschiede wurden nachfolgend paarweise Vergleiche zwischen den Keramiken und Poliersystemen (ohne und mit Paste) gemacht. Innerhalb jeder ANOVA-Auswertung wurde ein post-hoc Tukey test durchgeführt, um zu analysieren welche Mittelwerte sich signifikant voneinander unterscheiden $(\alpha=0,05)$. Die $\mathrm{p}$-Werte sind nach Bonferroni-Korrektur adjustiert im Text angegeben.

Ra PS 1 / 2 ohne Paste

\begin{tabular}{|c|c|c|c|c|c|c|c|c|c|c|}
\hline \multirow[b]{2}{*}{ Cell No } & \multicolumn{10}{|c|}{ Tukey HSD test; variable Ra 1 (Kopie von Statistik in Workbook1) Approximate Probabilities for Post Hoc Tests Error: Between MS $=, 01694, \mathrm{df}=111,00$ Include condition: v4 = 'ohne' } \\
\hline & Poliersystem & Material & \begin{tabular}{|c|}
$\{1\}$ \\
20218 \\
\end{tabular} & \begin{tabular}{|c|}
$\{2\}$ \\
22927 \\
\end{tabular} & \begin{tabular}{|c|}
$\{3\}$ \\
36653 \\
\end{tabular} & \begin{tabular}{|c|}
$\{4\}$ \\
, 29159 \\
\end{tabular} & \begin{tabular}{|c|}
$\{5\}$ \\
17401 \\
\end{tabular} & \begin{tabular}{|c|}
$\{6\}$ \\
.18703 \\
\end{tabular} & \begin{tabular}{|c|}
$\{7\}$ \\
27118 \\
\end{tabular} & \begin{tabular}{|c|}
$\{8\}$ \\
1,1696 \\
\end{tabular} \\
\hline 1 & 1 & Cercon ht & & 0,999195 & 0,017124 & 0,566463 & 0,998963 & 0,999984 & 0,843049 & 0,000118 \\
\hline 2 & 1 & Cercon $x t$ & 0,999195 & & 0,084930 & 0,892806 & 0,940641 & 0,986568 & 0,988453 & 0,000118 \\
\hline 3 & 1 & Celtra Press & 0,017124 & 0,084930 & & 0,762983 & 0,002423 & 0,006149 & 0,505617 & 0,000118 \\
\hline 4 & 1 & Celtra Duo & 0,566463 & 0,892806 & 0,762983 & & 0,217539 & 0,359722 & 0,999894 & 0,000118 \\
\hline 5 & 2 & Cercon ht & 0,998963 & 0,940641 & 0,002423 & 0,217539 & & 0,999994 & 0,480561 & 0,000118 \\
\hline 6 & 2 & Cercon $x t$ & 0,999984 & 0,986568 & 0,006149 & 0,359722 & 0,999994 & & 0,661300 & 0,000118 \\
\hline 7 & 2 & Celtra Press & 0,843049 & 0,988453 & 0,505617 & 0,999894 & 0,480561 & 0,661300 & & 0,000118 \\
\hline 8 & 2 & Celtra Duo & 0,000118 & 0,000118 & 0,000118 & 0,000118 & 0,000118 & 0,000118 & 0,000118 & \\
\hline
\end{tabular}

Ra PS 1 / 2 mit Paste

\begin{tabular}{|c|c|c|c|c|c|c|c|c|c|c|}
\hline \multirow[b]{2}{*}{ Cell No. } & \multicolumn{10}{|c|}{ Tukey HSD test; variable Ra 1 (Kopie von Statistik in Workbook1) Approximate Probabilities for Post Hoc Tests Error: Between MS = ,01539, df = 103,00 Include condition: v4 = 'mit' } \\
\hline & Poliersystem & Material & \begin{tabular}{|c|}
$\{1\}$ \\
.15713 \\
\end{tabular} & \begin{tabular}{|c|}
$\{2\}$ \\
.17204 \\
\end{tabular} & \begin{tabular}{|c|}
$\{3\}$ \\
23215 \\
\end{tabular} & \begin{tabular}{|c|}
$\{4\}$ \\
34220 \\
\end{tabular} & \begin{tabular}{|c|}
$\{5\}$ \\
08092 \\
\end{tabular} & \begin{tabular}{|c|}
$\{6\}$ \\
11356 \\
\end{tabular} & \begin{tabular}{|c|}
$\{7\}$ \\
.11734 \\
\end{tabular} & \begin{tabular}{|c|}
$\{8\}$ \\
60854 \\
\end{tabular} \\
\hline 1 & & Cercon ht & & 0,999984 & 0,766855 & 0,003596 & 0,734111 & 0,982558 & 0,989769 & 0,000119 \\
\hline 2 & & Cercon xt & 0,999984 & & 0,911915 & 0,010252 & 0,525063 & 0,915598 & 0,939603 & 0,000119 \\
\hline 3 & & Celtra Press & 0,766855 & 0,911915 & & 0,302192 & 0,041205 & 0,215063 & 0,251304 & 0,000119 \\
\hline 4 & 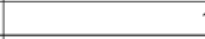 & Celtra Duo & 0,003596 & 0,010252 & 0,302192 & & 0,000123 & 0,000212 & 0,000250 & 0,000122 \\
\hline 5 & & Cercon ht & 0,734111 & 0,525063 & 0,041205 & 0,000123 & & 0,996986 & 0,994013 & 0,000119 \\
\hline 6 & & Cercon xt & 0,982558 & 0,915598 & 0,215063 & 0,000212 & 0,996986 & & 1,000000 & 0,000119 \\
\hline 7 & & Celtra Press & 0,989769 & 0,939603 & 0,251304 & 0,000250 & 0,994013 & 1,000000 & & 0,000119 \\
\hline 8 & 2 & Celtra Duo & 0,000119 & 0,000119 & 0,000119 & 0,000122 & 0,000119 & 0,000119 & 0,000119 & \\
\hline
\end{tabular}

Ra PS 1 mit / ohne Paste

\begin{tabular}{|c|c|c|c|c|c|c|c|c|c|c|}
\hline \multirow[b]{2}{*}{ Cell No. } & \multicolumn{10}{|c|}{ Tukey HSD test; variable Ra 1 (Kopie von Statistik in Workbook1) Approximate Probabilities for Post Hoc Tests Error: Between MS $=, 00965, \mathrm{df}=107,00$ Include condition: v2 $=1$} \\
\hline & Material & Polierpaste & \begin{tabular}{|c|}
$\{1\}$ \\
20218 \\
\end{tabular} & \begin{tabular}{|c|}
$\{2\}$ \\
15713 \\
\end{tabular} & \begin{tabular}{|c|}
$\{3\}$ \\
22927 \\
\end{tabular} & \begin{tabular}{|c|}
$\{4\}$ \\
.17204 \\
\end{tabular} & \begin{tabular}{|c|}
$\{5\}$ \\
, 36653 \\
\end{tabular} & \begin{tabular}{|c|}
$\{6\}$ \\
.23215 \\
\end{tabular} & \begin{tabular}{|c|}
$\{7\}$ \\
, 29159 \\
\end{tabular} & \begin{tabular}{|c|}
$\{8\}$ \\
, 34220 \\
\end{tabular} \\
\hline 1 & Cercon ht & ohne & & 0,919942 & 0,994984 & 0,991333 & 0,000435 & 0,992552 & 0,210070 & 0,005147 \\
\hline 2 & Cercon ht & mit & 0,919942 & & 0,502746 & 0,999924 & 0,000120 & 0,498342 & 0,008493 & 0,000174 \\
\hline 3 & Cercon $x t$ & ohne & 0,994984 & 0,502746 & & 0,768225 & 0,005305 & 1,000000 & 0,663107 & 0,049860 \\
\hline 4 & Cercon xt & mit & 0,991333 & 0,999924 & 0,768225 & & 0,000130 & 0,755992 & 0,029905 & 0,000433 \\
\hline 5 & Celtra Press & ohne & 0,000435 & 0,000120 & 0,005305 & 0,000130 & & 0,010771 & 0,428727 & 0,997729 \\
\hline 6 & Celtra Press & $\mathrm{mit}$ & 0,992552 & 0,498342 & 1,000000 & 0,755992 & 0,010771 & & 0,751318 & 0,081128 \\
\hline 7 & Celtra Duo & ohne & 0,210070 & 0,008493 & 0,663107 & 0,029905 & 0,428727 & 0,751318 & & 0,861666 \\
\hline 8 & Celtra Duo & mit & 0,005147 & 0,000174 & 0,049860 & 0,000433 & 0,997729 & 0,081128 & 0,861666 & \\
\hline
\end{tabular}

Ra PS 2 mit / ohne Paste

\begin{tabular}{|c|c|c|c|c|c|c|c|c|c|c|}
\hline \multirow[b]{2}{*}{ Cell No. } & \multicolumn{10}{|c|}{ Tukey HSD test; variable Ra 1 (Kopie von Statistik in Workbook1) Approximate Probabilities for Post Hoc Tests Error: Between MS $=, 02274, \mathrm{df}=107,00$ Include condition: v2 $=2$} \\
\hline & Material & Polierpaste & \begin{tabular}{|c|}
$\{1\}$ \\
.17401 \\
\end{tabular} & \begin{tabular}{|c|}
$\{2\}$ \\
.08092 \\
\end{tabular} & \begin{tabular}{|c|}
$\{3\}$ \\
.18703 \\
\end{tabular} & \begin{tabular}{|c|}
$\{4\}$ \\
.11356 \\
\end{tabular} & $\begin{array}{c}\{5\} \\
.27118 \\
\end{array}$ & \begin{tabular}{|c|}
$\{6\}$ \\
.11734 \\
\end{tabular} & \begin{tabular}{|l|}
$\{7\}$ \\
1,1696 \\
\end{tabular} & \begin{tabular}{|c|}
$\{8\}$ \\
.60854 \\
\end{tabular} \\
\hline 1 & Cercon ht & ohne & & 0,711856 & 0,999998 & 0,959942 & 0,665099 & 0,971868 & 0,000119 & 0,000119 \\
\hline 2 & Cercon ht & mit & 0,711856 & & 0,558344 & 0,999169 & 0,024827 & 0,998261 & 0,000119 & 0,000119 \\
\hline 3 & Cercon xt & ohne & 0,999998 & 0,558344 & & 0,892799 & 0,804905 & 0,916826 & 0,000119 & 0,000119 \\
\hline 4 & Cercon xt & mit & 0,959942 & 0,999169 & 0,892799 & & 0,114996 & 1,000000 & 0,000119 & 0,000119 \\
\hline 5 & Celtra Press & ohne & 0,665099 & 0,024827 & 0,804905 & 0,114996 & & 0,134244 & 0,000119 & 0,000119 \\
\hline 6 & Celtra Press & mit & 0,971868 & 0,998261 & 0,916826 & 1,000000 & 0,134244 & & 0,000119 & 0,000119 \\
\hline 7 & Celtra Duo & ohne & 0,000119 & 0,000119 & 0,000119 & 0,000119 & 0,000119 & 0,000119 & & 0,000119 \\
\hline 8 & Celtra Duo & mit & 0,000119 & 0,000119 & 0,000119 & 0,000119 & 0,000119 & 0,000119 & 0,000119 & \\
\hline
\end{tabular}

Abbildung 23: post-hoc Tukey tests der ANOVA-Auswertung 
Die ZLS-Keramiken Celtra ${ }^{\circledR}$ Press und Celtra ${ }^{\circledR}$ Duo haben höhere Mittenrauwerte als die Zirkonoxide Cercon ${ }^{\circledR}$ ht und Cercon ${ }^{\circledR}$ xt. Zwischen den Werten der Zirkonoxidkeramiken untereinander gibt es jedoch keinen signifikanten Unterschied (siehe Abbildung 23).

Celtra ${ }^{\circledR}$ Duo ist im Poliersystem 2 ohne und mit Paste $(\mathrm{p}=0,0028)$ und im Poliersystem 1 mit Paste ( $\mathrm{p}=0,0028 ; \mathrm{p}=0,0056 ; \mathrm{p}=0,011)$ signifikant unterschiedlich zu den anderen Keramiken. Diese Keramik hat mit Ra-Werten von 1,17 $\mu \mathrm{m}$ ohne und 0,61 $\mu \mathrm{m}$ mit Diamantpolierpaste im Poliersystem 2 die im Durchschnitt höchsten Werte. Im Vergleich hierzu weisen die anderen Keramiken Werte von 0,17 bis 0,27 $\mu \mathrm{m}$ ohne Paste und 0,08 - 0,12 $\mu \mathrm{m}$ mit Paste auf. Die Werte im Poliersystem 1 mit Paste liegen bei Celtra ${ }^{\circledR}$ Duo signifikant höher mit 0,34 $\mu \mathrm{m}$, während bei den anderen Keramiken Werte von 0,16 bis $0,23 \mu \mathrm{m}$ ermittelt wurden.

Insgesamt haben alle Prüfgruppen (Ausnahme Celtra® Duo im PS 1) ohne Polierpaste höhere Mittenrauwerte als die mit Polierpaste. Eine statistische Signifikanz ist aber, wie schon angegeben, nur bei den Ra-Werten von Celtra ${ }^{\circledR}$ Duo im Poliersystem 2 (ohne/mit Paste) und im Poliersystem 1 (mit Paste) zu sehen. Das dreistufige Poliersystem 2 weist geringere Rauheitswerte auf als das zweistufige Poliersystem 1 (Ausnahme Celtra® Duo). Allerdings ist auch hier keine statistische Signifikanz feststellbar. 


\subsection{Mittenrautiefe $\mathbf{R z}$}

In der Tabelle 8 sind die durchschnittlichen Rz-Werte der Prüfkörper dargestellt.

Tabelle 8: Rz-Werte jeder Keramikart im PS 1 und 2, mit und ohne Paste

\begin{tabular}{|l|r|r|r|r|}
\hline $\mathbf{R z}$ in $\boldsymbol{\mu m}$ & PS 1 ohne Paste & PS 1 mit Paste & PS 2 ohne Paste & PS 2 mit Paste \\
\hline Cercon ${ }^{\circledR} \mathrm{ht}$ & 1,28 & 0,97 & 1,04 & 0,51 \\
\hline Cercon ${ }^{\circledR} \mathrm{xt}$ & 1,45 & 1,08 & 1,30 & 0,87 \\
\hline Celtra ${ }^{\circledR}$ Press & 2,54 & 1,77 & 1,93 & 0,73 \\
\hline Celtra ${ }^{\circledR}$ Duo & 2,42 & 3,28 & 7,11 & 3,57 \\
\hline
\end{tabular}

Auch bei den Rz-Werten hat Cercon ${ }^{\circledR}$ ht in jeder Kategorie (PS 1/2, ohne/mit Paste) wie schon bei den Ra-Werten die niedrigsten Werte. Diese liegen im Durchschnitt bei $1,28 \mu \mathrm{m}$ und 1,04 $\mu \mathrm{m}$ ohne Paste und 0,97 $\mu \mathrm{m}$ und 0,51 $\mu \mathrm{m}$ mit Paste in den Poliersystemen 1 und 2. Die Rz-Werte der Zirkonoxide Cercon ${ }^{\circledR}$ ht und Cercon ${ }^{\circledR}$ xt sind zueinander nicht signifikant unterschiedlich.

Die Rz-Werte von Celtra® Press sind im Vergleich zu den Werten der Zirkonoxide höher, der Unterschied ist aber nicht statistisch signifikant.

Im Poliersystem 2 zeigen sich bei Celtra ${ }^{\circledR}$ Duo wesentlich höhere Werte von 7,11 $\mu \mathrm{m}$ (ohne Paste) und 3,57 $\mu \mathrm{m}$ (mit Paste). Der Unterschied zu den anderen Keramiken ist statistisch signifikant.

Eine Reduktion der Rz-Werte zeigt sich über eine Behandlung der Prüfkörper mit Polierpaste. Bei den Zirkonoxiden und Celtra® Press ist der Wert durch die zusätzliche Bearbeitung mit einer Diamantpolierpaste im Durchschnitt um 0,6 $\mu \mathrm{m}$ geringer. Es zeigt sich aber keine statistische Signifikanz. Im Poliersystem 1 zeigt sich bei Celtra® Duo eine Erhöhung der Rz-Werte um 0,86 $\mu \mathrm{m}$ nach Bearbeitung mit Polierpaste. Dagegen sind die Rz-Werte bei dieser Keramik im Poliersystem 2 statistisch signifikant um 3,54 $\mu \mathrm{m}$ reduziert. 


\subsubsection{Quantile-Quantile Plots Rz}

Die Rz-Werte jeder Keramik wurden als Variablen erfasst und eine Normalverteilung konnte so bestätigt werden (Abbildung 24).
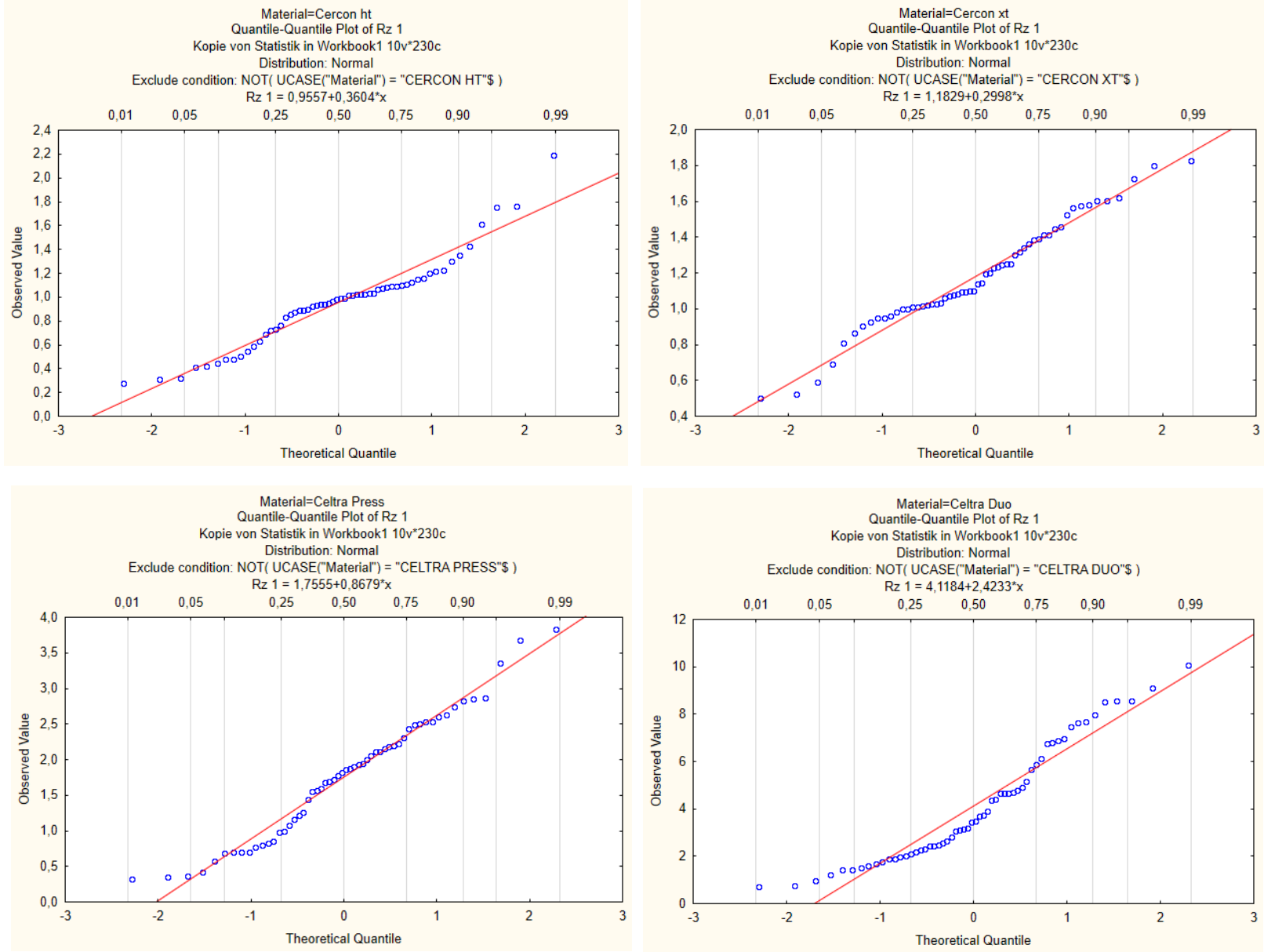

Abbildung 24: Quantile-Quantile Plots der Variablen Rz in Bezug auf jede Keramik

\subsubsection{Statistische Auswertung über two-way ANOVA und post-hoc Tukey test}

Es wurde eine Auswertung über eine two-way ANOVA durchgeführt, da die Daten normalverteilt sind. Über die Variable Rz konnte die Keramikart mit den Poliersystemen und der Paste (ohne/mit) variiert werden. 
In den folgenden zwei Grafiken sind die ermittelten Rz-Werte für die unterschiedlichen Keramikmaterialien in Abhängigkeit vom verwendeten Poliersystem (Poliersystem 1: blau, Poliersystem 2: rot) und der Polierpaste (ohne/mit) dargestellt (Abbildung 25, 26).

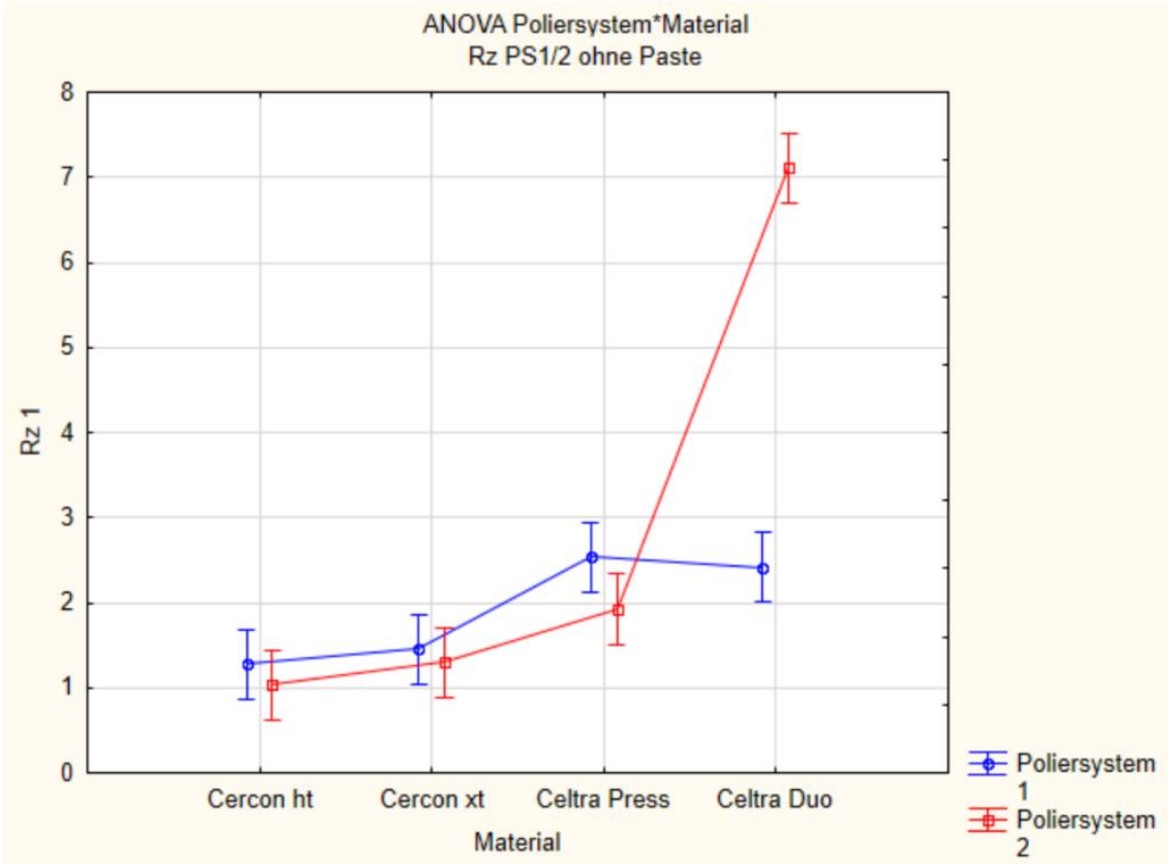

Abbildung 25: Rz-Wert ohne Paste in Abhängigkeit vom Poliersystem

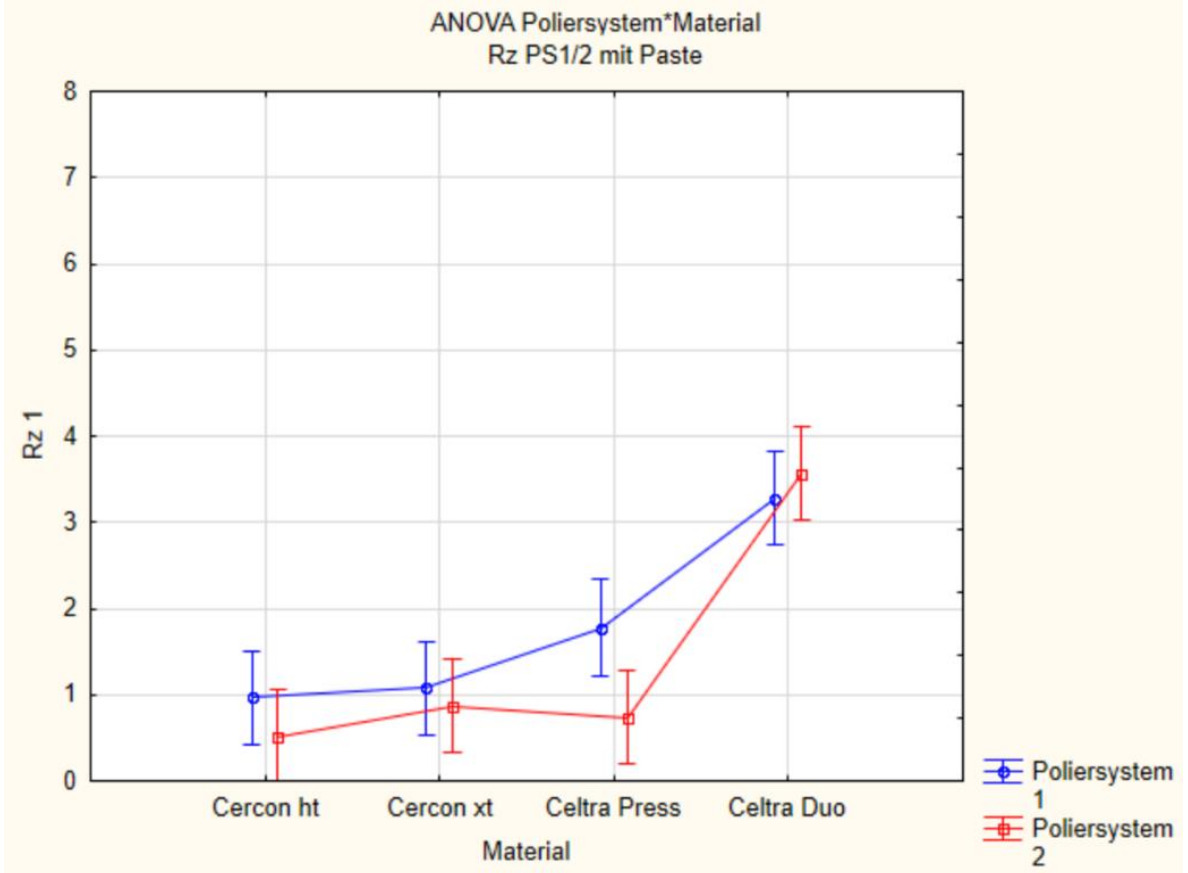

Abbildung 26: Rz-Wert mit Paste in Abhängigkeit vom Poliersystem 
In den weiteren zwei Grafiken sind die Keramiken in den Poliersystemen in Abhängigkeit von der Polierpaste (ohne Paste: blau, mit Paste: rot) gegenübergestellt (Abbildung 27, 28).

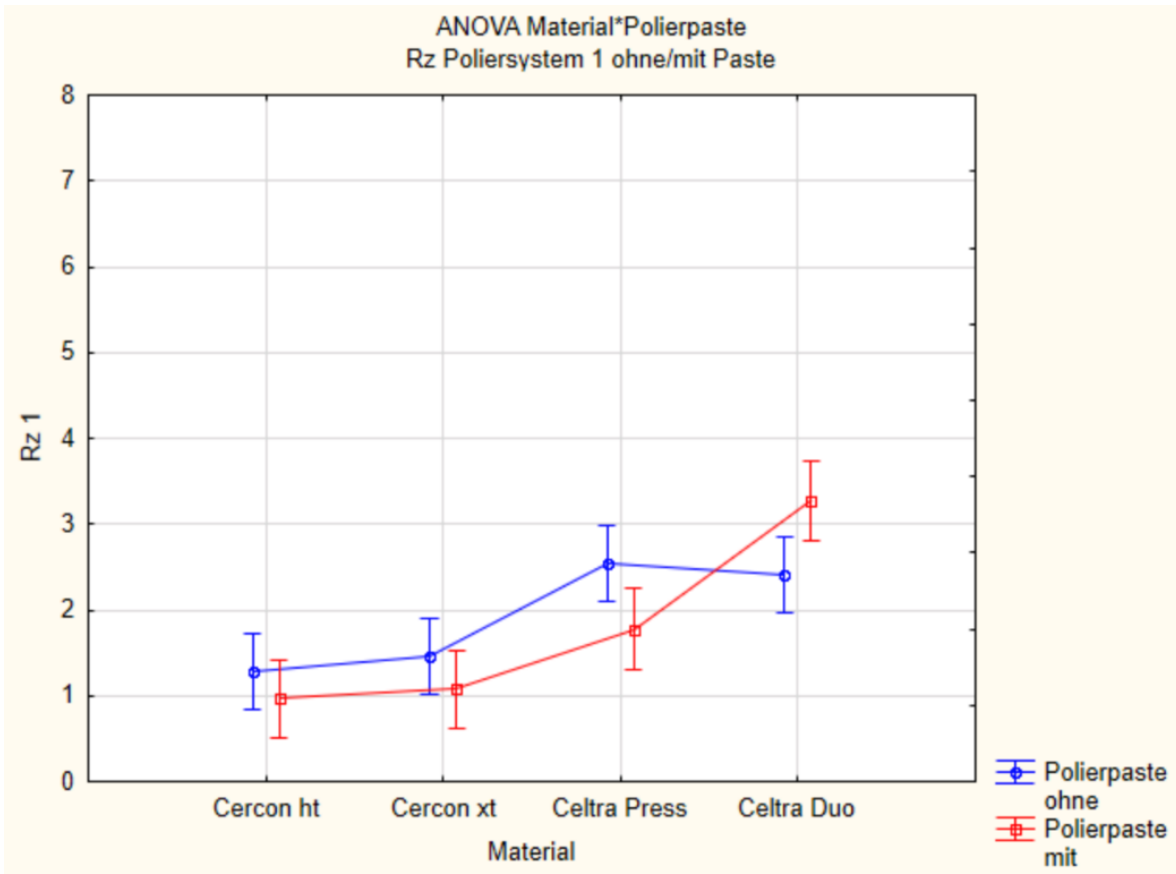

Abbildung 27: Rz-Wert im Poliersystem 1 in Abhängigkeit von der Polierpaste

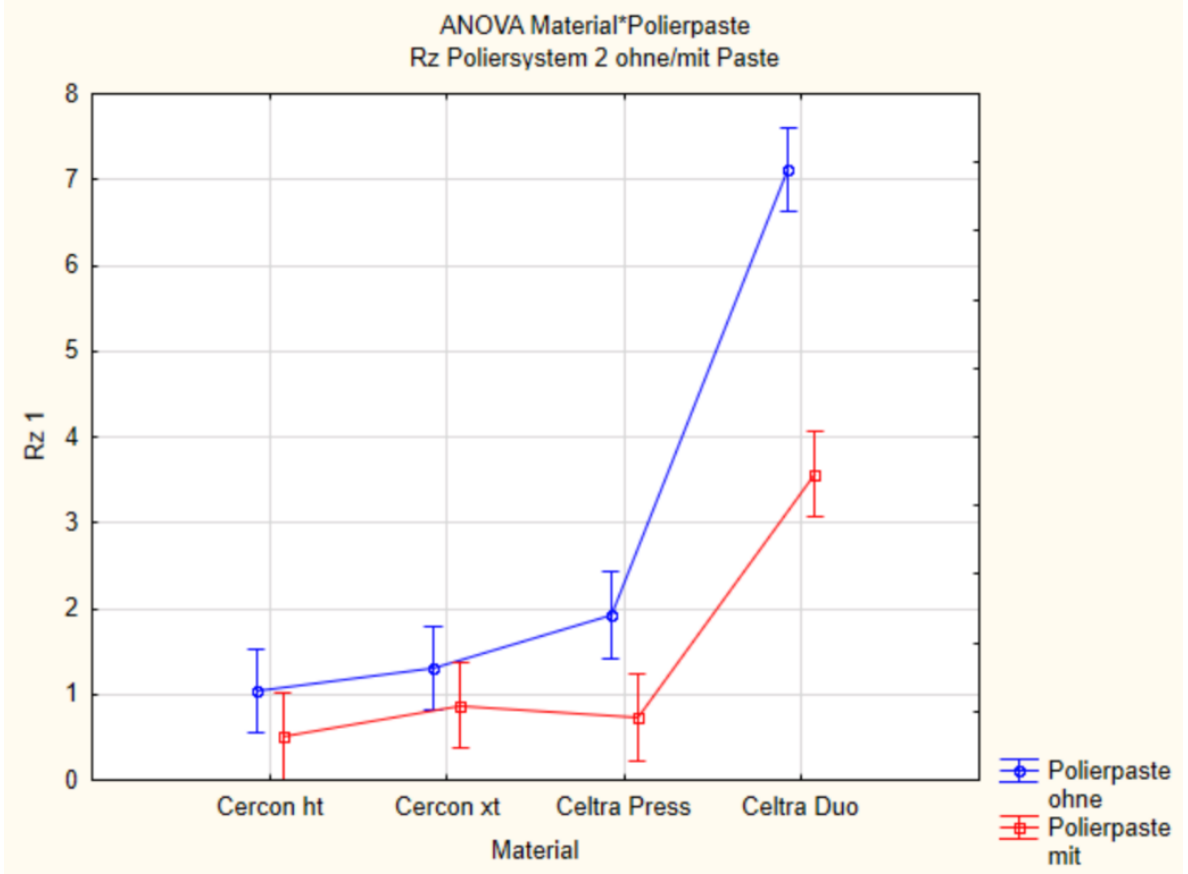

Abbildung 28: Rz-Wert im Poliersystem 2 in Abhängigkeit von der Polierpaste 
Bei der Varianzanalyse ergab sich ein signifikantes Ergebnis $(p<0,0001)$. Daher wurde innerhalb jeder ANOVA-Auswertung ein post-hoc Tukey test mit einer anschließenden Bonferroni-Korrektur durchgeführt.

Rz PS 1 / 2 ohne Paste

\begin{tabular}{|c|c|c|c|c|c|c|c|c|c|c|}
\hline \multirow[b]{2}{*}{ Cell No. } & \multicolumn{10}{|c|}{ Tukey HSD test; variable Rz 1 (Kopie von Statistik in Workbook1) Approximate Probabilities for Post Hoc Tests Error: Between MS =,63208, df = 111,00 Include condition: v4 = 'ohne' } \\
\hline & \begin{tabular}{|l|} 
Poliersystem \\
\end{tabular} & \begin{tabular}{|l|} 
Material \\
\end{tabular} & \begin{tabular}{|c|}
$\{1\}$ \\
1,2789 \\
\end{tabular} & \begin{tabular}{||l|}
$\{2\}$ \\
1,4567 \\
\end{tabular} & $\begin{array}{c}3\} \\
2,5357 \\
\end{array}$ & \begin{tabular}{||c|}
$\{4\}$ \\
2,4191 \\
\end{tabular} & \begin{tabular}{||c|}
$\{5\}$ \\
1,0362 \\
\end{tabular} & \begin{tabular}{||c|}
$\{6\}$ \\
1,2979 \\
\end{tabular} & \begin{tabular}{|l|}
$\{7\}$ \\
1,9250 \\
\end{tabular} & \begin{tabular}{|c|}
$\{8\}$ \\
7,1145 \\
\end{tabular} \\
\hline 1 & 1 & Cercon ht & & 0,998707 & $7 \bigcirc 0,000939$ & 0,003710 & 0,990657 & 1,000000 & 0,367850 & 0,000118 \\
\hline 2 & 1 & Cercon $x t$ & 0,998707 & & 0,007509 & 0,026382 & 0,832390 & 0,999410 & 0,758265 & 0,000118 \\
\hline 3 & 1 & Celtra Press & 0,000939 & 0,007509 & & 0,999924 & 0,000142 & 0,001168 & 0,442574 & 0,000118 \\
\hline 4 & 1 & Celtra Duo & 0,003710 & 0,026382 & 0,999924 & & 0,000257 & 0,004638 & 0,704935 & 0,000118 \\
\hline 5 & 2 & Cercon ht & 0,990657 & 0,832390 & 0,000142 & 0,000257 & & 0,985415 & 0,062292 & 0,000118 \\
\hline 6 & 2 & Cercon xt & 1,000000 & 0,999410 & 0,001168 & 0,004638 & 0,985415 & & 0,407276 & 0,000118 \\
\hline 7 & 2 & Celtra Press & 0,367850 & 0,758265 & 0,442574 & 0,704935 & 0,062292 & 0,407276 & & 0,000118 \\
\hline 8 & 2 & Celtra Duo & 0,000118 & 0,000118 & 0,000118 & 0,000118 & 0,000118 & 0,000118 & 0,000118 & \\
\hline
\end{tabular}

Rz PS 1 / 2 mit Paste

\begin{tabular}{|c|c|c|c|c|c|c|c|c|c|c|c|}
\hline \multirow[b]{2}{*}{ Cell No. } & \multicolumn{11}{|c|}{ Tukey HSD test; variable Rz 1 (Kopie von Statistik in Workbook1) Approximate Probabilities for Post Hoc Tests Error: Between MS = 1,0414, df = 103,00 Include condition: v4 = 'mit' } \\
\hline & Poliersystem & & Material & \begin{tabular}{|c|}
$\{1\}$ \\
, 96694 \\
\end{tabular} & \begin{tabular}{|c|}
$\{2\}$ \\
1,0762 \\
\end{tabular} & \begin{tabular}{|c|}
$\{3\}$ \\
1,7743 \\
\end{tabular} & \begin{tabular}{||c|}
$\{4\}$ \\
3,2772 \\
\end{tabular} & \begin{tabular}{|c|}
$\{5\}$ \\
.51192 \\
\end{tabular} & \begin{tabular}{|c|}
$\{6\}$ \\
87297 \\
\end{tabular} & \begin{tabular}{|c|}
$\{7\}$ \\
73252 \\
\end{tabular} & \begin{tabular}{|l|}
$\{8\}$ \\
3,5700 \\
\end{tabular} \\
\hline 1 & & 1 & Cercon ht & & 0,999993 & 0,451537 & 0,000120 & 0,936015 & 0,999998 & 0,998761 & 0,000119 \\
\hline 2 & & 1 & Cercon xt & 0,999993 & & 0,637481 & 0,000121 & 0,825094 & 0,999536 & 0,986346 & 0,000119 \\
\hline 3 & & 1 & Celtra Press & 0,451537 & 0,637481 & & 0,005440 & 0,036140 & 0,307550 & 0,150380 & 0,000462 \\
\hline 4 & & 1 & Celtra Duo & 0,000120 & 0,000121 & 0,005440 & & 0,000119 & 0,000119 & 0,000119 & 0,994811 \\
\hline 5 & & 2 & Cercon ht & 0,936015 & 0,825094 & 0,036140 & 0,000119 & & 0,981808 & 0,999173 & 0,000119 \\
\hline 6 & & 2 & Cercon xt & 0,999998 & 0,999536 & 0,307550 & 0,000119 & 0,981808 & & 0,999961 & 0,000119 \\
\hline 7 & & 2 & Celtra Press & 0,998761 & 0,986346 & 0,150380 & 0,000119 & 0,999173 & 0,999961 & & 0,000119 \\
\hline 8 & & 2 & Celtra Duo & 0,000119 & 0,000119 & 0,000462 & 0,994811 & 0,000119 & 0,000119 & 0,000119 & \\
\hline
\end{tabular}

Rz PS 1 ohne / mit Paste

\begin{tabular}{|c|c|c|c|c|c|c|c|c|c|c|}
\hline \multirow[b]{2}{*}{ Cell No. } & \multicolumn{10}{|c|}{ Tukey HSD test; variable Rz 1 (Kopie von Statistik in Workbook1) Approximate Probabilities for Post Hoc Tests Error: Between MS $=, 75649, \mathrm{df}=107,00$ Include condition: v2 $=1$} \\
\hline & Material & Polierpaste & \begin{tabular}{|l|}
$\{1\}$ \\
1,2789
\end{tabular} & \begin{tabular}{|c|}
$\{2\}$ \\
96694 \\
\end{tabular} & \begin{tabular}{||c|}
$3\}$ \\
1,4567 \\
\end{tabular} & \begin{tabular}{|c|}
$4\}$ \\
1,0762 \\
\end{tabular} & \begin{tabular}{|c|}
$\{5\}$ \\
2,5357
\end{tabular} & \begin{tabular}{|c|}
$\{6\}$ \\
1,7743 \\
\end{tabular} & \begin{tabular}{||c|}
$\{7\}$ \\
2,4191 \\
\end{tabular} & \begin{tabular}{|c|}
$\{8\}$ \\
3,2772 \\
\end{tabular} \\
\hline 1 & Cercon ht & ohne & & 0,978353 & 0,999284 & 0,998476 & 0,003410 & 0,804277 & 0,011469 & 0,000119 \\
\hline 2 & Cercon ht & mit & 0,978353 & & 0,797643 & 0,999979 & 0,000217 & 0,247387 & 0,000565 & 0,000119 \\
\hline 3 & Cercon xt & ohne & 0,999284 & 0,797643 & & 0,936715 & 0,020819 & 0,978566 & 0,059121 & 0,000121 \\
\hline 4 & Cercon xt & mit & 0,998476 & 0,999979 & 0,936715 & & 0,000527 & 0,431977 & 0,001734 & 0,000119 \\
\hline 5 & Celtra Press & ohne & 0,003410 & 0,000217 & 0,020819 & 0,000527 & & 0,297907 & 0,999959 & 0,306659 \\
\hline 6 & Celtra Press & mit & 0,804277 & 0,247387 & 0,978566 & 0,431977 & 0,297907 & & 0,516044 & 0,000576 \\
\hline 7 & Celtra Duo & ohne & 0,011469 & 0,000565 & 0,059121 & 0,001734 & 0,999959 & 0,516044 & & 0,148412 \\
\hline 8 & Celtra Duo & mit & 0,000119 & 0,000119 & 0,000121 & 0,000119 & 0,306659 & 0,000576 & 0,148412 & \\
\hline
\end{tabular}

Rz PS 2 ohne / mit Paste

\begin{tabular}{|c|c|c|c|c|c|c|c|c|c|c|}
\hline \multirow[b]{2}{*}{ Cell No. } & \multicolumn{10}{|c|}{ Tukey HSD test; variable Rz 1 (Kopie von Statistik in Workbook1) Approximate Probabilities for Post Hoc Tests Error: Between MS $=, 90173, \mathrm{df}=107,00$ Include condition: v2 $=2$} \\
\hline & Material & Polierpaste & \begin{tabular}{|c|}
$\{1\}$ \\
1,0362 \\
\end{tabular} & \begin{tabular}{|c|}
$\{2\}$ \\
, 51192 \\
\end{tabular} & \begin{tabular}{|c|}
$\{3\}$ \\
1,2979 \\
\end{tabular} & \begin{tabular}{|c|}
$\{4\}$ \\
87297 \\
\end{tabular} & \begin{tabular}{||c|}
$\{5\}$ \\
1,9250 \\
\end{tabular} & \begin{tabular}{||c|}
$\{6\}$ \\
73252 \\
\end{tabular} & \begin{tabular}{|c|}
$\{7\}$ \\
7,1145 \\
\end{tabular} & \begin{tabular}{|c|}
$\{8\}$ \\
3,5700 \\
\end{tabular} \\
\hline 1 & Cercon ht & ohne & & 0,813452 & 0,995002 & 0,999805 & 0,199069 & 0,988893 & 0,000119 & 0,000119 \\
\hline 2 & Cercon ht & mit & 0,813452 & & 0,344207 & 0,972678 & 0,003650 & 0,998672 & 0,000119 & 0,000119 \\
\hline 3 & Cercon xt & ohne & 0,995002 & 0,344207 & & 0,929095 & 0,636835 & 0,748015 & 0,000119 & 0,000119 \\
\hline 崖 & Cercon xt & mit & 0,999805 & 0,972678 & 0,929095 & & 0,076544 & 0,999936 & 0,000119 & 0,000119 \\
\hline 5 & Celtra Press & ohne & 0,199069 & 0,003650 & 0,636835 & 0,076544 & & 0,026021 & 0,000119 & 0,000432 \\
\hline 6 & Celtra Press & mit & 0,988893 & 0,998672 & 0,748015 & 0,999936 & 0,026021 & & 0,000119 & 0,000119 \\
\hline 7 & Celtra Duo & ohne & 0,000119 & 0,000119 & 0,000119 & 0,000119 & 0,000119 & 0,000119 & & 0,000119 \\
\hline 8 & Celtra Duo & mit & \begin{tabular}{|c|} 
\\
0,000119
\end{tabular} & 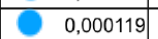 & 0,000119 & 0,000119 & 0,000432 & 0,000119 & 0,000119 & \\
\hline
\end{tabular}

Abbildung 29: post-hoc Tukey tests der ANOVA-Auswertung 
Die Mittenrautiefen der Zirkonoxide Cercon ${ }^{\circledR}$ ht und Cercon ${ }^{\circledR}$ xt sind geringer als die der ZLS-Keramiken Celtra® Press und Celtra ${ }^{\circledR}$ Duo. Bei den Zirkonoxiden wurden RzWerte von 1,04 bis 1,45 $\mu \mathrm{m}$ (ohne Paste) und 0,51 bis 1,08 $\mu \mathrm{m}$ (mit Paste) in den Poliersystemen ermittelt. Anhand der Abbildung 29 kann man sehen, dass es zwischen den Werten der Zirkonoxidkeramiken untereinander keinen signifikanten Unterschied gibt.

Einen signifikanten Unterschied zu allen anderen Keramiken weist Celtra® Duo sowohl im Poliersystem $2(\mathrm{p}=0,0028)$ mit 7,11 $\mu \mathrm{m}$ ohne und 3,57 $\mu \mathrm{m}$ mit Paste als auch mit $3,28 \mu \mathrm{m}$ im Poliersystem 1 mit Paste $(\mathrm{p}=0,0028 ; \mathrm{p}=0,0048)$ auf.

Im Gegensatz zu den Ra-Werten zeigt sich bei den Rz-Werten eine weitere statistische Signifikanz bei Celtra ${ }^{\circledR}$ Press in den Poliersystemen ohne Paste gegenüber Cercon ${ }^{\circledR}$ ht $(\mathrm{p}=0,025)$. Die Rz-Werte von Celtra ${ }^{\circledR}$ Press sind im Poliersystem 1 ohne Paste 2,54 $\mu \mathrm{m}$ (Cercon® ht im Vergleich: 1,28 $\mu \mathrm{m}$ ) und im Poliersystem 2 ohne Paste 1,93 $\mu \mathrm{m}$ (Cercon® ht im Vergleich: 1,04 $\mu \mathrm{m})$.

Mit Ausnahme von Celtra® Duo im PS 1 haben alle Prüfgruppen ohne Polierpaste höhere Mittenrautiefen als die mit Polierpaste. Eine statistische Signifikanz innerhalb der Mittenrautiefen liegt sowohl bei Celtra ${ }^{\circledR}$ Duo als auch bei Celtra ${ }^{\circledR}$ Press vor (siehe oben). Die Mittenrautiefen sind bei dem dreistufigen Poliersystem 2 geringer als bei dem zweistufigen Poliersystem 1 (Ausnahme Celtra ${ }^{\circledR}$ Duo). Eine statistische Signifikanz fehlt jedoch. 


\subsection{Maximale Einzelrautiefe Rmax}

Die durchschnittlichen Rmax-Werte der Prüfkörper sind in Tabelle 9 dargestellt.

Tabelle 9: Rmax-Werte jeder Keramikart im PS 1 und 2, mit und ohne Paste

\begin{tabular}{|l|r|r|r|r|}
\hline Rmax in $\boldsymbol{\mu m}$ & PS 1 ohne Paste & PS 1 mit Paste & PS 2 ohne Paste & PS 2 mit Paste \\
\hline Cercon $®$ ht & 1,59 & 1,36 & 1,52 & 0,90 \\
\hline Cercon $®$ xt & 1,81 & 1,32 & 1,95 & 1,35 \\
\hline Celtra ${ }^{\circledR}$ Press & 3,23 & 2,49 & 3,60 & 1,50 \\
\hline Celtra ${ }^{\circledR}$ Duo & 3,56 & 5,49 & 11,23 & 6,81 \\
\hline
\end{tabular}

Genau wie bei den Rz- und Ra-Werten haben die Zirkonoxide im Gegensatz zu den ZLSKeramiken geringere maximale Einzelrautiefen. Die Rmax-Werte von Cercon® ht und Cercon ${ }^{\circledR} \mathrm{xt}$ liegen zwischen 1,52 - 1,95 $\mu \mathrm{m}$ (ohne Paste) und 0,90 - 1,36 $\mu \mathrm{m}$ (mit Paste) in beiden Poliersystemen. Die Unterschiede innerhalb der Zirkonoxide und gegenüber Celtra® Press sind nicht statistisch signifikant.

Eine statistische Signifikanz ergibt sich bei den Rmax-Werten von Celtra ${ }^{\circledR}$ Duo mit 11,23 $\mu \mathrm{m}$ (ohne Paste) und 6,81 $\mu \mathrm{m}$ (mit Paste) im Poliersystem 2 und mit 5,49 $\mu \mathrm{m}$ im Poliersystem 1 (mit Paste).

Die zusätzliche Bearbeitung mit einer Diamantpolierpaste führt bei den Zirkonoxiden und Celtra ${ }^{\circledR}$ Press zu einer durchschnittlichen Reduktion der Rmax-Werte um 0,8 $\mu$ m. Dies ist jedoch nicht statistisch signifikant. Bei den Werten der Keramik Celtra® Duo im Poliersystem 1 zeigt sich nach Bearbeitung mit Diamantpolierpaste eine Erhöhung um 1,93 $\mu \mathrm{m}$. Im Poliersystem 2 dagegen wurde eine statistisch signifikante Reduktion nach Bearbeitung mit Polierpaste um einen Wert von 4,42 $\mu \mathrm{m}$ gemessen. 


\subsubsection{Quantile-Quantile Plots Rmax}

Bei den Quantile-Quantile Plots wurden die Rmax-Werte als Variablen jeder Keramik erfasst und zeigen eine Normalverteilung (Abbildung 30).
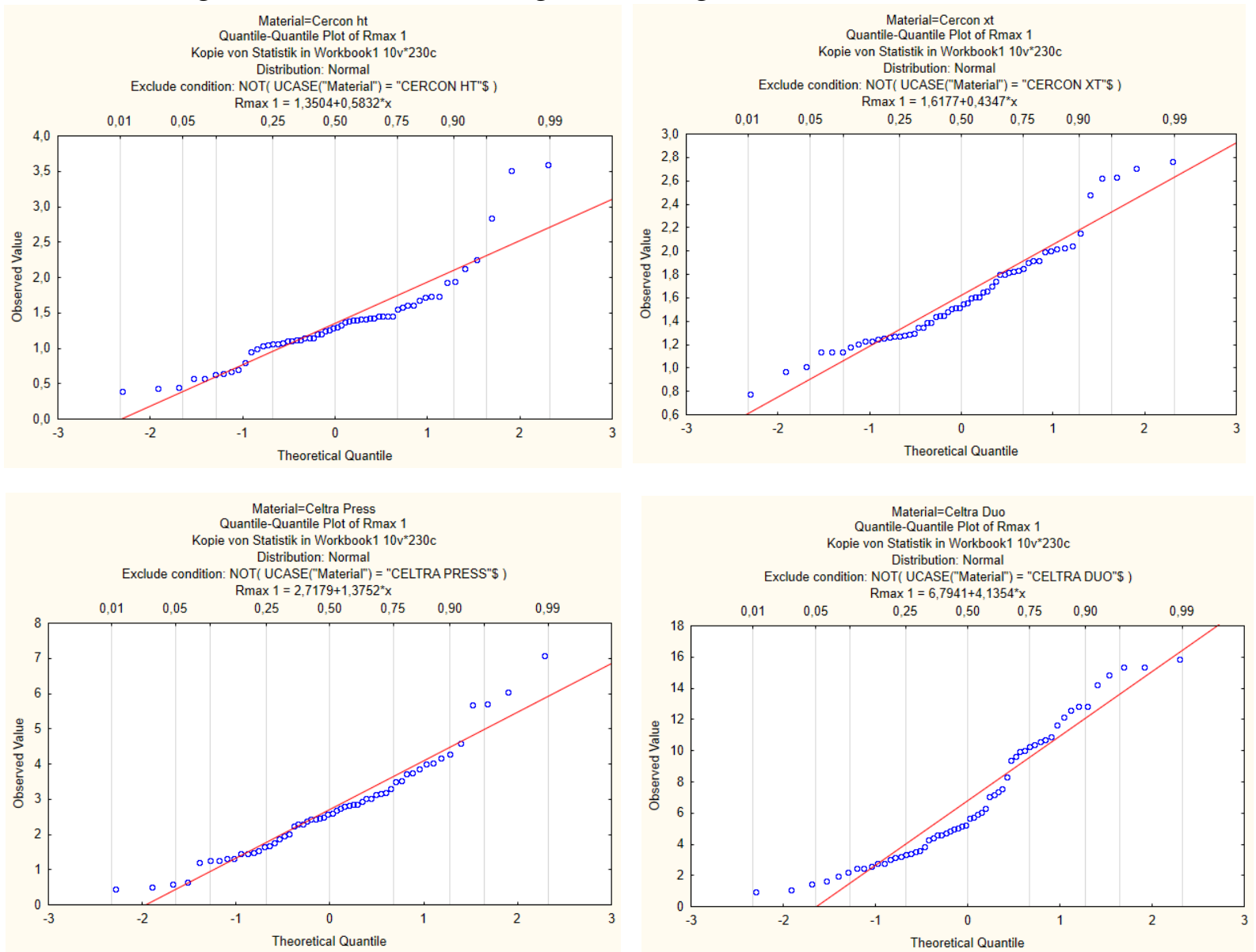

Abbildung 30: Quantile-Quantile Plots der Variablen Ra in Bezug auf jede Keramik

\subsubsection{Statistische Auswertung über two-way ANOVA und post-hoc Tukey test}

Die einzelnen Gruppen sind bei der maximalen Rautiefe Rmax normal verteilt. Es wurde, ebenso wie bei Ra und Rz, eine zweifaktorielle ANOVA durchgeführt. Die für die Keramikmaterialien ermittelten Rmax-Werte sind in den folgenden Grafiken in Abhängigkeit von den Poliersystemen (Poliersystem 1: blau, Poliersystem 2: rot) und der Polierpaste (ohne/mit) dargestellt (Abbildung 31, 32). 


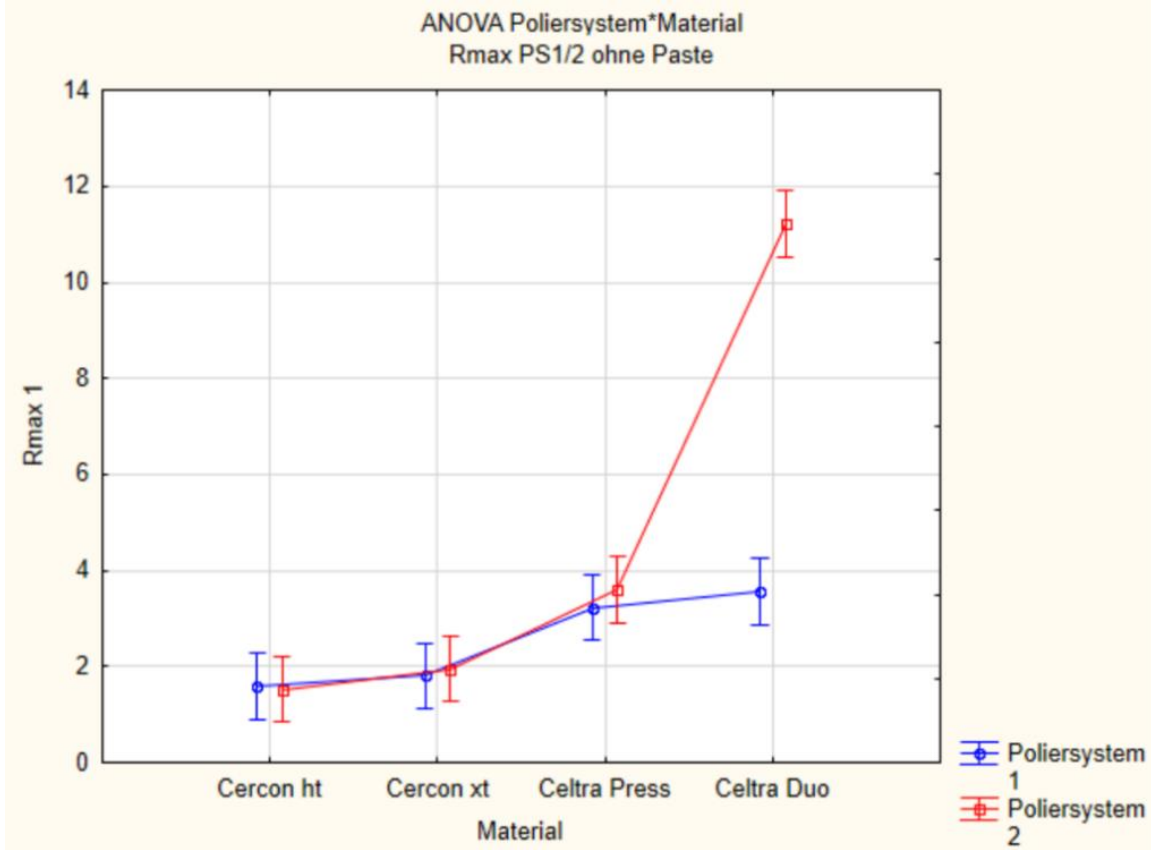

Abbildung 31: Rmax-Wert ohne Paste in Abhängigkeit vom Poliersystem

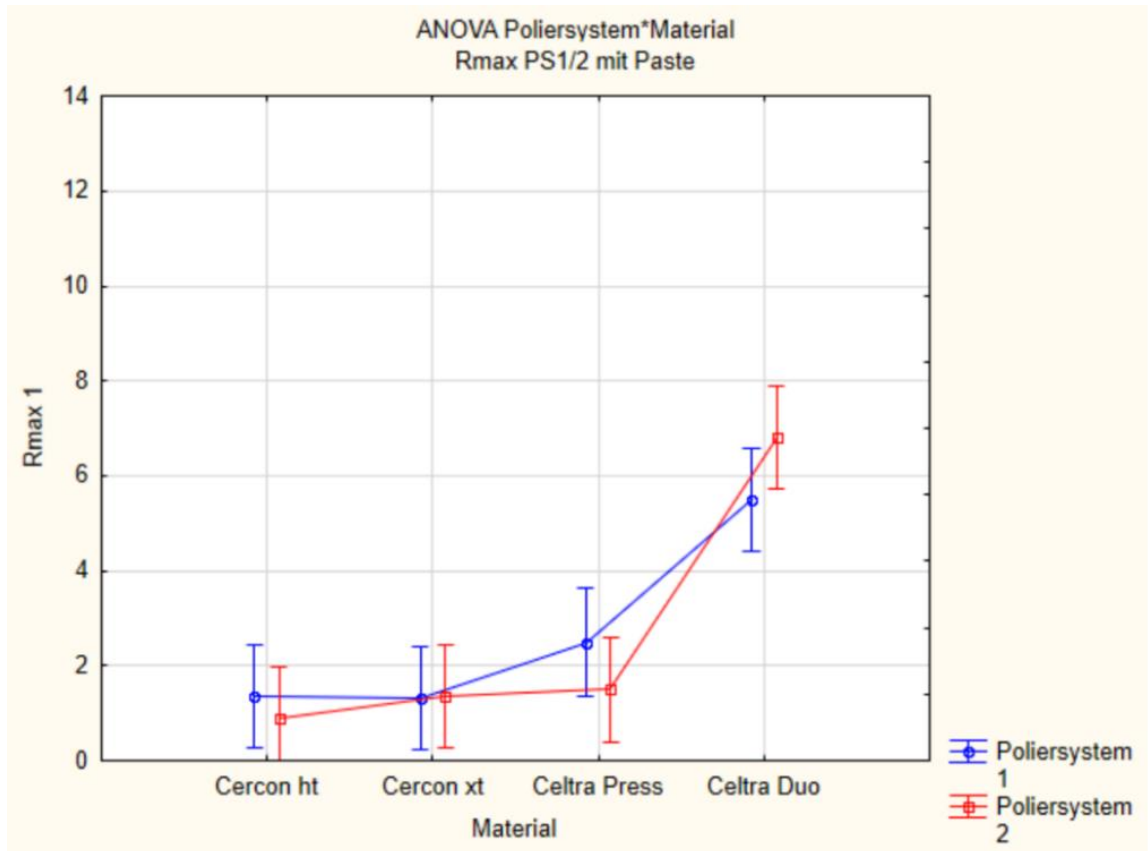

Abbildung 32: Rmax-Wert mit Paste in Abhängigkeit vom Poliersystem 
In den weiteren zwei Grafiken (Abbildung 33, 34) sind die Poliersysteme 1 und 2, jeweils in Abhängigkeit von der Polierpaste, abgebildet (ohne Paste: blau, mit Paste: rot).

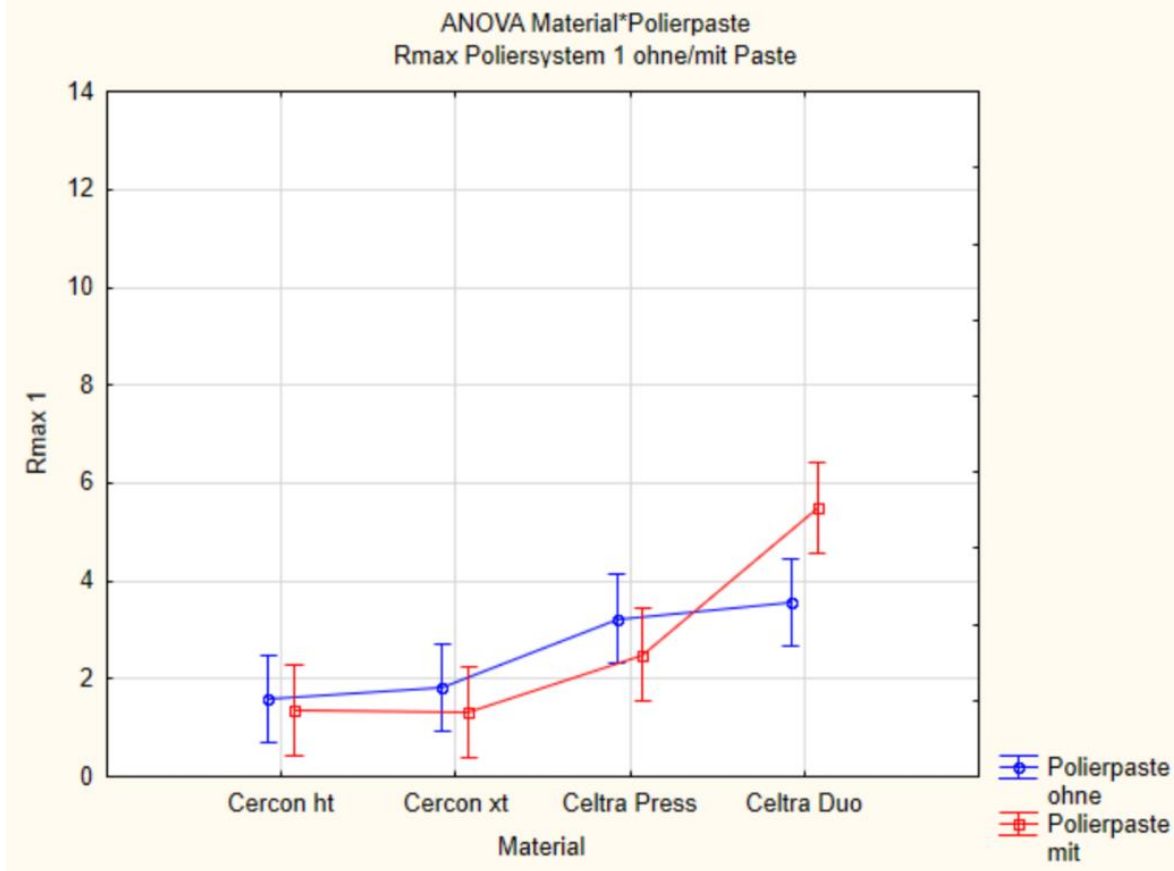

Abbildung 33: Rmax-Wert im Poliersystem 1 in Abhängigkeit von der Polierpaste

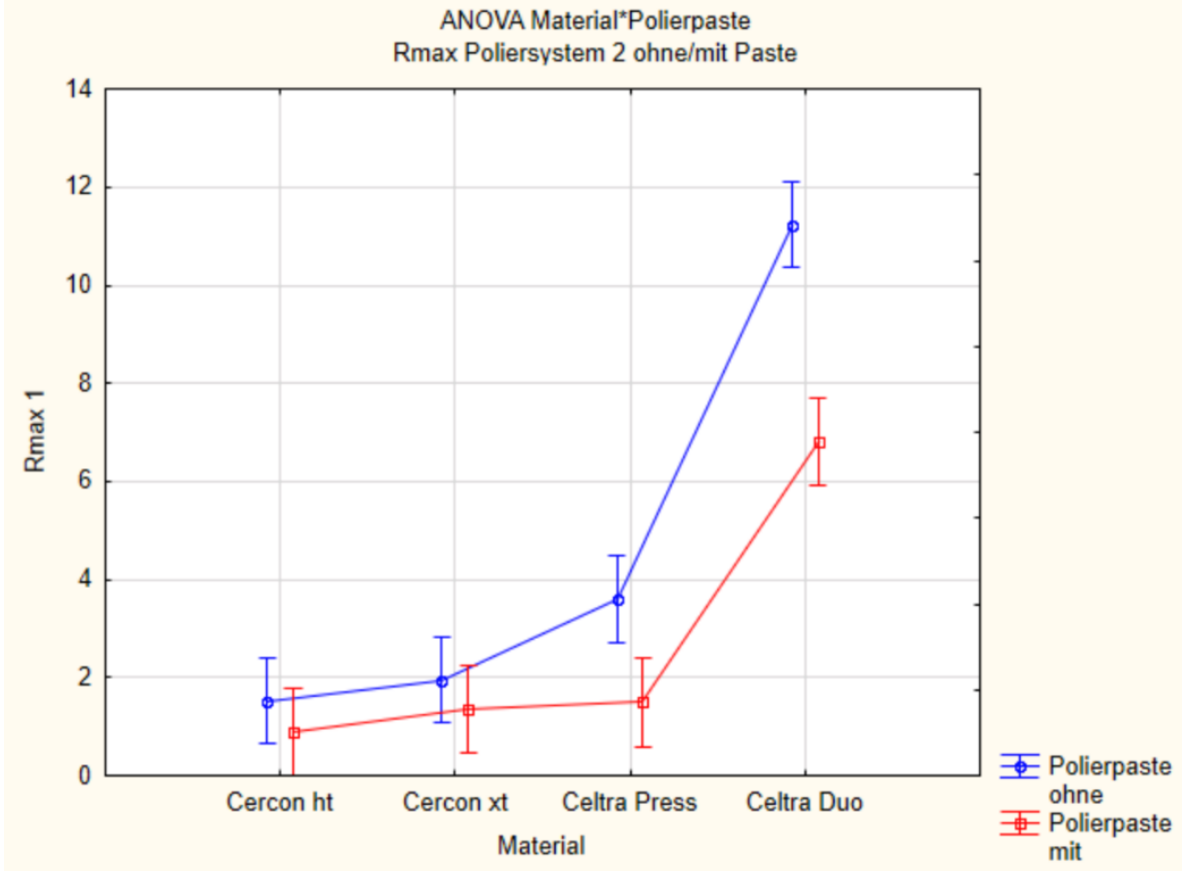

Abbildung 34: Rmax-Wert im Poliersystem 2 in Abhängigkeit von der Polierpaste 
Bei der Varianzanalyse ergab sich ein signifikantes Ergebnis ( $\mathrm{p}$ 0,0001). In Abbildung 35 sind die Ergebnisse der paarweisen Vergleiche der Parameter erkennbar. Die p-Werte wurden anschließend mit einem post-hoc Tukey test adjustiert und sind so im weiteren Text angegeben.

Rmax PS 1 / 2 ohne Paste

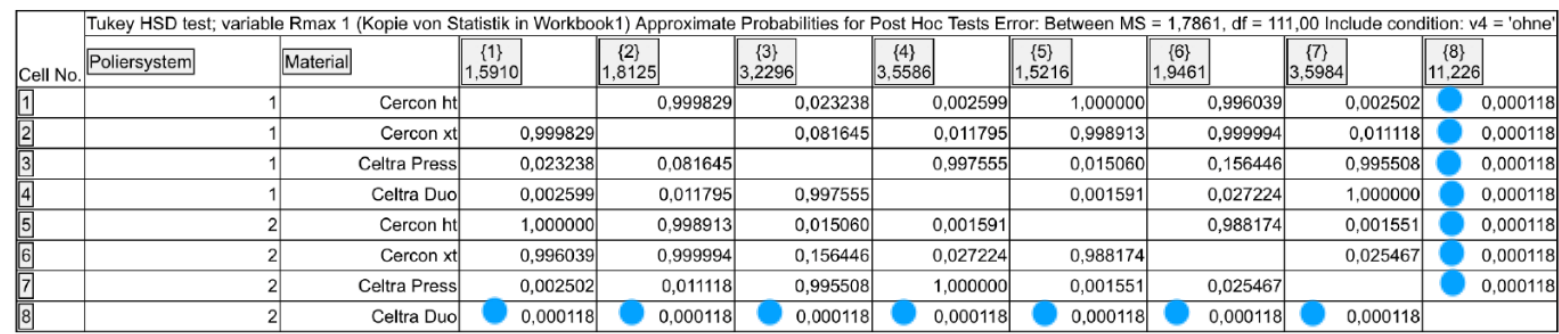

Rmax PS 1 / 2 mit Paste

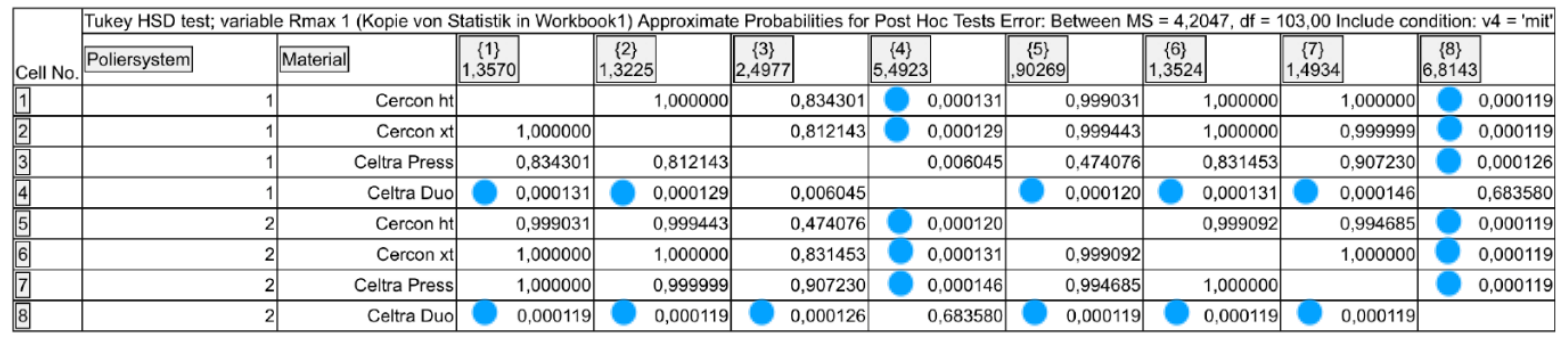

Rmax PS 1 ohne / mit Paste

\begin{tabular}{|c|c|c|c|c|c|c|c|c|c|c|}
\hline \multirow[b]{2}{*}{ Cell No } & \multicolumn{10}{|c|}{ Tukey HSD test; variable Rmax 1 (Kopie von Statistik in Workbook1) Approximate Probabilities for Post Hoc Tests Error: Between MS = 3,0489, df = 107,00 Include condition: v2 =1 } \\
\hline & Material & Polierpaste & \begin{tabular}{|c|}
$\{1\}$ \\
1,5910 \\
\end{tabular} & \begin{tabular}{|c|}
$\{2\}$ \\
1,3570 \\
\end{tabular} & \begin{tabular}{|c|}
$\{3\}$ \\
1,8125 \\
\end{tabular} & \begin{tabular}{|c|}
$\{4\}$ \\
1,3225 \\
\end{tabular} & \begin{tabular}{|c|}
$\{5\}$ \\
3,2296 \\
\end{tabular} & \begin{tabular}{||c|}
$\{6\}$ \\
2,4977 \\
\end{tabular} & \begin{tabular}{|c|}
$\{7\}$ \\
3,5586 \\
\end{tabular} & \begin{tabular}{|c|}
$\{8\}$ \\
5,4923 \\
\end{tabular} \\
\hline 1 & Cercon ht & ohne & & 0,999963 & 0,999972 & 0,999907 & 0,178773 & 0,868619 & 0,050858 & 0,000119 \\
\hline 2 & Cercon ht & mit & 0,999963 & & 0,996827 & 1,000000 & 0,085808 & 0,689713 & 0,021101 & 0,000119 \\
\hline 3 & Cercon xt & ohne & 0,999972 & 0,996827 & & 0,994991 & 0,346948 & 0,967897 & 0,122577 & 0,000121 \\
\hline 4 & Cercon $\mathrm{xt}$ & mit & 0,999907 & 1,000000 & 0,994991 & & 0,075009 & 0,656412 & 0,017970 & 0,000119 \\
\hline 5 & Celtra Press & ohne & 0,178773 & 0,085808 & 0,346948 & 0,075009 & & 0,954242 & 0,999596 & 0,015843 \\
\hline 6 & Celtra Press & mit & 0,868619 & 0,689713 & 0,967897 & 0,656412 & 0,954242 & & 0,747348 & 0,000640 \\
\hline 7 & Celtra Duo & ohne & 0,050858 & 0,021101 & 0,122577 & 0,017970 & 0,999596 & 0,747348 & & 0,067479 \\
\hline 8 & Celtra Duo & mit & 0,000119 & 0,000119 & 0,000121 & 0,000119 & 0,015843 & 0,000640 & 0,067479 & \\
\hline
\end{tabular}

Rmax PS 2 ohne / mit Paste

\begin{tabular}{|c|c|c|c|c|c|c|c|c|c|c|}
\hline \multirow[b]{2}{*}{ Cell No. } & \multicolumn{10}{|c|}{ Tukey HSD test; variable Rmax 1 (Kopie von Statistik in Workbook1) Approximate Probabilities for Post Hoc Tests Error: Between MS = 2,8514, df = 107,00 Include condition: v2 = 2} \\
\hline & Material & Polierpaste & \begin{tabular}{|c|}
$\{1\}$ \\
1,5216 \\
\end{tabular} & \begin{tabular}{|c|}
$\{2\}$ \\
900269 \\
\end{tabular} & \begin{tabular}{|c|}
$\{3\}$ \\
1,9461
\end{tabular} & \begin{tabular}{|c|}
$\{4\}$ \\
1,3524 \\
\end{tabular} & \begin{tabular}{|c|}
$\{5\}$ \\
3,5984 \\
\end{tabular} & \begin{tabular}{|c|}
$\{6\}$ \\
1,4934 \\
\end{tabular} & \begin{tabular}{|c|}
$\{7\}$ \\
11,226 \\
\end{tabular} & \begin{tabular}{|c|}
$\{8\}$ \\
6,8143 \\
\end{tabular} \\
\hline 1 & Cercon ht & ohne & & 0,975531 & 0,997190 & 0,999995 & 0,027022 & 1,000000 & 0,000119 & 0,000119 \\
\hline 2 & Cercon ht & mit & 0,975531 & & 0,710881 & 0,996751 & 0,001374 & 0,982986 & 0,000119 & 0,000119 \\
\hline 3 & Cercon $x t$ & ohne & 0,997190 & 0,710881 & & 0,980691 & 0,155835 & 0,996234 & 0,000119 & 0,000119 \\
\hline 4 & Cercon xt & mit & 0,999995 & 0,996751 & 0,980691 & & 0,014351 & 0,999999 & 0,000119 & 0,000119 \\
\hline 5 & Celtra Press & ohne & 0,027022 & 0,001374 & 0,155835 & 0,014351 & & 0,027941 & 0,000119 & 0,000162 \\
\hline 6 & Celtra Press & mit & 1,000000 & 0,982986 & 0,996234 & 0,999999 & 0,027941 & & 0,000119 & 0,000119 \\
\hline 7 & Celtra Duo & ohne & 0,000119 & $\begin{array}{l}0,000119 \\
\end{array}$ & 0,000119 & 0,000119 & 0,000119 & 0,000119 & & 0,000119 \\
\hline 8 & Celtra Duo & mit & 0,000119 & 0,000119 & 0,000119 & 0,000119 & 0,000162 & 0,000119 & 0,000119 & \\
\hline
\end{tabular}

Abbildung 35: post-hoc Tukey tests der ANOVA-Auswertung 
Die ZLS-Keramiken Celtra ${ }^{\circledR}$ Press und Celtra ${ }^{\circledR}$ Duo haben höhere maximale Mittenrautiefen als die Zirkonoxide Cercon® ht und Cercon ${ }^{\circledR}$ xt. Zwischen den Werten der Zirkonoxidkeramiken untereinander und im Vergleich zu Celtra ${ }^{\circledR}$ Press gibt es keine signifikanten Unterschiede (siehe Abbildung 35).

Für die Keramik Celtra ${ }^{\circledR}$ Duo wurden Rmax-Werte von 3,56 bis 11,23 $\mu$ m ermittelt. Für die Zirkonoxidkeramiken wurden Werte im Bereich von 0,90 bis $1,95 \mu \mathrm{m}$ und für Celtra ${ }^{\circledR}$ Press Werte im Bereich von 1,50 bis 3,60 $\mu \mathrm{m}$ gemessen. Diese Unterschiede erwiesen sich bei einem paarweisen Vergleich der Mittelwerte im Poliersystem 2 (ohne/mit Paste) und Poliersystem 1 (mit Paste) als statistisch signifikant $(\mathrm{p}=0,0028)$.

Das dreistufige Poliersystem 2 weist geringere maximale Einzelrautiefen auf (Ausnahme Celtra ${ }^{\circledR}$ Duo). Insgesamt haben alle Prüfgruppen (Ausnahme Celtra ${ }^{\circledR}$ Duo im PS 1) ohne Polierpaste höhere maximale Einzelrautiefen als die mit Polierpaste. Eine statistische Signifikanz ist aber nur bei Celtra® Duo zu sehen. 


\subsection{Zusammenfassung der Ergebnisse}

Für die Zirkonoxidkeramiken Cercon ${ }^{\circledR}$ ht und Cercon ${ }^{\circledR}$ xt wurden Ra-Werte von 0,17 bis $0,23 \mu \mathrm{m}$ (ohne Paste) und von 0,08 bis $0,17 \mu \mathrm{m}$ (mit Paste) ermittelt. Die RzWerte der Zirkonoxide liegen im Bereich von 1,04 bis 1,45 $\mu \mathrm{m}$ (ohne Paste) und 0,51 bis 1,08 $\mu \mathrm{m}$ (mit Paste). Bei den maximalen Einzelrautiefen Rmax wurden Werte von 1,52 bis $1,95 \mu \mathrm{m}$ (ohne Paste) und 0,90 bis 1,36 $\mu \mathrm{m}$ (mit Paste) gemessen. Diese Unterschiede erwiesen sich bei einem paarweisen Vergleich der Mittelwerte bei keinem der genannten Rauheitsparameter als statistisch signifikant. Bei den Oberflächen der Zirkonoxide zeigt sich im Vergleich zu den Glaskeramiken eine Tendenz zu glatteren Oberflächen.

Die ZLS-Keramik Celtra ${ }^{\circledR}$ Press weist Ra-Werte von 0,27 bis 0,37 $\mu \mathrm{m}$ (ohne Paste) und 0,12 bis $0,23 \mu \mathrm{m}$ (mit Paste) auf. Die durchschnittlichen Rz-Werte liegen bei 1,30 bis 1,45 $\mu \mathrm{m}$ (ohne Paste) und 0,87 bis 1,08 $\mu \mathrm{m}$ (mit Paste). Die Rmax-Werte betragen 1,81 bis $1,95 \mu \mathrm{m}$ (ohne Paste) und 1,32 bis 1,35 $\mu \mathrm{m}$ (mit Paste). Ein statistisch signifikanter Unterschied zu Cercon ${ }^{\circledR}$ ht ist bei den Rz-Werten in beiden Poliersystemen ohne Paste vorhanden.

Bei Celtra ${ }^{\circledR}$ Duo wurde eine statistische Signifikanz im Poliersystem 2 (ohne/mit Paste) und im Poliersystem 1 (mit Paste) gegenüber den anderen Keramiken ermittelt. Die RaWerte dieser Keramik reichen von 0,29 (Poliersystem 1) bis 1,17 $\mu \mathrm{m}$ (Poliersystem 2) ohne Paste und von 0,34 (Poliersystem 1) bis 0,61 $\mu \mathrm{m}$ (Poliersystem 2) mit Paste. Bei den Mittenrautiefen wurden Werte von 2,42 (Poliersystem 1) bis 7,11 $\mu \mathrm{m}$ (Poliersystem 2) ohne Paste und 3,28 (Poliersystem 1) bis 3,57 $\mu \mathrm{m}$ (Poliersystem 2) mit Paste gemessen. Die maximalen Einzelrautiefen Rmax liegen bei 3,57 (Poliersystem 1) bis 11,23 $\mu \mathrm{m}$ (Poliersystem 2) ohne Paste und 5,49 (Poliersystem 1) bis 6,81 $\mu \mathrm{m}$ (Poliersystem 2) mit Paste.

Es lässt sich eine Tendenz aufzeigen, dass mit dem Einsatz von Diamantpolierpasten geringere Oberflächenrauigkeiten erzielt werden. Die Veränderung der Oberflächenparameter (Reduktion: $\downarrow$ und Erhöhung: $\uparrow$ ) ist in Tabelle 10 dargestellt. 
Tabelle 10: Effekt der Polierpaste auf die Oberflächenparameter

\begin{tabular}{|l|l|l|l|l|l|l|}
\hline Poliersystem & \multicolumn{3}{|c|}{ Poliersystem 1} & \multicolumn{3}{c|}{ Poliersystem 2} \\
\hline Parameter $(\mu \mathrm{m})$ & $\mathrm{Ra}$ & $\mathrm{Rz}$ & $\mathrm{Rmax}$ & $\mathrm{Ra}$ & $\mathrm{Rz}$ & $\mathrm{Rmax}$ \\
\hline Cercon${ }^{\circledR}$ ht & $\downarrow 0,04$ & $\downarrow 0,31$ & $\downarrow 0,23$ & $\downarrow 0,09$ & $\downarrow 0,53$ & $\downarrow 0,62$ \\
\hline Cercon ${ }^{\circledR} \mathbf{~ x t}$ & $\downarrow 0,06$ & $\downarrow 0,37$ & $\downarrow 0,49$ & $\downarrow 0,08$ & $\downarrow 0,43$ & $\downarrow 0,60$ \\
\hline Celtra ${ }^{\circledR}$ Press & $\downarrow 0,14$ & $\downarrow 0,77$ & $\downarrow 0,74$ & $\downarrow 0,15$ & $\downarrow 1,20$ & $\downarrow 2,10$ \\
\hline Celtra ${ }^{\circledR}$ Duo & $\uparrow 0,05$ & $\uparrow 0,86$ & $\uparrow 1,93$ & $\downarrow 0,56$ & $\downarrow 3,54$ & $\downarrow 4,42$ \\
\hline
\end{tabular}

Der Effekt der Diamantpolierpaste ist jedoch nur bei Celtra ${ }^{\circledR}$ Duo im Poliersystem 2 statistisch signifikant. Die effektive Reduktion der Oberflächenparameter beträgt hier im Durchschnitt $0,56 \mu \mathrm{m}$ bei Ra; 3,54 $\mu \mathrm{m}$ bei Rz und 4,42 $\mu \mathrm{m}$ bei Rmax. 


\section{Diskussion}

\subsection{Zusammenfassung der Kernaussagen}

Im Poliersystem 1 (Polierer für $\mathrm{ZrO}_{2}$, Komet Dental, Lemgo) lässt sich kein statistisch signifikanter Einfluss der unterschiedlichen Keramiken auf die Kennwerte Ra, Rz und Rmax nachweisen. Dieses Poliersystem kann zur universellen Politur der untersuchten Keramiken genutzt werden.

Im Poliersystem 2 (ZiLMaster, SHOFU Dental GmbH, Ratingen) zeigt sich ein signifikanter Einfluss der Keramik Celtra ${ }^{\circledR}$ Duo auf die ermittelten Oberflächenkennwerte. Die ZLS-Keramik Celtra® Duo zeigt dabei im Poliersystem 2 (ohne/mit Paste) und Poliersystem 1 (mit Paste) signifikant höhere Rauheitswerte (Ra, Rz, Rmax) als die anderen untersuchten Materialien Cercon ${ }^{\circledR}$ ht, Cerco® xt und Celtra ${ }^{\circledR}$ Press.

Die Endbearbeitung mit Diamantpolierpasten führt zu einer Verringerung der Oberflächenrauigkeit. Diese Reduktion der Oberflächenparameter ist bei den Zirkonoxiden in beiden Poliersystemen ähnlich und liegt im Durchschnitt bei 0,07 $\mu \mathrm{m}(\mathrm{Ra}) ; 0,41 \mu \mathrm{m}(\mathrm{Rz})$ und $0,49 \mu \mathrm{m}(\operatorname{Rmax})$.

Bei Celtra ${ }^{\circledR}$ Press beträgt die Reduktion der Parameter im Poliersystem 1: 0,14 $\mu \mathrm{m}(\mathrm{Ra})$; 0,77 $\mu \mathrm{m}(\mathrm{Rz}) ; 0,74 \mu \mathrm{m}(\mathrm{Rmax})$ und im Poliersystem 2: 0,15 $\mu \mathrm{m}(\mathrm{Ra}) ; 1,2 \mu \mathrm{m}(\mathrm{Rz}) ; 2,1$ $\mu \mathrm{m}(\mathrm{Rmax})$.

Im Poliersystem 1 zeigt sich bei Celtra ${ }^{\circledR}$ Duo kein Effekt nach der Bearbeitung mit Diamantpolierpaste. Es erfolgt eine Erhöhung der Parameter (Ra um 0,05 $\mu \mathrm{m}$; Rz um 0,86 $\mu \mathrm{m}$ und Rmax um 1,93 $\mu \mathrm{m}$ ). Statistisch signifikant erweist sich der Effekt der Polierpaste bei Celtra ${ }^{\circledR}$ Duo im Poliersystem 2. Hier beträgt die effektive Reduktion der Oberflächenparameter im Durchschnitt 0,56 $\mu \mathrm{m}$ bei Ra; 3,54 $\mu \mathrm{m}$ bei Rz und 4,42 $\mu \mathrm{m}$ bei Rmax. 


\subsection{Diskussion der Ergebnisse im Vergleich mit relevanter Literatur}

In der vorliegenden Studie wurde ein flaches Prüfkörper-Design gewählt, um eine identische Oberflächengeometrie für den Vergleich zu sichern. Diese In-vitro-Prüfkörpergeometrie entspricht nicht der Oberfläche von Kronen oder Brückenkonstruktionen in der Praxis, ist aber für die Auswertung über eine Oberflächenprofilometrie besonders geeignet. Das flache Prüfkörper-Design hat sich bereits in einigen anderen Studien bewährt (Kou et al. 2006; Subasi und Inan 2012; Hmaidouch et al. 2014; Pott et al. 2018).

Die Oberflächenbearbeitung in dieser Studie erfolgte über eine Politur und nicht über einen Glanzbrand. In Studien von Janyavula et al. (2013) und Park et al. (2014) wurden durchschnittliche Ra-Werte von $0,17 \mu \mathrm{m}$ nach Politur im Vergleich zu 0,76 $\mu \mathrm{m}$ nach Glasurbrand ermittelt (Janyavula et al. 2013; Park et al. 2014). Die Werte nach Politur aus diesen Studien stimmen mit den Ra-Werten der vorliegenden Studie überein. In einer Studie von Amaya-Pajares et al. (2016) ergaben sich bei Zirkonoxiden Ra-Werte von 0,12 bis $0,24 \mu \mathrm{m}$ nach Glanzbrand und von 0,04 bis $0,07 \mu \mathrm{m}$ nach Politur. Die Ra-Werte der vorliegenden Untersuchungen sind vergleichbar mit denen nach Glanzbrand. Weiterhin untersuchte Amaya-Pajares et al. (2016) IPS® Empress (Leuzit-Glaskeramik) und IPS® e.max (Lithium-Disilikat-Glaskeramik) nach Glanzbrand. Die Ra-Werte reichten bei den Glaskeramiken von 0,29 bis 0,37 $\mu \mathrm{m}$ (Amaya-Pajares et al. 2016). Die Glaskeramiken zeigten höhere Rauheitswerte als die Zirkonoxide. Dies stimmt mit den Ergebnissen der vorliegenden Studie überein.

Als Ziel der Politur gibt Marxkors et al. (2012) eine Bearbeitung der Oberfläche bis zum Hochglanz, welcher bei einer maximalen Rautiefe Ra von 0,25 $\mu \mathrm{m}$ erreicht ist, vor (Marxkors et al. 2012). Beide Zirkonoxidkeramiken unterschreiten diesen Wert in beiden Poliersystemen (ohne/mit Paste). Auch die ZLS-Keramik Celtra ${ }^{\circledR}$ Press unterschreitet 0,25 $\mu \mathrm{m}$ im Poliersystem 2 (mit Paste). Bei Celtra ${ }^{\circledR}$ Duo liegen die Ra-Werte im Poliersystem 1 noch nah an einem Ra-Wert von 0,25 $\mu \mathrm{m}$. Im Poliersystem 2 wird dieser RaWert bei Celtra ${ }^{\circledR}$ Duo jedoch stark überschritten.

In Studien von Aravind et al. (2013), Amer et al. (2014) und Preis et al. (2015) wurden bei verschiedenen Poliersystemen für die Endpolitur von keramischen Restaurationen Ra-Werte zwischen 0,24 bis $0,79 \mu \mathrm{m}$ für Silikatkeramiken und 0,12 bis 0,2 $\mu \mathrm{m}$ für Zirkonoxidkeramiken gemessen (Aravind et al. 2013; Amer et al. 2014; Preis et al. 2015b). Die genannten Ra-Werte werden von den Ergebnissen der vorliegenden Arbeit bestätigt. Bei der Anwendung des Poliersystems 1 werden im Vergleich zu den Zirkonoxiden 
tendenziell höhere Rauheitswerte für die ZLS-Keramiken Celtra® Press und Celtra ${ }^{\circledR}$ Duo ermittelt. Diese Auswertungen stimmen mit den Ergebnissen bislang publizierter Studien überein. In diesen Studien wurden ebenfalls höhere Oberflächenrauigkeiten von Glaskeramiken im Vergleich zu Zirkonoxiden festgestellt (Aravind et al. 2013; Amer et al. 2014; Preis et al. 2015b).

Celtra ${ }^{\circledR}$ Press weist in beiden Poliersystemen vergleichbare Rauheitsparameter zu anderen Glaskeramiken auf (Aravind et al. 2013; Amer et al. 2014; Preis et al. 2015b). Bei Celtra® Duo ist die Oberflächenqualität abhängig vom eingesetzten Poliersystem. Der Effekt des Poliersystems zeigt einen signifikanten Einfluss der erzielbaren Oberflächengüte bei diesem Material.

Bei Steiner et al. (2015) wurden spezielle Zirkonoxid-Poliersysteme für Presskeramiken, Leuzitkeramiken, Lithium-Disilikatkeramiken, Feldspatkeramiken und Presskeramiken (IPS $®$ Empress, IPS ${ }$ e.max, VITAPM $® 9$, Cergo ${ }^{\circledR}$ Kiss, Imagine $®$ Press X) untersucht. Es wurden Ra-Werte von unter 0,5 $\mu \mathrm{m}$ gemessen (Steiner et al. 2015). Diese Ergebnisse sind in guter Übereinstimmung mit den Ra-Werten der Zirkonoxide und Celtra® Press der vorliegenden Arbeit. Celtra ${ }^{\circledR}$ Duo liegt mit einem Ra-Wert von 1,17 $\mu$ m (PS 2 ohne Paste) und 0,61 $\mu \mathrm{m}$ (PS 2 mit Paste) über 0,5 $\mu \mathrm{m}$. Im Poliersystem 2 ohne Paste weist diese ZLS-Keramik also deutlich höhere Rauheitswerte auf.

Das Poliersystem 1 (Komet Dental, Lemgo) ist nach Herstellerangaben für Zirkonoxid-, Aluminiumoxid- und Presskeramiken geeignet (Komet Dental 2016). Die Ergebnisse der vorliegenden Studie bestätigen, dass die mit diesem System polierten Oberflächen Kennwerte ( $\mathrm{Ra}, \mathrm{Rz}, \mathrm{Rmax}$ ) erreichen, die mit den bislang in der Literatur publizierten Kenndaten in guter Übereinstimmung sind (Aravind et al. 2013; Janyavula et al. 2013; Amer et al. 2014; Park et al. 2014; Preis et al. 2015b; Steiner et al. 2015; Amaya-Pajares et al. 2016). Dies gilt gleichermaßen für die Zirkonoxid- und ZLS-Keramiken.

Das Poliersystem 2 (ZiLMaster, SHOFU Dental GmbH, Ratingen) ist laut Hersteller für Zirkonoxid- und Lithiumdisilikatkeramiken geeignet (SHOFU Dental GmbH 2016). Die Ergebnisse der Politur sind in der vorliegenden Studie signifikant von dem zu polierenden Werkstoff beeinflusst. Bei den Zirkonoxidkeramiken zeigt das Poliersystem 2 - genau wie Poliersystem 1 - vergleichbare Werte, die mit den Literaturangaben übereinstimmen. Bei Celtra Duo zeigen sich dagegen signifikant höhere Werte für das Poliersystem 2 im Vergleich zum Poliersystem 1. 
In einer Untersuchung von Preis et al. (2015) wurden Zirkonoxide (Cercon® base, Cercon ${ }^{\circledR}$ ht), eine Feldspatkeramik (Cercon ${ }^{\circledR}$ ceram) und eine Lithiumdisilikatkeramik (IPS® e.max) untersucht. In der vorliegenden Studie wurden die Zirkonoxide Cercon ${ }^{\circledR}$ ht (2. Generation) und Cercon® xt (3. Generation) untersucht. Es handelt sich hierbei um Weiterentwicklungen des Werkstoffes Cercon ${ }^{\circledR}$ base. Bei Cercon ${ }^{\circledR}$ ht wurden Ra-Werte von $0,08-0,20 \mu \mathrm{m}$ und bei Cercon ${ }^{\circledR}$ xt von 0,11 - 0,23 $\mu \mathrm{m}$ ermittelt. Diese Ra-Werte sind in guter Übereinstimmung mit den Werten von Preis et al. (2015), welche zwischen $0,06-0,26 \mu \mathrm{m}$ liegen (Preis et al. 2015a).

In einem Poliersystem von Preis et al. (2015) wurde ein Wert von 0,65 $\mu \mathrm{m}$ ermittelt, welcher von den anderen Werten abwich (Preis et al. 2015a). Auch in der vorliegenden Untersuchung gab es einen durchschnittlichen Ra-Wert, der sich von den anderen Werten absetzt (Celtra ${ }^{\circledR}$ Duo im Poliersystem 2 ohne Paste: $\left.1,17 \mu \mathrm{m}\right)$.

Weiterhin beschreiben Preis et al. (2015) eine signifikante Reduktion der Oberflächenrauigkeit bereits nach dem ersten Polierschritt. Die weiteren Polierschritte, die in den zwei- und dreistufigen Poliersystemen dieser Studie erfolgten, verringerten die Oberflächenrauigkeit gleichermaßen. Die zweistufigen Systeme sind nicht statistisch signifikant unterschiedlich zu den dreistufigen (Preis et al. 2015a). Diese Ergebnisse werden durch die Resultate der vorliegenden Studie - in welcher ebenfalls ein zwei- und ein dreistufiges Poliersystem untersucht wurden - bestätigt. In der vorliegenden Studie kann für drei der vier untersuchten Keramiken (Cercon ${ }^{\circledR}$ ht, Cercon ${ }^{\circledR}$ xt, Celtra ${ }^{\circledR}$ Press) kein statistisch signifikanter Unterschied in den Poliersystemen - ob zwei- oder dreistufig - festgestellt werden.

In einer Studie von Camacho et al. (2006) wird die Endbearbeitung mit einer zusätzlichen Polierpaste empfohlen, da die Oberflächen der Probekörper der Kontrollgruppe ohne Paste höhere Rauheitswerte aufweisen (Camacho et al. 2006). In einer Studie von Aravind et al. (2013) wurde der positive Effekt einer Diamantpolierpaste auf die Oberflächenrauigkeiten der Prüfkörper gleichfalls hervorgehoben (Aravind et al. 2013). In der vorliegenden Untersuchung zeigt sich in den Oberflächenparametern der Nutzen einer zusätzlichen Politur mit Diamantpolierpasten. Die Endbearbeitung erfolgte hier mit der Diamant Polierpaste 9300 Körnung D3 (Komet Dental, Lemgo) und dem Dura-Polish DZ (SHOFU Dental GmbH, Ratingen). Ein statistisch signifikanter Unterschied durch eine Verbesserung der Oberflächenrauigkeiten lässt sich im Poliersystem 2 bei Celtra® Duo feststellen. Hier wurde eine Reduktion der Ra-Werte (um 0,56 $\mu \mathrm{m}$,) der Rz-Werte (um 3,54 $\mu \mathrm{m}$ ) und 
der Rmax-Werte (um 4,42 $\mu \mathrm{m}$ ) gemessen. Der Effekt der Diamantpolierpaste in der vorliegenden Studie zeigt sich bei den Zirkonoxiden und Celtra ${ }^{\circledR}$ Press durch eine durchschnittliche Reduktion der Ra-Werte (um 0,09 $\mu \mathrm{m}$ ), der Rz-Werte (um 0,6 $\mu \mathrm{m}$ ) und der Rmax-Werte (um 0,8 $\mu \mathrm{m}$ ). Es lässt sich eine Tendenz aufzeigen, dass mit dem Einsatz von Diamantpolierpasten geringere Oberflächenrauigkeiten erzielt werden. Es handelt sich allerdings nicht um eine statistische Signifikanz. Für das Erreichen einer maximalen Oberflächengüte kann dennoch die Endbearbeitung mit einer Diamantpolierpaste empfohlen werden.

Nach der Politur liegen die ermittelten Ra-Werte bei den Zirkonoxiden Cercon® ht und Cercon ${ }^{\circledR}$ xt bei 0,08 bis $0,23 \mu \mathrm{m}$. Bei Celtra ${ }^{\circledR}$ Press sind die Ra-Werte zwischen 0,12 bis $0,37 \mu \mathrm{m}$. Diese Werte stimmen mit der aktuellen Studienlage zur Oberflächengüte nach Politur überein. Die Oberflächenbearbeitung muss jedoch nicht durch eine Politur, sondern kann auch über einen Glanzbrand erfolgen. In Studien von Janyavula et al. (2013) und Park et al. (2014) wurden bei Zirkonoxiden durchschnittliche Rauheitswerte von $0,17 \mu \mathrm{m}$ nach Politur im Vergleich zu 0,76 $\mu \mathrm{m}$ nach Glasurbrand ermittelt (Janyavula et al. 2013; Park et al. 2014). In der vorliegenden Studie wurden die untersuchten Keramiken nur innerhalb der Poliersysteme miteinander verglichen. Es erfolgte keine Gegenüberstellung der Oberflächengüte nach einem im Labor vorgenommenen Glanzbrand. Die Werte von Cercon® ht und Cercon ${ }^{\circledR}$ xt stimmen mit denen der genannten Studien nach Politur überein.

Auch von Amaya-Pajares et al. (2016) wurden Zirkonoxidkeramiken nach Politur mit denen nach einem Glanzbrand verglichen. Die Rauheitswerte betrugen hier 0,12-0,24 $\mu \mathrm{m}$ nach Glanzbrand und 0,04-0,07 $\mu \mathrm{m}$ nach Politur (Amaya-Pajares et al. 2016). Bei Cercon® ht wurden nach Politur (Poliersystem 2 mit Paste) Durchschnittswerte von 0,08 $\mu \mathrm{m}$ ermittelt. Diese Ra-Werte nähern sich den Ergebnissen der genannten Studie an. Die anderen Ra-Werte von Cercon ${ }^{\circledR}$ ht und Cercon ${ }^{\circledR}$ xt lagen jedoch im Bereich der Ergebnisse von glasierten Oberflächen. 


\subsection{Stärken und Limitationen der vorliegenden Studie}

\subsubsection{Stärken der vorliegenden Studie}

Zahnmedizinische Restaurationen werden zunehmend unter dem Einsatz von dentalen Hochleistungskeramiken gefertigt, die für die Herstellung von monolithischen Versorgungen geeignet sind. Bei der Materialauswahl lag der Fokus auf neu entwickelten Werkstoffvarianten, die für monolithische Versorgungen geeignet sind und über die es noch wenig Daten über das Polierverhalten gibt. Hierzu gehören Neuentwicklungen aus der Gruppe der ZLS- und Zirkonoxidkeramiken. Damit eine gute Gegenüberstellung dieser beiden Keramikarten gewährleistet ist, wurden aus beiden Gruppen jeweils zwei Werkstoffe untereinander und miteinander verglichen. Unter diesem Gesichtspunkt kann die vorliegende Arbeit einen Beitrag zur werkstoffkundlichen Bewertung dieser bislang noch wenig untersuchten Materialgruppe liefern.

Eine weitere Stärke ist die Einbeziehung unterschiedlicher Einflussfaktoren durch das cross-over Versuchsdesign: Material und Poliersystem (ohne/mit Polierpaste). Insgesamt wurden 120 Prüfkörper der Keramikwerkstoffe an zwei Flächen bearbeitet. Somit konnten 240 Flächen zur Auswertung herangezogen werden. Die erste Subgruppe stellen die vier Keramiken dar, die mit jeweils 30 Prüfkörpern untersucht wurden. Weitere Subgruppen wurden durch die zwei Poliersysteme (jeweils ohne/mit Diamantpolierpaste) präsentiert. Die ausreichend hohe Prüfkörperanzahl ermöglicht eine statistische Auswertung mit einer Adjustierung des zweistufigen Testverfahrens für multiple Testungen nach Bonferroni.

Die Untersuchung von Ra, Rz und Rmax ermöglicht eine detaillierte Analyse der Oberflächenstruktur. In einigen Studien wird allein der Ra-Wert ermittelt, welcher nur die arithmetischen Mittenrauwerte der Oberfläche diagnostiziert. Mit den zusätzlichen Rzund Rmax-Werten kann eine noch bessere Charakterisierung der Oberfläche durchgeführt werden. Mit den Parametern Rz und Rmax werden zusätzlich die Mittenrautiefen und die maximalen Einzelrautiefen (Spitzen/Peaks) der Messung dargestellt. In den Poliersystemen - jeweils ohne Paste - wurde eine statistische Signifikanz bei den Mittenrautiefen Rz von Celtra ${ }^{\circledR}$ Press im Vergleich zu Cercon ${ }^{\circledR}$ ht festgestellt. Über die Ra-Werte wurde nur ein signifikanter Einfluss von Celtra ${ }^{\circledR}$ Duo im Vergleich zu den anderen Keramiken analysiert. 
Die Ausmessung der Prüfkörperoberflächen erfolgte mittels des MarSurf XR20 Oberflächenmessplatzes (Mahr GmbH, Göttingen) und der MarSurf Software (Mahr GmbH, Göttingen). Dieses moderne Ausmessungssystem gehört zu der Gruppe der Hochleistungsgeräte der Oberflächenmesstechnik. Die Ausmessung erfolgte über das Tastschnittverfahren, einer erprobten Methodik der taktilen Oberflächenauswertung von Prüfkörpern im Bereich der Dentalkeramiken. Bei der taktilen Auswertung besteht ein mechanischer Kontakt mit dem Prüfkörper, welcher eine punktförmige Auswertung mit einem großen Höhenmessbereich ermöglicht. Mit dieser Technik kann die Auswertung auch bei gewölbten und spiegelnden Oberflächen sichergestellt werden (Camacho et al. 2006; Kou et al. 2006; Preis et al. 2011; Amer et al. 2014; Hmaidouch et al. 2014; Preis et al. 2015a). Die taktile Oberflächenauswertung steht der optischen Messmethode mittels eines LaserMikroskops gegenüber. Die optische Auswertung kommt auch im Bereich der Dentalkeramiken zur Anwendung. Bei dieser Auswertungsmethode besteht allerdings die Gefahr, dass bei gewölbten und spiegelnden Oberflächen Messunsicherheiten auftreten (Mitov et al. 2012; Aravind et al. 2013; Lawson et al. 2014; Luangruangrong et al. 2014; Park et al. 2017).

Zur Qualitätssicherung wurde der Planschliff gleichartig anhand des Nassplanschleifers (DIGIREP 251, metkon, Bursa) durchgeführt. Die Parameter Anpresskraft/Zentraldruck, Drehzahl und Zeit wurden am Gerät fest eingestellt. Die Prüfkörper konnten somit vollautomatisch und reproduzierbar beschliffen werden.

Insgesamt bietet die angewandte Methodik eine umfassende Bewertung der unterschiedlichen Aspekte der Oberflächenqualität auf der Basis des aktuell anerkannten messtechnischen Standards. Der Vorteil liegt hierbei in einer guten Vergleichbarkeit der in dieser Studie gewonnenen Ergebnisse mit bereits publizierten Daten zu anderen Keramiksystemen oder Polierverfahren.

\subsubsection{Limitationen der vorliegenden Studie}

Eine Variation der Drehzahlen wurde aufgrund der begrenzten Prüfkörperanzahl nicht vorgenommen. In der vorliegenden Arbeit wurden die Poliervorgänge ausschließlich auf der Basis der von den Herstellern vorgegebenen Drehzahlen durchgeführt. Darin liegt eine Limitation der Studie. 
Eine weitere Limitation der Arbeit liegt in dem manuellen Anpressdruck, der nicht einstellbar bzw. reproduzierbar ist. Die Prüfkörper wurden manuell mit den Poliersystemen und Diamantpolierpasten bearbeitet. Als Probengeometrie wurden scheiben- und quaderförmige Prüfkörper verwendet, welche gut in der Handhabung sind. Das flache Prüfkörperdesign spiegelt nicht die klinische Realität wider. Es ermöglicht aber eine gute messtechnische Auswertung und hat sich bereits in anderen Studien bewährt. Die Prüfkörper wurden gleichmäßig von einem Anwender in eine Richtung poliert. Insbesondere die manuell durchgeführte Politur birgt das Risiko einer erhöhten Variationsbreite der Ergebnisse. Dies ist sicherlich als versuchstechnische Limitation zu bewerten. Andererseits entspricht das manuelle Polierverfahren auch der klinischen Anwendung und ist daher von einer höheren klinischen Relevanz als ein maschinell durchgeführter Politurvorgang.

\subsubsection{Zusammenfassung der Stärken und Limitationen}

Stärken der vorliegenden Studie sind:

- die klinische Relevanz der ausgewählten Materialien,

- die Methodik,

- eine ausreichende Anzahl an Prüfkörpern und Subgruppen

- und die multiparametrische Oberflächenmesstechnik.

Die Studie wird limitiert durch:

- eine konstante Drehzahleinstellung auf der Basis der Herstellerangaben,

- das Prüfkörperdesign,

- $\quad$ sowie dem manuellen, jedoch praxisnahem Anpressdruck.

Trotz der Limitationen dieser In-vitro-Studie konnte das Polierverhalten aktueller neu entwickelter Hochleistungswerkstoffe gut charakterisiert werden. Die Studie kann somit einen Beitrag zur werkstoffkundlichen Bewertung dieser bislang noch wenig untersuchten Werkstoffgruppen liefern. 


\subsection{Klinische Relevanz und Ausblick}

Im Mittelpunkt der vorliegenden In-vitro-Studie steht die Polierbarkeit neu entwickelter keramischer Werkstoffe. Die untersuchten Keramiken zählen zu der neuen Generation der Hochleistungskeramiken, welche speziell für die Anfertigung monolithischer Restaurationen geeignet sind. Im Rahmen dieser Studie erfolgte eine Untersuchung hinsichtlich des Polierverhaltens von zirkonoxidverstärkten Glaskeramiken und transluzenten Zirkonoxidvarianten. Bei den untersuchten Dentalkeramiken handelt es sich um Cercon ${ }^{\circledR}$ ht, Cercon ${ }^{\circledR}$ xt, Celtra ${ }^{\circledR}$ Press und Celtra ${ }^{\circledR}$ Duo, jeweils in zwei verschiedenen Poliersystemen (jeweils ohne/mit Diamantpolierpaste).

\subsubsection{Fragestellung 1}

Die erste Fragestellung bezieht sich auf die Polierbarkeit der vier Dentalkeramiken in zwei Universalpoliersystemen für Zirkonoxid- und ZLS-Keramiken. Zusätzlich stehen Unterschiede im Oberflächenprofil zwischen den vier Keramiken im Fokus.

Bei den Zirkonoxiden stehen die zweite Generation (Cercon® ht) und die dritte Generation $\left(\right.$ Cercon $\left.{ }^{\circledR} \mathrm{xt}\right)$ im Vergleich zueinander. Beide Materialien sind Weiterentwicklungen des Werkstoffes Cercon ${ }^{\circledR}$ base. Bei Cercon ${ }^{\circledR}$ ht wurden Ra-Werte von 0,08-0,20 $\mu \mathrm{m}$ ermittelt. Cercon ${ }^{\circledR} \mathrm{xt}$ ist im Vergleich zu Cercon ${ }^{\circledR}$ ht transluzenter und hat eine reduzierte Festigkeit. Daten bezüglich der Polierbarkeit der dritten Generation der Zirkonoxide (Cercon $\left.{ }^{\circledR} \mathrm{xt}\right)$ sind bislang noch selten. In der vorliegenden Untersuchung wurden bei Cercon® xt Ra-Werte von 0,11 - 0,23 $\mu \mathrm{m}$ gemessen. Diese Werte sind geringfügig höher als die von Cercon ${ }^{\circledR}$ ht. Insgesamt sind die Unterschiede im Oberflächenprofil jedoch nicht statistisch signifikant und stimmen gut mit den Ergebnissen der aktuellen Studienlage überein. Somit lässt sich festhalten, dass die Polierdaten der dritten Generation der Zirkonoxide mit denen der zweiten Generation übereinstimmen. Die Oberflächenparameter der beiden Zirkonoxidgenerationen sind ähnlich, die dritte Generation schafft keine Verbesserung.

Insgesamt lassen sich die Zirkonoxidkeramiken - auch im Vergleich zu den Glaskeramiken - sehr gut polieren. Diese Keramiken sind somit gut für die Herstellung monolithischer Restaurationen geeignet. Glatte Oberflächen sind für eine reduzierte Plaqueakkumulation und eine möglichst geringe Abrasivität wünschenswert. 
Die untersuchten Glaskeramiken zeigen tendenziell höhere Rauheitswerte als die Zirkonoxide. Diese Ergebnisse sind in guter Übereinstimmung mit den Ergebnissen bislang publizierter Studien. Laut Herstellerangaben soll die Oberfläche bei den untersuchten ZLS-Keramiken durch die in die Glasmatrix eingelagerten Lithium-Silikat-Kristallite gut polierbar sein. Bei der ZLS-Keramik Celtra® Press wurden in beiden Poliersystemen vergleichbare Werte zu anderen Glaskeramiken ermittelt. Die Oberflächengüte von Celtra ${ }^{\circledR}$ Duo ist jedoch abhängig vom eingesetzten Poliersystem. Es zeigt sich hier ein signifikanter Einfluss des Poliersystems auf die erzielbare Oberflächenqualität. Prinzipiell ist diese Keramik gut zu polieren, aber nicht mit jedem Poliersystem. Die gute Polierbarkeit, welche vom Hersteller ausgeschrieben ist, lässt sich somit für Celtra ${ }^{\circledR}$ Duo nicht universell bestätigen.

Das Poliersystem 1 (Polierer für $\mathrm{ZrO}_{2}$, Komet Dental, Lemgo) ist universell einsetzbar für alle untersuchten Keramiken. Bei dem Poliersystem 2 (ZiLMaster, SHOFU Dental GmbH, Ratingen) wurden bei Celtra ${ }^{\circledR}$ Duo statistisch signifikant höhere Oberflächenrauheiten ermittelt als bei den anderen Keramiken. Ob dieser Unterschied dem Poliersystem oder der Keramik geschuldet ist, lässt sich nicht herausstellen.

Bei dem Poliersystem 1 handelt es sich um ein zweistufiges und bei dem Poliersystem 2 um ein dreistufiges System. In der vorliegenden Studie kann für Cercon® ht, Cercon® xt und Celtra ${ }^{\circledR}$ Press kein statistisch signifikanter Unterschied innerhalb der Poliersysteme festgestellt werden. Bei diesen Keramiken lassen sich sowohl mit zwei- als auch mit dreistufigen Systemen Oberflächenqualitäten erreichen, die für einen Einsatz bei monolithischen Restaurationen als günstig zu bewerten sind. Bei der ZLS-Keramik Celtra® Duo zeigt sich dagegen eine signifikante Abhängigkeit der erzielbaren Oberflächengüte vom Poliersystem.

\subsubsection{Fragestellung 2}

In der zweiten Fragestellung wurde der Effekt der Endbearbeitung mit Diamantpolierpasten analysiert. Jeweils die Hälfte der Prüfkörper wurde zusätzlich - nach der Bearbeitung mit den Poliersystemen - mit einer Polierpaste behandelt. Die genutzten Pasten haben einen hohen Gehalt an Industriediamanten und sind für die Hochglanzpolitur von Keramikrestaurationen geeignet. 
In einigen Studien wird die zusätzliche Bearbeitung mit einer Polierpaste empfohlen. Die Ergebnisse der vorliegenden Studie zeigen einen statistisch signifikanten Unterschied bei Celtra ${ }^{\circledR}$ Duo im Poliersystem 2. Bei den anderen Keramiken zeigt sich nach Bearbeitung mit Diamantpolierpaste eine geringgradige Verbesserung der Oberflächenqualität, die sich aber nicht als statistisch signifikant erweist.

Für eine maximale Oberflächengüte wird die Endbearbeitung mit einer Diamantpolierpaste empfohlen. Dies zeigt sich als klinische Konsequenz aus der vorliegenden Untersuchung und der aktuellen Studienlage.

\subsubsection{Ausblick}

Die untersuchten Keramiken stehen im Vergleich zu anderen Keramiken für monolithische Restaurationen, wie bespielweise IPS® e.max oder IPS® Empress. Die Rauheitswerte der vorliegenden Untersuchung sind in guter Übereinstimmung mit den Ergebnissen bereits publizierter Studien zur Oberflächenrauigkeit von etablierten Dentalkeramiken. Somit kann geschlussfolgert werden, dass die neu entwickelten Keramiken ein vergleichbares Polierverfahren aufweisen wie bislang verfügbare Hochleistungskeramiken.

Die vorliegende Studie zeigt, dass mit der Politur vergleichbare oder bessere Oberflächengüten als mit Glanzbrand-behandelten Oberflächen zu erreichen sind. Diese Ergebnisse haben eine große Konsequenz für die klinische Praxis. Nach dem Einschleifen von Restaurationen ist also nicht zwangsläufig ein Glanzbrand erforderlich.

Das Poliersystem 1 kann universell eingesetzt werden.

Das Poliersystem 2 ist für die Zirkonoxide und Celtra ${ }^{\circledR}$ Press zu empfehlen. Bei Celtra ${ }^{\circledR}$ Duo werden über dieses Poliersystem schlechtere Oberflächenparameter erreicht.

Die geringste Oberflächenrauigkeit wird, wie auch in vorangegangenen Untersuchungen, durch die abschließende Anwendung einer Diamantpolierpaste erzielt. Die Verbesserung der Oberflächenqualität bei den Zirkonoxidkeramiken und Celtra ${ }^{\circledR}$ Press ist im Vergleich zur alleinigen Anwendung von zwei- und dreistufigen Poliersystemen jedoch nicht statistisch signifikant. Der Einsatz einer Diamantpolierpaste ist somit unter dem Aspekt der Kosten-Nutzen-Abwägung nur als optionaler Arbeitsschritt in der klinischen Anwendung zu empfehlen. Für das untersuchte Material Celtra® Duo lässt sich eine signifikante 
Verbesserung der Oberflächenqualität durch die Anwendung einer Diamantpolierpaste bei Nutzung des Poliersystems 2 feststellen.

Der klinische Nutzen der Anwendung einer Diamantpolierpaste hängt somit vom zu polierendem Werkstoff und auch vom angewendeten Poliersystem ab. 


\section{$5 \quad$ Zusammenfassung}

Im Rahmen dieser Studie wurde das Polierverhalten neu entwickelter hochfester Keramikwerkstoffe in vitro untersucht. Zahnmedizinische Restaurationen werden zunehmend unter Einsatz dentaler Hochleistungskeramiken gefertigt, die für die Herstellung von monolithischen Versorgungen geeignet sind. Zirkonoxidverstärkte Glaskeramiken und transluzente Zirkonoxidvarianten stellen dabei neu entwickelte Werkstoffvarianten dar.

Bei den Keramiken dieser Studie handelt es sich um eine Zirkonoxidkeramik der 2. Generation $\left(\right.$ Cercon $\left.{ }^{\circledR} \mathrm{ht}\right)$, eine Zirkonoxidkeramik der 3. Generation (Cercon ${ }^{\circledR} \mathrm{xt}$ ), eine CAD/CAM ZLS-Keramik (Celtra ${ }^{\circledR}$ Duo) und eine ZLS-Keramik für das Pressverfahren (Celtra ${ }^{\circledR}$ Press). Im Fokus der Untersuchungen stand die Frage, ob es zwischen den Keramiken und Poliersystemen Unterschiede im Oberflächenprofil gibt. Des Weiteren wurde die Endbearbeitung der Keramiken mit Diamantpolierpasten analysiert.

Die Prüfkörper wurden nach einem Planschliff, jeweils mit einem zweistufigen Poliersystem (Polierer für $\mathrm{ZrO}_{2}$, Komet Dental, Lemgo) und einem dreistufigen Poliersystem (ZiLMaster, SHOFU Dental GmbH, Ratingen), bearbeitet. Anschließend erfolgte die Endbearbeitung mit einer zugehörigen Diamantpolierpaste. Die Oberflächengüte wurde mittels Tastschnittverfahren ausgewertet und anschließend statistisch analysiert.

Im Poliersystem 1 (Polierer für $\mathrm{ZrO}_{2}$, Komet Dental, Lemgo) lässt sich kein statistisch

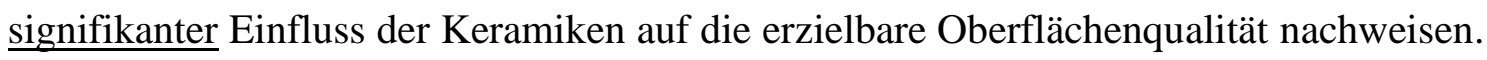
Es kann somit zur universellen Politur der untersuchten Keramiken genutzt werden.

Im Poliersystem 2 (ZiLMaster, SHOFU Dental GmbH, Ratingen) zeigt sich ein statis-

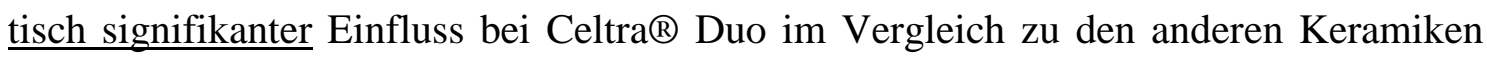
Cercon ${ }^{\circledR}$ ht, Cercon ${ }^{\circledR}$ xt und Celtra ${ }^{\circledR}$ Press. Bei dieser ZLS-Keramik ergeben sich in diesem Poliersystem signifikant höhere Rauheitswerte (Ra, Rz, Rmax) im Vergleich zu den anderen Keramiken.

Ein weiterer signifikanter Einfluss ist bei den Mittenrautiefen $(\mathrm{Rz})$ in beiden Poliersystemen (jeweils ohne Paste) von Celtra ${ }^{\circledR}$ Press gegenüber Cercon ${ }^{\circledR}$ ht festzustellen.

Bei der Endbearbeitung der Zirkonoxide und Celtra ${ }^{\circledR}$ Press mit Diamantpolierpasten lässt sich eine Tendenz aufzeigen, dass die Oberflächenrauigkeit durch die zusätzliche Politur mit einer Diamantpolierpaste reduziert werden kann. Die Ergebnisse sind aber nicht statistisch signifikant, und der klinische Nutzen ist abschließend nicht zu beurteilen. 
Bei Celtra ${ }^{\circledR}$ Duo ist der Effekt der Diamantpolierpaste im Poliersystem 2 statistisch signifikant.

Die Rauheitswerte der untersuchten Keramiken in der vorliegenden Studie sind in guter Übereinstimmung mit publizierten Daten etablierter Dentalkeramiken. 


\section{Literaturverzeichnis}

Alghazzawi TF (2016): Advancements in CAD/CAM technology: Options for practical implementation. J Prosthodontic Res $\underline{60}, 72-84$

Amaya-Pajares SP, Ritter AV, Vera Resendiz C, Henson BR, Culp L, Donovan TE (2016): Effect of Finishing and Polishing on the Surface Roughness of Four Ceramic Materials after Occlusal Adjustment. J Esthet Restor Dent 28, 382-396

Amer R, Kurklu D, Kateeb E, Seghi RR (2014): Three-body wear potential of dental yttrium-stabilized zirconia ceramic after grinding, polishing, and glazing treatments. J Prosthet Dent $\underline{112}, 1151-1155$

Aravind P, Razak PA, Francis PG, Issac JK, Shanoj RP, Sasikumar TP (2013): Comparative evaluation of the efficiency of four ceramic finishing systems. J Int Oral Health $\underline{5}$, $59-64$

Aykent F, Yondem I, Ozyesil AG, Gunal SK, Avunduk MC, Ozkan S (2010): Effect of different finishing techniques for restorative materials on surface roughness and bacterial adhesion. J Prosthet Dent $\underline{103}, 221-227$

Baroudi K, Ibraheem SN (2015): Assessment of Chair-side Computer-Aided Design and Computer-Aided Manufacturing Restorations: A Review of the Literature. J Int Oral Health $\underline{7}, 96-104$

Belli R, Wendler M, Ligny D, Cicconi MR, Petschelt A, Peterlik H, Lohbauer U (2017): Chairside CAD/CAM materials. Part 1: Measurement of elastic constants and microstructural characterization. Dent Mater $\underline{33}, 84-98$

Beuer F, Edelhoff D, Gernet W, Sorensen JA (2009a): Three-year clinical prospective evaluation of zirconia-based posterior fixed dental prostheses (FDPs). Clin Oral Investig $\underline{13}, 445-451$

Beuer F, Schweiger J, Eichberger M, Kappert HF, Gernert W, Edelhoff D (2009b): High-strength CAD/CAM-fabricated veneering material sintered to zirconia copings -a new fabrication mode for all-ceramic restorations. Dent Mater 25, 121-128

Beuer F, Stimmelmayr M, Gueth JF, Edelhoff D, Naumann M (2012): In vitro performance of full-contour zirconia single crowns. Dent Mater 28, 449-456 
Burgess JO, Janyavula S, Lawson NC, Lucas TJ, Cakir D (2014): Enamel wear opposing polished and aged zirconia. Oper Dent $\underline{39}$, 189-194

Camacho GB, Vinha D, Panzeri H, Nonaka T, Goncalves M (2006): Surface roughness of a dental ceramic after polishing with different vehicles and diamond pastes. Braz Dent J $\underline{17}, 191-194$

Chen YM, Smales RJ, Yip KH, Sung WJ (2008): Translucency and biaxial flexural strength of four ceramic core materials. Dent Mater 24, 1506-1511

Cionca N, Hashim D, Mombelli A (2017): Zirconia dental implants: where are we now, and where are we heading? Periodontol $2000 \underline{73}, 241-258$

Craig R, Powers J, Wataha J: Zahnärztliche Werkstoffe: Eigenschaften und Verarbeitung. 1. Auflage; Elsevier Urban \& Fischer, München 2006

Dentsply Sirona Prosthetics: Celtra® Press/Factfile. dentsplysirona.com 2016. URL: https://www.dentsplysirona.com/content/dam/dentsply/pim/de_DE/Prosthetics/Fixed/High_strength_glass_ceramic/Celtra_Press/PR_Celtra_Press_Factfile_dt_2017_05.pdf; Zugriff am 04.01.2018

Dentsply Sirona Prosthetics: Cercon®/Factfile. dentsplysirona.com 2017a. URL: https://www.dentsplysirona.com/content/dam/dentsply/pim/de_DE/Prosthetics/CAD_CAM_materials/Materials/Zirconia/PR_Cercon_xt_FactFile_DE_2017_07.pdf; Zugriff am 04.01.2018

Dentsply Sirona Prosthetics: Celtra® Duo/Developed to make a difference. dentsplysirona.com 2017b. ULR: https://www.dentsplysirona.com/content/dam/dentsply/pim/en_US/Prosthetics/Fixed/High_strength_glass_ceramic/Celtra_Duo/BRO_Celtra_Duo_USA_EN_2017_08.pdf; Zugriff am 04.01.2018 Erdelt KJ, Beuer F, Schweiger J, Eichberger M, Gernet W (2004): Die Biegefestigkeit von weißkörper-gefrästem Zirkonoxid. Quintessenz Zahntech $\underline{30}$, 942-954

Fasbinder DJ (2010): Digital dentistry: innovation for restorative treatment. Compend Contin Educ Dent $\underline{31}, 2-11$

Fasbinder DJ, Neiva GF (2016): Surface Evaluation of Polishing Techniques for New Resilient CAD/CAM Restorative Materials. J Esthet Restor Dent 28, 56-66 Flury S, Lussi A, Zimmerli B (2010): Performance of different polishing techniques for direct CAD/CAM ceramic restorations. Oper Dent $\underline{35}, 470-481$ 
Gaus W, Muche R: Medizinische Statistik. 2. Auflage; Schattauer Verlag, Stuttgart 2017

Ghazal M, Kern M (2009): The influence of antagonistic surface roughness on the wear of human enamel and nanofilled composite resin artificial teeth. J Prosthet Dent $\underline{101}$, 342-349

Gins C (2012): Wunsch und Wirklichkeit. ZWR 121, 129-190

Gracis S, Thompson VP, Ferencz JL, Silva NR, Bonfante EA (2015): A new classification system for all-ceramic and ceramic-like restorative materials. Int J Prosthodont $\underline{28}$, $227-235$

Harms V: Medizinische Statistik. 8. völlig neu bearbeitete Auflage; Harms Verlag, Lindhöft 2012

Heintze SD, Rousson V (2010): Survival of zirconia- and metal-supported fixed dental prostheses: a systematic review. Int J Prosthodont $\underline{23}$, 493-502

Heintze SD, Cavalleri A, Forjanic M, Zellweger G, Rousson V (2008): Wear of ceramic and antagonist--a systematic evaluation of influencing factors in vitro. Dent Mater $\underline{24}$, 433-449

Hmaidouch R, Müller WD, Lauer HC, Weigl P (2014): Surface roughness of zirconia for full-contour crowns after clinically simulated grinding and polishing. Int J Oral Sci $\underline{6}, 241-246$

Hoffmann A (2009): Oberflächenbearbeitung von Zirkoniumdioxid. Quintessenz Zahntech $\underline{35}, 1640-1652$

Janyavula S, Lawson N, Cakir D, Beck P, Ramp LC, Burgess JO (2013): The wear of polished and glazed zirconia against enamel. J Prosthet Dent 109, 22-29

Jefferies SR (2007): Abrasive finishing and polishing in restorative dentistry: a state-ofthe-art review. Dent Clin North Am 1, 379-97

Jiang L, Liao Y, Wan Q, Li W (2011): Effects of sintering temperature and particle size on the translucency of zirconium dioxide dental ceramic. J Mater Sci Mater Med 22, $2429-2435$

Jones CS, Billington RW, Pearson GJ (2004): The in vivo perception of roughness of restorations. Br Dent J $\underline{196}, 42-45$ 
Jung T, Borchers L: Schleif- und Poliermittel. In: Eichner K, Kappert H (Hrsg.): Zahnärztliche Werkstoffe und ihre Verarbeitung. Band 1: Grundlagen und ihre Verarbeitung; 8. unveränderte Auflage; Georg Thieme Verlag, Stuttgart 2005, 373-384

Jung YS, Lee JW, Choi YJ, Ahn JS, Shin SW, Huh JB (2010): A study on the in-vitro wear of the natural tooth structure by opposing zirconia or dental porcelain. J Adv Prosthodont $\underline{2}, 111-115$

Kang SH, Chang J, Son HH (2013): Flexural strength and microstructure of two lithium disilicate glass ceramics for CAD/CAM restoration in the dental clinic. Restor Dent En$\operatorname{dod} \underline{38}, 134-140$

Kelly JR, Benetti P (2011): Ceramic materials in dentistry: historical evolution and current practice. Aust Dent J 56, 84-96

Kern M, Kohal RJ, Mehl A, Pospiech P, Frankenberger R, Reiss B, Wiedhahn K, Kunzelmann KH: Dentalkeramiken - Struktur und Einsatzzweck. In: AG Keramik (Hrsg.): Vollkeramik auf einen Blick: Leitfaden zur Indikation, Werkstoffauswahl, Vorbereitung und Eingliederung von vollkeramischen Restaurationen. 5. dt. Auflage; AG Keramik, Ettlingen 2012b, 6

Kern M, Kohal RJ, Mehl A, Pospiech P, Frankenberger R, Reiss B, Wiedhahn K, Kunzelmann KH: Vollkeramik - individuell, ästhetisch und metallfrei. In: AG Keramik (Hrsg.): Vollkeramik auf einen Blick: Leitfaden zur Indikation, Werkstoffauswahl, Vorbereitung und Eingliederung von vollkeramischen Restaurationen. 5. dt. Auflage; AG Keramik, Ettlingen 2012a, 7-9

Kern M, Sasse M, Wolfart S (2012c): Ten-year outcome of three-unit fixed dental prostheses made from monolithic lithium disilicate ceramic. J Am Dent Assoc 143, $234-240$

Khayat W, Chebib N, Finkelman M, Khayat S, Ali A (2018): Effect of grinding and polishing on roughness and strength of zirconia. J Prosthet Dent $\underline{119}, 626-631$

Komet Dental: Polierer für $\mathrm{ZrO}_{2}$ /Produktinformation. kometdental.de 2016. URL: https://www.kometdental.de/ /media/KometDental/Product\%20Info/SyncFolder/410667_pdf.pdf; Zugriff am 04.01.2018

Komet Dental: Diamantpolierpaste/Produktbeschreibung. kometstore.de 2018. URL: https://www.kometstore.de/V2/de-DE/Products/Products-Kometdental/9300.aspx; Zugriff am 04.01.2018 
Kou W, Molin M, Sjogren G (2006): Surface roughness of five different dental ceramic core materials after grinding and polishing. J Oral Rehabil $\underline{33}$, 117-124

Kozmacs C, Hollmann B, Arnold WH, Naumova E, Piwowarczyk A (2017): Polishing of Monolithic Zirconia Crowns-Results of Different Dental Practitioner Groups. Dent J (Basel) 5, 30-39

Krüger S, Deubener J, Ritzberger C, Höland W (2013): Nucleation kinetics of lithium metasilicate in $\mathrm{ZrO} 2$-bearing lithium disilicate glasses for dental application. Int J Appl Glass Sci $\underline{4}, 9-19$

Lang R, Friedl KH (2013): Kleben oder nicht kleben? Der richtige Umgang mit vollkeramischen Restaurationen. ZMK $\underline{29}$, 434-442

Lawson NC, Janyavula S, Syklawer S, McLaren EA, Burgess JO (2014): Wear of enamel opposing zirconia and lithium disilicate after adjustment, polishing and glazing. $\mathbf{J}$ Dent $\underline{42}, 1586-1591$

Li RW, Chow TW, Matinlinna JP (2014): Ceramic dental biomaterials and CAD/CAM technology: state of the art. J Prosthodont Res $\underline{58}, 208-216$

Luangruangrong P, Cook NB, Sabrah AH, Hara AT, Bottino MC (2014): Influence of full-contour zirconia surface roughness on wear of glass-ceramics. J Prosthodont $\underline{23}$, 198-205

Ma L, Guess PC, Zhang Y (2013): Load-bearing properties of minimal-invasive monolithic lithium disilicate and zirconia occlusal onlays: finite element and theoretical analyses. Dent Mater 29, 742-751

Marxkors R, Meiners H, Geis-Gerstorfer J: Taschenbuch der zahnärztlichen Werkstoffkunde. 6. überarbeitete Auflage; Dt. Zahnärzte-Verlag, Köln 2012

Matzinger M, Hahnel S, Preis V, Rosentritt M (2018): Polishing effects and wear performance of chairside CAD/CAM materials. Clin Oral Investig $\underline{73}, 18-24$

Mahr GmbH Göttingen: MarSurf/Oberflächenkenngrößen. messraum.ch 2015. URL: http://www.messraum.ch/files/marsurf--3762814--po--surface_texture_parameters--a2-2015--de.pdf; Zugriff am 05.01.2018

Mitov G, Heintze SD, Walz S, Woll K, Muecklich F, Pospiech P (2012): Wear behavior of dental Y-TZP ceramic against natural enamel after different finishing procedures. Dent Mater 28, 909-918 
Miyazaki T, Nakamura T, Matsumura H, Ban S, Kobayashi T (2013): Current status of zirconia restoration. J Prosthodont Res 57, 236-261

Mühlemann S, Bernini JM, Sener B, Hämmerle CHF, Özcan M (2018): Effect of Aging on Stained Monolithic Resin-Ceramic CAD/CAM Materials: Quantitative and Qualitative Analysis of Surface Roughness. J Prosthodont 10, 129-149

Odatsu T, Jimbo R, Wennerberg A, Watanabe I, Sawase T (2013): Effect of polishing and finishing procedures on the surface integrity of restorative ceramics. Am J Dent $\underline{26}$, 51-55

Ozkan P, Yilmaz K (2010): Profilometer evaluation of the effect of various polishing methods on the surface roughness in dental ceramics of different structures subjected to repeated firings. Quintessence Int $\underline{41}, 125-131$

Park C, Vang MS, Park SW, Lim HP (2017): Effect of various polishing systems on the surface roughness and phase transformation of zirconia and the durability of the polishing systems. J Prosthet Dent 117, 430-437

Park JH, Park S, Lee K, Yun KD, Lim HP (2014): Antagonist wear of three CAD/CAM anatomic contour zirconia ceramics. J Prosthet Dent $\underline{111}$, 20-29

Pieger S, Salman A, Bidra AS (2014): Clinical outcomes of lithium disilicate single crowns and partial fixed dental prostheses: a systematic review. J Prosthet Dent $\underline{112}$, $22-30$

Pospiech P: Vollkeramische Restaurationen: Werkstoffkundliche und klinische Aspekte. In: Gernet W, Biffar R, Schwenzer N, Ehrenfeld M (Hrsg.): Zahnärztliche Prothetik. 4. Auflage; Georg Thieme Verlag, Stuttgart 2011, 68-82

Pospiech P, Kern M (2016): Verblendet vs. Monolithisch. ZWR 125, 430-436

Pott PC, Hoffmann JP, Stiesch M, Eisenburger M (2018): Polish of interface areas between zirconia, silicate-ceramic, and composite with diamond-containing systems. J Adv Prosthodont 10, 315-320

Preis V, Rosentritt M (2017): Was wir bislang wissen: Die neue Generation des hochtransluzenten Zirkonoxids. Teamwork 20, 50-55

Preis V, Behr M, Kolbeck C, Hahnel S, Handel G, Rosentritt M (2011): Wear performance of substructure ceramics and veneering porcelains. Dent Mater 27, 796-804 
Preis V, Behr M, Handel G, Schneider-Feyrer S, Hahnel S, Rosentritt M (2012): Wear performance of dental ceramics after grinding and polishing treatments. J Mech Behav Biomed Mater $\underline{10}, 13-22$

Preis V, Weiser F, Handel G, Rosentritt M (2013): Wear performance of monolithic dental ceramics with different surface treatments. Quintessence Int $\underline{44}, 393-405$

Preis V, Grumser K, Schneider-Feyrer S, Behr M, Rosentritt M (2015a): The effectiveness of polishing kits: influence on surface roughness of zirconia. Int J Prosthodont $\underline{28}$, $149-151$

Preis V, Schmalzbauer M, Bougeard D, Schneider-Feyrer S, Rosentritt M (2015b):

Surface properties of monolithic zirconia after dental adjustment treatments and in vitro wear simulation. J Dent $\underline{43}, 133-139$

Raptis NV, Michalakis KX, Hirayama H (2006): Optical behavior of current ceramic systems. Int J Periodontics Restorative Dent 26, 31-41

Rinke S: Vollkeramik. Quintessenz-Verlag, Berlin 2012

Rinke S, Pabel AK, Rödiger M, Ziebolz D (2016): Chairside Fabrication of an All-Ceramic Partial Crown Using a Zirconia-Reinforced Lithium Silicate Ceramic. Case Rep Dent $\underline{10}, 35-41$

Rodiger O, Kappert HF, Marinello CP (2004): In-vitro-Bruchlasttests von 3-gliedrigen Seitenzahnbrücken hergestellt im Procera-Verfahren. Schweiz Monatsschr Zahnmed $\underline{114}, 207-213$

Rösler J, Harders H, Bäker M: Mechanisches Verhalten der Werkstoffe. 5. aktualisierte und erweiterte Auflage; Springer Vieweg, Wiesbaden 2016

Sabrah AH, Cook NB, Luangruangrong P, Hara AT, Bottino MC (2013): Full-contour Y-TZP ceramic surface roughness effect on synthetic hydroxyapatite wear. Dent Mater $\underline{29}, 666-673$

Sasahara RM, Ribeiro Fda C, Cesar PF, Yoshimura HN (2006): Influence of the finishing technique on surface roughness of dental porcelains with different microstructures. Oper Dent $\underline{31}, 577-583$

Schmitter M, Mueller D, Rues S (2012): Chipping behaviour of all-ceramic crowns with zirconia framework and CAD/CAM manufactured veneer. J Dent $\underline{40}, 154-162$ 
Sethi S, Kakade D, Jambhekar S, Jain V (2013): An in vitro investigation to compare the surface roughness of auto glazed, reglazed and chair side polished surfaces of Ivoclar and Vita feldspathic porcelain. J Indian Prosthodont Soc 13, 478-485

Shenoy A, Shenoy N (2010): Dental ceramics: An update. J Conserv Dent 13, 195-203 SHOFU Dental GmbH: ZiLMaster/Adjustment Kits. shofu.de 2016. URL: https://www.shofu.de/wp-content/uploads/2016/03/ZiLMaster-BRO-UK-2016-07.pdf; Zugriff am 04.01.2018

SHOFU Dental GmbH: Dura-Polish/Polierpastensystem. shofu.de 2018. URL: https://www.shofu.de/wp-content/uploads/2018/06/Dura-Polish-Dura-Polish-DIA-InfoDE.pdf; Zugriff am 04.01.2018

Silva TM, Salvia AC, Carvalho RF, Pagani C, Rocha DM, Silva EG (2014): Polishing for glass ceramics: which protocol? J Prosthodont Res $\underline{58}, 160-170$

Spitznagel FA, Boldt J, Gierthmuehlen PC (2018): CAD/CAM Ceramic Restorative Materials for Natural Teeth. J Dent Res 97, 1082-1091

Stawarczyk B, Ozcan M, Schmutz F, Trottmann A, Roos M, Hämmerle CHF (2013): Two-body wear of monolithic, veneered and glazed zirconia and their corresponding enamel antagonists. Acta Odontol Scand $\underline{71}, 102-112$

Stawarczyk B, Frevert K, Ender A, Roos M, Sener B, Wimmer T (2016a): Comparison of four monolithic zirconia materials with conventional ones: Contrast ratio, grain size, four-point flexural strength and two-body wear. J Mech Behav Biomed Mater $\underline{59}$, 128138

Stawarczyk B, Keul C, Eichberger M, Figge D, Edelhoff D, Lümkemann N (2016b): Werkstoffkunde-Update: Zirkonoxid und seine Generationen - von verblendet bis monolithisch. Quintessenz Zahntech $\underline{42}$, 740-765

Steiner R, Beier US, Heiss-Kisielewsky I, Engelmeier R, Dumfahrt H, Dhima M (2015): Adjusting dental ceramics: An in vitro evaluation of the ability of various ceramic polishing kits to mimic glazed dental ceramic surface. J Prosthet Dent $\underline{113}$, 616622

Strub J, Kern M, Türp J, Witkowski S, Heydecke G, Wolfart S: Curriculum Prothetik. Band 2: Artikulatoren, Ästhetik, Werkstoffkunde, festsitzende Prothetik; 4. überarbeitete und erweiterte Auflage; Quintessenz-Verlag, Berlin 2011 
Subasi MG, Inan Ö (2012): Evaluation of the topographical surface changes and roughness of zirconia after different surface treatments. Lasers Med Sci 27, 735-742

Tinschert J, Götzen N, Natt G: Oxidkeramiken. In: Tinschert J, Natt G (Hrsg.): Oxidkeramiken und CAD/CAM-Technologien: Atlas für Klinik, Labortechnik und Werkstoffkunde; mit 48 Tabellen. Dt. Zahnärzte-Verlag, Köln 2007, 5-46

Volk R: Rauheitsmessung: Theorie und Praxis. 3. Auflage; Beuth Verlag, Berlin 2018 Wang F, Chen JH, Wang H (2009): Surface roughness of a novel dental porcelain following different polishing procedures. Int J Prosthodont 22, 178-180

Weiß C: Basiswissen Medizinische Statistik. 6. überarbeitete Auflage; Springer Verlag, Berlin 2013

Wendler M, Belli R, Petschelt A, Mevec D, Harrer W, Lube T, Danzer R, Lohbauer U (2017): Chairside CAD/CAM materials. Part 2: Flexural strength testing. Dent Mater $\underline{33}, 99-109$

Zarone F, Russo S, Sorrentino R (2011): From porcelain-fused-to-metal to zirconia: clinical and experimental considerations. Dent Mater 27, 83-96

Zarone F, Ferrari M, Mangano FG, Leone R, Sorrentino R (2016): "Digitally Oriented Materials": Focus on Lithium Disilicate Ceramics. Int J Dent 10, 84-94

Zhang Y, Lawn BR (2018): Novel Zirconia Materials in Dentistry. J Dent Res 97, 140147

Zinelis S, Thomas A, Syres K, Silikas N, Eliades G (2010): Surface characterization of zirconia dental implants. Dent Mater 26, 295-305 


\section{Danksagung}

Mein Dank gilt meinem Doktorvater PD Dr. Sven Rinke für die ausgezeichnete Betreuung bei der Erstellung dieser Arbeit.

Weiterer Dank gilt Dr. Torsten Wassmann für die Unterstützung bei der Durchführung der Experimente im Labor der Zahnklinik Göttingen.

Die Ausmessung der Prüfkörper erfolgte bei der Mahr GmbH Göttingen. Ich möchte mich an dieser Stelle bei der Mahr GmbH Göttingen und bei Patricia Johnen für die herzliche Betreuung bedanken. 